\title{
A component based model for the prediction of the product yields of the pyrolysis of a biomass particle
}

Brian C. Eberly

West Virginia University

Follow this and additional works at: https://researchrepository.wvu.edu/etd

\section{Recommended Citation}

Eberly, Brian C., "A component based model for the prediction of the product yields of the pyrolysis of a biomass particle" (2010). Graduate Theses, Dissertations, and Problem Reports. 2154.

https://researchrepository.wvu.edu/etd/2154

This Thesis is protected by copyright and/or related rights. It has been brought to you by the The Research Repository @ WVU with permission from the rights-holder(s). You are free to use this Thesis in any way that is permitted by the copyright and related rights legislation that applies to your use. For other uses you must obtain permission from the rights-holder(s) directly, unless additional rights are indicated by a Creative Commons license in the record and/ or on the work itself. This Thesis has been accepted for inclusion in WVU Graduate Theses, Dissertations, and Problem Reports collection by an authorized administrator of The Research Repository @ WVU. For more information, please contact researchrepository@mail.wvu.edu. 
A Component Based Model For The Prediction Of The Product Yields Of The Pyrolysis Of A Biomass Particle

By

Brian C. Eberly

\begin{abstract}
A Thesis
Submitted to

The College of Engineering and Mineral Resources

at

West Virginia University

In partial fulfillment of the requirements

for the degree of

\author{
Master of Science \\ in \\ Mechanical Engineering \\ Nathan Weiland, Ph. D., Chair \\ Jagannath Nanduri, Ph. D. \\ Ismail Celik, Ph. D.
}

Department of Mechanical and Aerospace Engineering

Morgantown, West Virginia 


\title{
Abstract \\ A Component Based Model For The Prediction Of The Product Yields Of The Pyrolysis Of A Biomass Particle
}

\author{
Brian C. Eberly
}

Pyrolysis of biomass can produce several useful, renewable products: biochar for soil amendment and long-term carbon sequestration; tars for chemicals and biofuels; and syngas as an energy and biofuel production feedstock. The ability to predict the relative yields of gas, tar and char from the pyrolysis process of various biomasses will enable optimization of pyrolysis process for specific yield ratios. Component based kinetic and 1-D pyrolysis models are developed wherein the woody biomass is characterized by the mass percentage of its three primary components: cellulose, hemicellulose and lignin. Using dual stage mechanisms for primary component pyrolysis and tar cracking reactions, a kinetic model was built to simulate the pyrolysis of the biomass surrogate. The kinetic model was validated against published experimental data for experiments where thermal gradients and fluid flow could be neglected. This kinetic model was incorporated as a source term into a particle model which accounts for fluid flow through porous media. The particle model was validated against published and in-house experimental data for various biomass types. The kinetic model accurately predicts the yields of char, tar, and syngas as well as gas species concentrations to a lower degree of accuracy for biomass pyrolysis where particle sizes are small enough that the reaction is kinetically limited and sweep gas flows keep tar cracking to a minimum. The particle model predicts char, tar and syngas yields accurately provided sweep gas flow is high enough to minimize extra-particle tar cracking and heating rates are slow enough to keep the maximum temperature difference between the inside and outside of the particle less than $10^{\circ} \mathrm{C}$. A criterion was developed to determine this maximum temperature difference. The particle model is able to predict gas species trends but fails to predict absolute values. These models can be incorporated into full multi-scale simulations of pyrolysis reactors, with the goal of optimizing various process variables for increasing specific product yields. 


\section{Acknowledgements}

A graduate degree is a funny thing. In the world of academia Masters Degrees are often looked upon as nothing more than a stepping stone to a $\mathrm{PhD}$, one which also marks the spot were some choose to leave the path. Outside of the world of higher education, a graduate degree is something else all together, a mystery to most; a fancy piece of paper. Having spent a lot of time in academia, I was under the impression that I fully understood what an MS would require of me; however I could not have been more mistaken and the truncated time table that both the project and I imposed left no time for "figuring things out". My whirl wind degree owes much to the guidance of my co-advisors Dr. Weiland and Dr Nanduri, who gave the correct dosages of assistance and autonomy for me to be able to complete this project without having to hold my hand. Also the outside

perspective of Dr. Celik often served to steer me in the right direction when I got lost in the fog of my preconceptions. The experimental side of this project would not have been done without the work of Nick Means, who put up with me and performed many of the tedious tasks that were needed. I also would not have been able to manage this endeavor without my wonderful fiancée, Natalie, who had to deal with my preoccupied mind and served to keep me grounded and present. 
Abstract

Acknowledgements

iii

Table of Contents

iv

List of Tables

vi

List of Figures

vii

Nomenclature

ix

Chapter 1: An Introduction to Biomass Pyrolysis

1.1 Introduction

1

1.2 Production

1.3 Products and Applications

2

Chapter 2: Project Overview and Justification

2.1 Objective and Scope

2.2 Literature Survey

2.3 Summary

Chapter 3: Pyrolysis Modeling

$\begin{array}{lll}3.1 & 15\end{array}$

$\begin{array}{ll}3.2 & 15 \\ 3.3 & \text { Kinetic Model }\end{array}$

3.3 Large Particle Model 22

Chapter 4: Pyrolysis Experiments

$\begin{array}{lll}4.1 & 35\end{array}$

$\begin{array}{ll}4.2 & \text { Apparatus } \\ 4.3 & 35\end{array}$

4.3 Biomass Feedstock Preparation 36

4.4 Procedure and Results 38

Chapter 5: Model validation

$\begin{array}{lll}5.1 & \text { Introduction } & 42\end{array}$

5.2 Thermogravimetric Analysis 42

5.3 Fixed Bed with Small Particle Size 43

5.4 Fixed Bed with Large Particle Size 43

5.5 Validation Results 44

Chapter 6: Conclusion

$\begin{array}{lll}6.1 & \text { Conclusion } & 59\end{array}$

$\begin{array}{lll}\text { 6.2 Recommendations for future work } & 61\end{array}$

$\begin{array}{ll}\text { References } & 62\end{array}$ 
Appendix B: Matlab programs 


\section{List of Tables}

Table 2.1: Reaction Rate Constants for biomass components

Table 3.1: Kinetic rate data

Table 3.2: Concentration factors for gas evolution

Table 3.3: Properties used in thermal analysis

Table 3.4 Physical properties of wood 33

Table 4.1: Proximate analysis of red oak 37

Table 4.2: Ultimate analysis and heating value for red oak 38

Table 4.3: Example mass balance for a fixed bed reactor experiment 39

Table 4.4: Pyrolysis experiment test matrix and results 40

Table 5.1 Biomass composition for simulations 


\section{List of Figures}

$\begin{array}{ll}\text { Figure 2.1: Various global reaction mechanisms } & 10\end{array}$

$\begin{array}{ll}\text { Figure 2.2: Several semi-global reaction mechanisms } & 11\end{array}$

Figure 3.1: Primary pyrolysis reaction mechanism, adapted from [8] 16

$\begin{array}{ll}\text { Figure 3.2: Tar cracking reaction mechanism } & 17\end{array}$

$\begin{array}{ll}\text { Figure 3.3: Global component based pyrolysis reaction mechanism } & 19\end{array}$

Figure 3.4: Simulations of transient surface and center temperatures 25 for heated wood cylinders

Figure 4.1: Schematic of the fixed bed pyrolysis reactor 36

Figure 4.2: Mass fraction yields of oak cylinders at different 41 Argon flow rates, $10^{\circ} \mathrm{C} / \mathrm{min}$ and $650^{\circ} \mathrm{C}$

Figure 5.1: TGA simulation and experimental data for cellulose, $\quad 46$ hemicellulose, and lignin

Figure 5.2: TGA of simulation and experimental data for switchgrass 47

Figure 5.3: TGA simulation and experimental data for hardwood 48

Figure 5.4: TGA simulation and experimental data for rice husk 48

Figure 5.5: Product yields at different pyrolysis temperatures for 49 fine particle pine. Simulation vs. Experiments

Figure 5.6: Product yields at different pyrolysis temperatures for

T. Catappa. Simulation vs. Experiments

Figure 5.7: Gas species yields at different pyrolysis temperatures for fine $\quad 51$ particle pine. Simulation vs. Experiments, using new concentration factors

Figure 5.8: Gas species yields at different pyrolysis temperatures for fine particle pine. Simulation vs. Experiments, using old concentration factors 52

Figure 5.9: Product yields at different pyrolysis temperatures for 53 oak cylinders. Simulation vs. Experiments 
Figure 5.10: Gas species fraction based on a) initial wood mass and

b) total gas mass for oak cylinders at $10 \mathrm{~K} / \mathrm{min}$ and $250 \mathrm{~mL} / \mathrm{min} \mathrm{Ar}$

Figure 5.11: Product yields at different reaction temperatures for large particle pyrolysis of T. Catappa. Simulation vs. Experiments

Figure 5.12: Tar yields at different reaction temperatures for T Catappa

Figure 5.13: Gas yields at different reaction temperatures for T Catappa

58 


\section{English}

\section{Nomenclature}

\begin{tabular}{|c|c|}
\hline $\mathrm{a}$ & Gaussian coefficients \\
\hline A & Pre-exponential factor \\
\hline $\mathrm{b}$ & Gaussian right hand side \\
\hline $\mathrm{C}$ & Gas species concentration \\
\hline $\mathrm{D}$ & Diameter \\
\hline $\mathrm{D}_{\text {dif }}$ & Diffusion coefficient \\
\hline $\mathrm{E}$ & Activation energy \\
\hline $\mathrm{k}$ & Reaction rate constant \\
\hline $\mathrm{K}$ & Permeability \\
\hline $\mathrm{L}$ & Particle characteristic half length \\
\hline $\mathrm{n}$ & Reaction order \\
\hline $\mathrm{P}$ & Pressure \\
\hline $\mathrm{R}$ & Particle radius \\
\hline$\overline{\mathrm{R}}$ & Universal gas constant \\
\hline $\mathrm{R}_{\mathrm{v}}$ & Pyrolysis vapor specific gas constant \\
\hline S & Source term \\
\hline $\mathrm{t}$ & Time \\
\hline $\mathrm{T}$ & Temperature \\
\hline $\mathrm{u}$ & Velocity \\
\hline $\mathrm{x}$ & Position \\
\hline $\mathrm{X}$ & Smallest Particle dimension \\
\hline Y & Mass fraction \\
\hline
\end{tabular}




$\begin{array}{ll}\text { Greek } & \\ \alpha & \text { Thermal diffusivity } \\ \beta & \text { Concentration Factor } \\ \delta & \text { Non-dimension characteristic length } \\ \varepsilon & \text { Porosity } \\ \eta & \text { Non-dimensional radius } \\ \lambda & \text { Thermal conductivity } \\ \mu & \text { Viscosity } \\ \rho & \text { Density } \\ \gamma & \text { Fraction of tar that cracks to gas } \\ \Phi & \text { Non-dimensional temperature } \\ \Pi & \text { Ratio of convection to diffusion } \\ \Omega_{\text {edge }} & \text { Temperature ramp rate }\end{array}$

\section{Subscripts}

$\begin{array}{ll}\mathrm{c} & \text { Center } \\ \mathrm{e} & \text { East } \\ \mathrm{i} & \text { Biomass component } \\ \mathrm{j} & \text { Intermediate component } \\ \mathrm{k} & \text { Gas component } \\ \mathrm{o} & \text { Characteristic value } \\ \mathrm{t} & \text { Tar } \\ \mathrm{w} & \text { West }\end{array}$


C

$\mathrm{H}$

L

Lignin

Cellulose

Hemicellulose 


\section{Chapter 1: An Introduction to Pyrolysis}

\subsection{Introduction}

Pyrolysis is the thermal decomposition of material in the absence of oxygen. Biomass is a general term that usually refers to any plant/animal based material. There are four main categories of biomass; woody biomass is derived from wood and can be used to describe large logs, small branches, saw dust, and wood industry waste; herbaceous biomass comes from leafy plant sources like leaves and grasses; animal biomass can be meat industry waste or animal excrement; and other miscellaneous biomass that does not fall into any of the other categories can be seeds, nut shells, fruit pits, grain hulls, or algae to name a few.

Commercially, biomass feedstocks can be waste products of industries, like nut shells or lumber waste, or from crops grown specifically for pyrolysis feedstocks, such as switchgrass. All plant-based biomass generally can be characterized by their relative composition of five components; cellulose, hemicellulose, lignin, extractives, and ash. Cellulose, hemicellulose and lignin are families of large hydrocarbon polymers that make up a large portion of the biomass. Extractive content are organic compounds that can be removed with a solvent such as ethanol, acetone or water. Ash refers to any non-organic compounds present in the biomass, generally in the form of salts. The following chapter gives a brief overview of the methods used for conducting pyrolysis and the products that are derived from the process. 


\subsection{Production}

There are two major regimes for pyrolysis; fast pyrolysis and slow pyrolysis, which are aptly named for the apparent heating rate experienced by the biomass during the process. While the fast pyrolysis regime is beyond the scope of this work it is worth giving brief attention for comparison purposes. For the sake of this work, fast pyrolysis will encompass any process were the apparent biomass heating rate is in excess of $50^{\circ} \mathrm{C} / \mathrm{min}$. Fast pyrolysis reactors take many forms and are mainly designed to increase heat transfer to the biomass particles. As pointed out in [1], fast pyrolysis is accomplished in fluidized bed reactors, entrained flow reactors, rotating disc/cone reactors and many similar designs. These processes generally give high tar yields, upwards of $60 \%$, and low char yields, less than $15 \%$ [1]. Due to high heating rates, large temperature gradients develop inside the particle and thermal and kinetic timescales are comparable.

The other production regime, slow pyrolysis, where heating rates are less than $50^{\circ} \mathrm{C} / \mathrm{min}$, is generally performed in variations of fixed bed reactors. With low heating rates, internal temperature gradients are less dramatic and reaction kinetics dominate [1]. A typical batch slow pyrolysis reactor consists of a chamber with a controlled atmosphere. Biomass is loaded or fed into the chamber, which is heated via hot purge gas, wall heating or a combination of the two to a specific reaction temperature and held for a specific time. The reactor is then allowed to cool. These batch reactors must be loaded and emptied for a finite amount of biomass. Continuous reactors can be made by feeding biomass through controlled temperature chambers so it experiences the desired 
heating rates. Purge gases may be used to maintain an inert atmosphere and to remove volatiles from the reaction chamber. Tar vapors may be condensed and gases collected.

\subsection{Products and applications}

Pyrolysis has three major products; char, tar and gas. Chars consist of porous carbon rich solids, the relative composition, heating value, and porosity of which is a strong function of the pyrolysis conditions. Char has long been used as a fuel for domestic heating and cooking; however it is also a possible fuel for power plants, either as a complete replacement for coal or as a supplement in a co-firing situation. Chars are also used in industry either as a feedstock for activated carbons or as a reducing agent for metallurgical production. As shown in [2], chars can also be used as a soil amendment, where it is often referred to as biochar, to improve moisture retention and increase available plant nutrients. When used as a soil amendment, chars remain in the soil unchanged, resulting in permanent carbon sequestration.

Tar is a general term that refers to any pyrolysis volatile that can be condensed. Water falls into this classification and usually makes up a substantial portion of the tar produced. Of more interest are the organic compounds that are evolved which usually contain alcohols, acetic acid, phenols, levoglucosan and aldehydes as well as other larger organic compounds [3]. Pyrolysis tars are given a substantial amount of focus $[4,5,6]$ because they can be used as feedstock for production of commonly used fuels, their liquid nature allows for easy transportation and higher energy densities, despite their unstable and corrosive tendencies. Tars can also be burned directly, though this is not as 
common due to the variability in the composition of tar. Tar composition is highly dependent on feedstock, heating rate, reaction temperature, and residence time.

Pyrolysis vapors that do not condense easily are known as gas or syngas. Syngas is mostly composed of $\mathrm{CO}_{2}$ and $\mathrm{CO}$ with smaller amounts of $\mathrm{CH}_{4}$ and $\mathrm{H}_{2}$, while having trace amounts of larger hydrocarbon gases like ethane, propane and ethene. Pyrolysis gas can be burned directly due to the high concentration of $\mathrm{CO}$; however it can be advantageous to further process pyrolysis gases to increase the amount of $\mathrm{CH}_{4}, \mathrm{H}_{2}$ and CO. 


\section{Chapter 2: Project Overview and Justification}

\subsection{Objective and Scope}

It has been shown that high porosity char, when used as a soil amendment (biochar) not only improves moisture retention and increases available plant nutrients, but also remains unchanged for thousands of years, thereby permanently sequestering carbon [2]. However, the production of biochar as a single product is not very economically attractive; therefore it is desirable to have added value co-products. Generally pyrolysis tars are made in fast pyrolysis reactors that produce low porosity chars which are not useful as a soil amendment, therefore pyrolysis gas, which can be burned directly as an energy source or used as a feedstock for the production of fuels or other chemicals, is the only option for a co-product in biochar production. To achieve maximum productivity, it is necessary to minimize tar yields while maximizing char and gas yields. This can be achieved by further reaction of pyrolysis tars, which are known to crack into char and gas at reaction temperatures given ample reaction time. To this end a model is needed to predict the relative yields of tar, char and gas at a variety of pyrolysis and tar cracking conditions including; heating rate, reaction temperature, particle size, and feedstock species. In addition to predicting char, tar and gas yields, since the gas will be a valuable product, it is desirable to predict the composition of the gas. The composition affects the syngas heating value and determines the type of chemical and liquid fuels which can be

created from it. While there exists in the literature proposed models that can fulfill several of these requirements, none has been located that can meet all of these needs. Therefore the objective of this work is to develop a model for the prediction of slow 
pyrolysis yields of biomass, particularly syngas composition, accounting for various biomass species and particle sizes.

\subsection{Literature Survey}

Before developing a pyrolysis model, it is necessary to review the work that has already been done in this area to avoid redundant efforts and to determine the commonly accepted methods for pyrolysis modeling. Pyrolysis publications tend to fall into one of two categories, kinetic modeling and parametric studies. Parametric studies are a qualitative investigation of the effects of changing reaction parameters in a particular pyrolysis reactor while modeling studies follow a set of experiments to identify reaction mechanisms and physical models and to quantify the pyrolysis behavior to be able to predict the results. Modeling studies can be further distinguished into those that only focus on reaction kinetics and those which investigate physical phenomena such as heat transfer and mass transport.

One of the most significant qualitative concepts to pyrolysis modeling is that pyrolysis tars undergo a tar cracking reaction decreasing the amount of tar and increasing the gas and char. This concept has been investigated and discussed by many, including Phan et al [6], Gilbert et al. [7] and Fagbemi et al.[3]. Phan et al. [6] was investigating the effect of biomass bed depth in a fixed bed reactor. Pyrolysis experiments were performed with a range of final temperatures and the same temperature ramp rate and bed depth. This was repeated with the bed depth doubled. The results from these experiments [6] show a decrease in tar with a larger bed depth; this decrease is more pronounced as the final temperature is increased. Phan et al. [6] explains this by 
suggesting the char in the bed acts as a catalyst for tar cracking, having a larger bed increases the amount of time the tar is in contact with the char. Gilbert et al. [7] also investigated the catalytic affect that char has on tar cracking by passing pyrolysis vapors over a hot char bed. Their findings indicate that not only does the char increase the amount of tar cracking, but the flow rate of purge gas has an influence on how much tar cracks by affecting the residence time the tar vapors have in char. Fagbemi et al. [3] investigates the cracking of tars from three different biomasses, wood, coconut shell and straw. They [3] conclude that increasing reaction temperature increases the amount of tar cracking. Fagbemi et al. [3] also conclude that tars from different biomasses react similarly and present reaction rate data for the tar cracking reaction.

Given that the current work aims to quantitatively model pyrolysis behavior it is worth looking at other works involving the modeling of pyrolysis. There have been a number works attempting to develop kinetic pyrolysis reaction models such as those presented in Koufopanos et al.[8] and Miller and Bellan [4], as well as a number of reviews, Basu et al. [5] and Di Blasi [1] to identify a few, that compare and contrast the different models. There have also been works such as Lee et al. [9] that attempt to develop reaction rates to be used with previously developed models.

There are several aspects of a useful pyrolysis kinetic model that most researchers seem to agree upon. First, to be able account for variations in biomass feedstock, a kinetic model must not be specific for a single biomass. For example, the kinetic rate constants presented by Lee et. al. [9] for the pyrolysis of switchgrass, are most likely only valid for predicting the pyrolysis of switchgrass. However the models proposed by 
Koufopanos et al. [8] and Miller and Bellan [4] are component based, meaning a biomass is characterized by the relative composition of cellulose, hemicellulose and lignin, and this is taken into account for modeling. This generic model is developed using the superposition of the pyrolysis behavior of the three components alone. Initially proposed by Koufopanos et al. [8], superposition has been used and tested by others. Wang et al. [10], Yang et al. [11] and Worasuwannarak et al.[12] performed experiments to determine the validity of superposition and to find, if any, interactions between biomass components. As in most works, these three $[10,11,12]$ use xylan as a surrogate for hemicellulose, because hemicellulose is difficult to isolate from biomass and xylan is one of the major polymers that composes hemicellulose. In these $[10,11,12]$ works, individual components were pyrolyzed and then mixtures of components were pyrolyzed and the results were compared. If no interactions occur, the mixture behaviors should represent the superposition of the behaviors of their components. While Wang et al. [10] and Worasuwannarek et al. [12] concluded that there are interactions between some components, Yang et al [11] concluded that there are no significant interactions; the difference appears to be in the perception of significant. The majority of the interactions seen in [12] are for the distribution of volatiles (tar and gas species). Worasuwannarek et al. [12] point out that there are interactions between volatile species, water and tar for example in a cellulose-lignin mixture. The additional water produced by the lignin in the mixture suppresses the otherwise high tar production from cellulose. It is unclear whether these interactions occur in the pyrolysis reaction of are the result of secondary gas phase reactions. However, for this study, any component interactions will be considered small. 
The second commonly agreed notion is that the pyrolysis reaction follows the Arrhenius relationship described by equations 2.1. and 2.2.

$$
\begin{aligned}
& k=-A e^{\left(-\frac{E}{\bar{R} T}\right)} \\
& \frac{d Y}{d t}=k Y^{n}
\end{aligned}
$$

Where $\mathrm{k}$ is the reaction rate, $A$ is a pre-exponential coefficient, $E$ is the activation energy, $\bar{R}$ is the universal gas constant, $T$ is the temperature, $t$ is time, $n$ is the reaction order and $Y$ is the mass fraction.

The third common agreement is also the area for the most disagreement; the pyrolysis reaction is too complex to know exactly what happens, therefore a simple reaction mechanism must be used. The disagreement lies in which reaction mechanism is valid. As pointed out by Miller and Bellan [4], most have strengths and weaknesses that should be considered against the requirements for the intended use. Figure 2.1 shows several reaction mechanisms which could be characterized as "global", meaning they focus mainly on products and reactants. Figure 2.2 shows several semi-global mechanisms which do not necessarily account for every intermediate species, but still contain many intermediate reactions. Some mechanisms can be very detailed as seen in Ranzi et al. [13], but this comes with an increased computational cost with limited improvement on predictions.

Many reaction mechanisms exist for cellulose of a specific biomass and the activation energies and pre-exponential coefficients can be found for these specific cases, 
but Koufopanos et al. [8] published reaction rate constants for each of the three biomass components, which can be found in Table 2.1. The reaction mechanism used by Koufopanos et al. [8] can be seen in Figure 2.1b and forms the basis for the mechanism developed here.

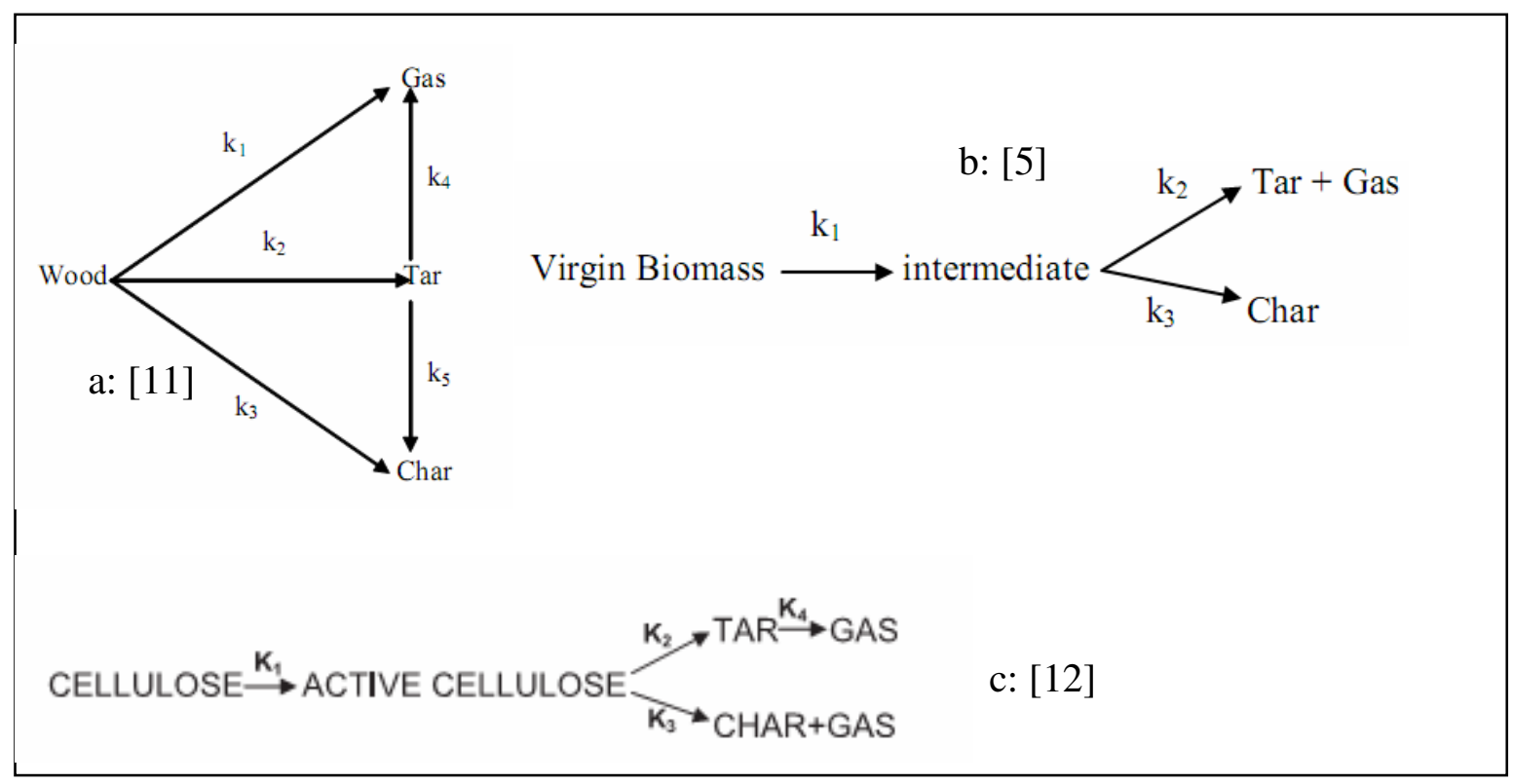

Figure 2.1: Various global reaction mechanisms.

Table 2.1: Reaction Rate Constants for biomass components [8]

\begin{tabular}{lccccccccc}
\hline Material & Reaction 1 & \multicolumn{2}{c}{ Reaction 2 } & \multicolumn{3}{c}{ Reaction 3 } \\
& Order & $A_{1}$ & \multicolumn{1}{c}{$E_{1}$} & Order & $A_{2}$ & $E_{2}$ & Order & $A_{3}$ & $E_{3}$ \\
\hline Cellulose & 0 & $2.2 \times 10^{14}$ & 167.5 & 1.5 & $9.4 \times 10^{15}$ & 216.6 & 1.5 & $3.1 \times 10^{13}$ & 196.0 \\
Hemicellulose & 0 & $3.3 \times 10^{6}$ & 72.4 & 1.5 & $1.1 \times 10^{14}$ & 174.1 & 1.5 & $2.5 \times 10^{13}$ & 172.0 \\
Lignin & 0 & $3.3 \times 10^{12}$ & 147.7 & 1.5 & $8.6 \times 10^{8}$ & 137.1 & 1.5 & $4.4 \times 10^{7}$ & 122.1 \\
\hline
\end{tabular}

In the Koufopanos et al. [8] mechanism (Figure 2.1b), there is an intermediate step, reaction 1, which is the production of an intermediate biomass component. This intermediate can be viewed as an activated component which forms but does not contribute to mass loss and from which the other products form. It should be noted that this mechanism [8] has been reported to break down at high temperatures and high heating rates [4]. 


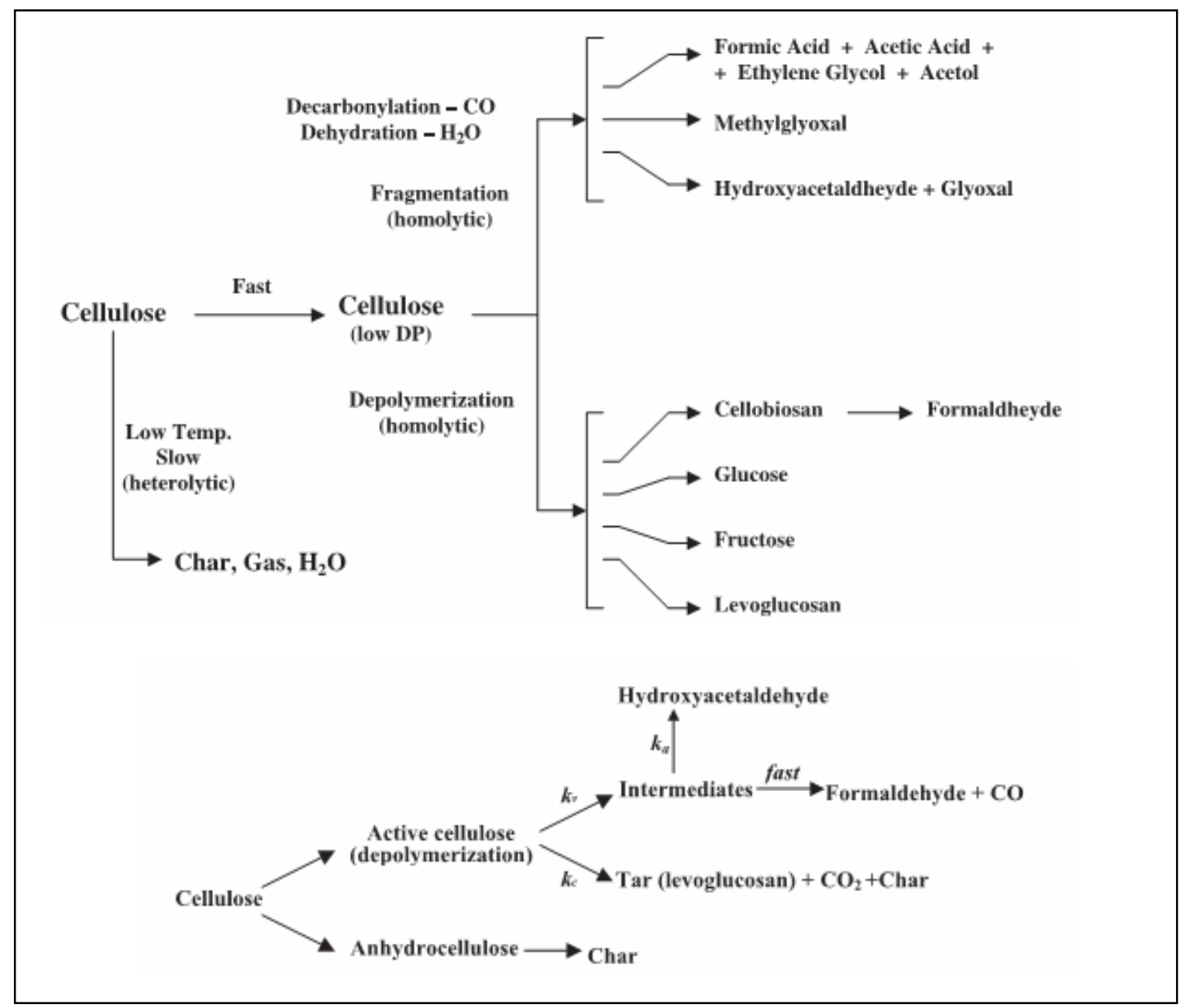

Figure 2.2: Several semi-global mechanisms reviewed by Di Blasi [1]

Miller and Bellan [4] list four predictions that a pyrolysis model should be able to accomplish. It should predict time evolution of solid mass loss during heating, product yields, product yield variations with reaction temperature, and product yield variations with different biomass feedstocks. These criteria will be benchmarks for measuring the success of the current study. 
Physical modeling of a pyrolysis system can be as important as chemical modeling. The two major phenomenons are heat transfer and mass transport, which both are essentially the effects of particle size. Miller and Bellan [4] put much focus in their model to account for particle size, both for heat transfer and for mass transport inside the biomass particle. While Miller and Bellan [4] obtained acceptable model performance, they were focusing on pyrolysis involving high temperature ramp rates, which, for the sake of the current work, does not carry the same considerations. Miller and Bellan [4] also point out that there exists a critical particle size that marks the threshold where heat transfer and mass transport can be neglected. This particle size is related to several other parameters, but mainly temperature ramp rate.

Another work, Park et al.[14] investigated the heat transfer and mass transport in large wood spheres. Again, their model produced acceptable results; however the heating rates used were beyond the scope of this current work as well.

In a detailed review, Di Blasi [1] addresses the topic of flow inside a biomass particle and points out that while tar vapors are in the particle they are exposed to high temperatures and have relatively long in-particle residence times due to flow restrictions. Di Blasi [1] states that generally, the in-particle modeling of convection transport is achieved by applying Darcy's law.

The composition of pyrolysis syngas is of specific importance because the syngas is desired as a product. The composition affects the heating value of the syngas when 
used as an energy sources and the economic value was used as a chemical feedstock. Lee et al. [9] pyrolyzed switchgrass and measured the gases evolved. $\mathrm{CO}$ and $\mathrm{CO}_{2}$ were the major species present. Yang et al. [15] pyrolyzed individual biomass components and published the evolution rates for $\mathrm{CO}, \mathrm{CO}_{2}, \mathrm{CH}_{4}, \mathrm{H}_{2}$, and $\mathrm{C}_{2} \mathrm{H}_{\mathrm{x}}$. This data might be useful for developing a model for predicting the gas concentration; however the large sample size required to produce enough gas for measuring might have led to tar cracking which makes the gas data the composite result of both primary pyrolysis and tar cracking. In an attempt to quantify tar cracking, Rath et al. [16] pyrolyzed birch wood with a heated tube reactor downstream of the pyrolysis reactor for tar cracking. They measured evolution rates for $\mathrm{CO}, \mathrm{CO}_{2}, \mathrm{CH}_{4}, \mathrm{H}_{2}, \mathrm{C}_{2} \mathrm{H}_{4}, \mathrm{C}_{2} \mathrm{H}_{6}$, and $\mathrm{C}_{2} \mathrm{H}_{2}$. This is also the combined result of primary pyrolysis and tar cracking. Di Blasi [1] produced and extensive review covering chemical and physical aspects of biomass pyrolysis and states that the general composition of biomass pyrolysis syngas is primarily $\mathrm{CO}, \mathrm{CO}_{2}$, and $\mathrm{CH}_{4}$ with small amounts of $\mathrm{H}_{2}$ and $\mathrm{C}_{2} \mathrm{H}_{\mathrm{x}}$.

\subsection{Summary}

By sacrificing the small error that may be associated with the superposition of the reaction behavior of the three biomass components, cellulose, hemicellulose, and lignin, one obtains a more flexible model that can account for variations in biomass feedstock. Using Arrhenius type reactions, heating rate and reaction temperature affects can be captured. When particle size surpasses a critical dimension, which is related to temperature ramp rate, heat and mass transport must be taken in to consideration [4]. While many gas species have been observed forming from pyrolysis, $\mathrm{CO}$ and $\mathrm{CO}_{2}$ are 
known to be the predominant species with $\mathrm{CH}_{4}$ being less significant. Other species such as $\mathrm{H} 2$ and $\mathrm{C}_{2} \mathrm{H}_{\mathrm{x}}$ may be present in trace amount, but may not be important. Since the aim of this work is to minimize tar formation and it is known that pyrolysis tars undergo a cracking reaction which destroys tar and creates gas, it is important to be able to predict the tar cracking reaction. The development of a model that incorporates all of these features is considered in the following section. 


\section{Chapter 3: Pyrolysis Modeling}

\subsection{Introduction}

In order to effectively design pyrolysis reactors, it is necessary to accurately predict the relative yields of pyrolysis products in order to achieve the desired outcome. Given that the chemical, physical and thermal processes that take place in a pyrolysis reactor are extremely complicated, these predictions are generally accomplished via computer modeling. This process can be grouped into two parts; kinetic model and large particle effects. The kinetic model focuses solely on transient chemical reactions while the large particle effects encompass heat transfer, mass transport and porosity changes. In this chapter the modeling schemes employed here are discussed.

\subsection{Kinetic Model}

The exact set of chemical reactions that occur during a pyrolysis reaction is not only complicated, but is also not known. Therefore it is generally accepted that a simple global reaction can be used to describe the event. For this work mass based Arrhenius type reactions 3.1 and 3.2 are considered.

$$
\begin{aligned}
& k=A e^{\frac{-E}{\bar{R} T}} \\
& \frac{d Y}{d t}=k Y^{n}
\end{aligned}
$$

Where $k$, is the reaction rate, $A$, is the pre-exponential, $E$ is the activation energy,

$\bar{R}$, is the universal gas constant, $T$ is temperature, $t$ is time, $Y$ is mass fraction, and $n$ is the reaction order. A given biomass is assumed to be a combination of cellulose, hemicellulose and lignin which follow independent chemical reactions, resulting in the 
overall reaction that is a superposition of the three separate reactions. The basic reaction mechanism proposed by Koufopanous et. al. (see Figure 2.1) [8] is chosen as a starting point for this model. Studies have shown $[4,8]$ that this model is accurate for the prediction of mass loss from a biomass sample at low heating rates with the knowledge of cellulose, hemicelluloses and lignin composition, the heating rate and the final temperature of the sample. The model [8] is valid if the sample size and particle size are sufficiently small so that tar cracking can be neglected. Also there exist in the literature published reaction rate constants (A's and E's) for each biomass component using this reaction mechanism. In the current work, the model [8] is modified in several ways.

The Koufopanous model [8] has several missing pieces. Since there are only two production/evolution reactions, one for char and one for volatiles (gas and tar combined), it lacks the ability to predict the yields of tar and gas. To be able to predict these products, a concentration factor is added as shown in Figure 3.1.

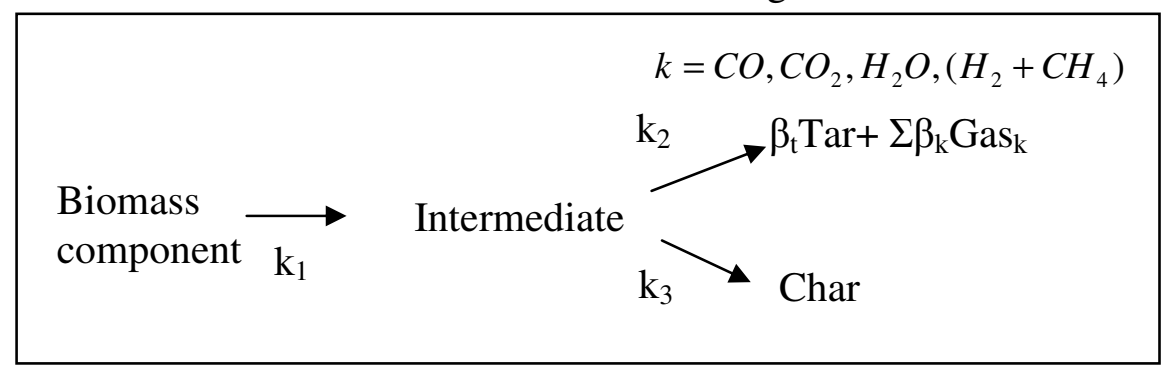

\section{Figure 3.1: Primary pyrolysis reaction mechanism, adapted from [8]}

Initially, due to lack of compatible data based on individual components, a fictitious temperature dependent function was assumed for the concentration factor $\beta_{t}$, which yielded poor predictions. Worasuwannark et al [12] published TGA experiments with temperature dependent mass fractions of Tar, $\mathrm{H}_{2} \mathrm{O}, \mathrm{CO}, \mathrm{CO}_{2}$, and $\mathrm{H}_{2}+\mathrm{CH}_{4}$, the 
combined concentration of hydrogen and methane. This data was used to develop new, data-based concentration factors both as average values over the entire temperature range and as temperature dependent functions. The average values were used due to the limited improvements seen by using the temperature dependent functions, to lighten the computational demand, and the fact that these experiments [12] were only reported at one temperature ramp rate. (see Table 3.2) Since water is a condensable species, and experimentally gets collected as tar, it is added in with the tar for this model. Since water does not participate in tar cracking, it is not lumped with tar through out the reaction, but is added to the total tar yield at the end. Is should be noted that considering competitive reactions for gas species may give a vast improvement over using concentration factors, but they were not used here due to the lack of experimental data to develop them.

A tar cracking reaction was added to account for variations in yields as residence times vary. This was accomplished by using the Arrhenius reaction proposed by Fagbemi, et al [3]; shown in Figure 3.2a.

a)

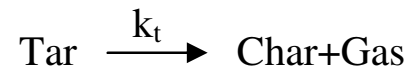

b)

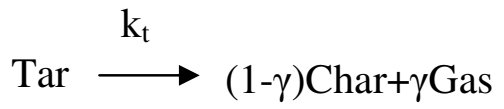

\section{Figure 3.2: a)Tar cracking reaction mechanism [3], b) modified tar cracking mechanism}

This mechanism is simple and Fagbemi et al [3] published reaction rate data for it as well as reaction rates proposed by others for comparison. All of the rates presents by Fagbemi et al. [3] were used and one was selected which had a large enough activation 
energy to prevent instantaneous tar cracking while being small enough that tar cracking still occurred. The mechanism was modified by including coefficients to account for the relative ratio of char to gas, while from experiments, char is observed on the reactor from tar cracking, $\gamma$ is assumed to be 1 in this work since char is over predicted slightly due to the lack of accounting for continued devolatilization and having tar crack to char would increase the over prediction. Reconciling this is an area of improvement which will be saved for future investigation.

To be able to predict gas species concentrations from tar cracking, gas evolution data from Gilbert et al [7] was used initially, however, this data included gas evolution from both primary pyrolysis and tar cracking, therefore the data from Worasuwannarak et al [12] was used to fit the concentration factors for tar cracking reactions. To do this, gas species distribution at the highest reported temperature for each biomass component were averaged and used to determine the gas species concentrations from tar cracking. This was done because at the highest temperature, the primary pyrolysis reaction should be mostly completed and only tar cracking and continued devolatilization are occurring. This is a definite area of improvement in the model; obtaining better data for tar cracking to specific gas species, since such data is not found in the literature independent of primary pyrolysis reaction.

In addition to the above changes to the Koufopanos mechanism, the intermediate reaction was changed from zeroth order $(n=0)$ to first order $(n=1)$, because as pointed out in [1], having a zero order relationship will cause the mass fractions to become negative unless a numerical constraint is applied. Also the reaction orders for intermediate lignin 
to volatiles and char (reaction 2 and 3) were changed from 1.5 to 3 , this was done to improve the transient predictions of lignin pyrolysis. Validation for these changes are provided in section 5.5.1.

The generalized component based pyrolysis mechanism is shown in Figure 3.3, the kinetic rate data is presented in Table 3.1 and the concentration factors for gas evolution are given in Table 3.2. The reaction rate constants for this semi-global mechanism were adopted from the literature $[3,8]$ and the concentration factors are developed using published pyrolysis gas evolution data [12] as discussed above.

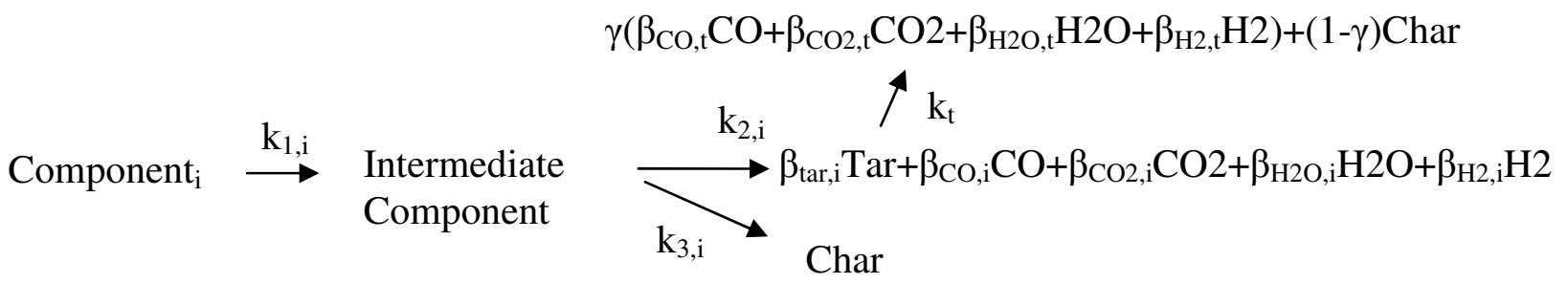

Figure 3.3: Global component based pyrolysis mechanism 
Table 3.1: Kinetic rate data

\begin{tabular}{|c|c|c|c|c|c|}
\hline & Reaction & $\begin{array}{c}\mathrm{A} \\
\left(\mathrm{s}^{-1}\right)\end{array}$ & $\begin{array}{c}\mathrm{E} \\
(\mathrm{kj} / \mathrm{kmol})\end{array}$ & $\mathrm{n}$ & Ref \\
\hline 1 & Cellulose $\rightarrow$ Int $_{\mathrm{Cel}}$ & $2.2 \times 10^{14}$ & 167.6 & $1^{*}$ & [8] \\
\hline 2 & Hemicellulose $\rightarrow$ Int $_{\text {Hemi }}$ & $3.3 \times 10^{6}$ & 72.4 & $1^{*}$ & [8] \\
\hline 3 & Lignin $\rightarrow$ Int $_{\text {Lig }}$ & $3.3 \times 10^{12}$ & 147.7 & $1^{*}$ & [8] \\
\hline 4 & Int $_{\mathrm{Cel}} \rightarrow$ volatiles $_{\mathrm{c}}$ & $9.4 \times 10^{15}$ & 215.6 & 1.5 & [8] \\
\hline 5 & Int $_{\mathrm{Hemi}} \rightarrow$ volatiles $_{\mathrm{h}}$ & $1.1 \times 10^{14}$ & 175.1 & 1.5 & [8] \\
\hline 6 & Int $_{\text {Lig }} \rightarrow$ volatiles $_{\mathrm{L}}$ & $8.6 \times 10^{8}$ & 137.1 & $3^{*}$ & [8] \\
\hline 7 & Int $_{\mathrm{Cel}} \rightarrow$ char & $3.1 \times 10^{13}$ & 196 & 1.5 & [8] \\
\hline 8 & Int $_{\text {Hemi }} \rightarrow$ char & $2.5 \times 10^{13}$ & 172 & 1.5 & [8] \\
\hline 9 & $\mathrm{Int}_{\mathrm{Lig}} \rightarrow$ char & $4.4 \times 10^{7}$ & 122.1 & $3^{*}$ & [8] \\
\hline 10 & $\operatorname{Tar} \rightarrow\left(\gamma \mathrm{Gas}_{\mathrm{t}}+(1-\gamma)\right.$ Char $)$ & $5.9 \times 10^{7}$ & 123.48 & 1 & {$[13]$} \\
\hline 11 & $\begin{aligned} & \text { volatiles } \rightarrow \beta_{\mathrm{CO} 2, \mathrm{C}} \mathrm{CO}_{2}+\beta_{\mathrm{CO}, \mathrm{C}} \mathrm{CO} \\
&+\beta_{\mathrm{H} 2, \mathrm{C}} \mathrm{H}_{2}+\beta_{\mathrm{t}, \mathrm{C}} \mathrm{Tar}+\beta_{\mathrm{H} 2 \mathrm{C}, \mathrm{C}} \mathrm{H}_{2} \mathrm{O}\end{aligned}$ & N/A & N/A & N/A & {$[12]^{+}$} \\
\hline 12 & $\begin{array}{c}\text { Volatiles }_{\mathrm{h}} \rightarrow \beta_{\mathrm{CO} 2, \mathrm{~h}} \mathrm{CO}_{2}+\beta_{\mathrm{CO}, \mathrm{h}} \mathrm{CO} \\
+\beta_{\mathrm{H} 2, \mathrm{~h}} \mathrm{H}_{2}+\beta_{\mathrm{t}, \mathrm{h}} \mathrm{Tar}+\beta_{\mathrm{H} 2 \mathrm{O}, \mathrm{h}} \mathrm{H}_{2} \mathrm{O}\end{array}$ & N/A & N/A & N/A & {$[12]^{+}$} \\
\hline 13 & $\begin{aligned} \text { volatiles }_{\mathrm{L}} & \rightarrow \beta_{\mathrm{CO} 2, \mathrm{~L}} \mathrm{CO}_{2}+\beta_{\mathrm{CO}, \mathrm{L}} \mathrm{CO} \\
& +\beta_{\mathrm{H} 2, \mathrm{~L}} \mathrm{H}_{2}+\beta_{\mathrm{t}, \mathrm{L}} \mathrm{Tar}+\beta_{\mathrm{H} 2 \mathrm{O}, \mathrm{L}} \mathrm{H}_{2} \mathrm{O}\end{aligned}$ & N/A & N/A & N/A & {$[12]^{+}$} \\
\hline 14 & $\begin{aligned} \mathrm{Gas}_{\mathrm{t}} \rightarrow & \beta_{\mathrm{CO} 2, \mathrm{t}} \mathrm{CO}_{2}+\beta_{\mathrm{CO}, \mathrm{t}} \mathrm{CO} \\
& +\beta_{\mathrm{H} 2, \mathrm{H}} \mathrm{H}_{2}+\beta_{\mathrm{H} 2 \mathrm{O}, \mathrm{H}} \mathrm{H}_{2} \mathrm{O}\end{aligned}$ & N/A & N/A & N/A & {$[12]^{+}$} \\
\hline
\end{tabular}

Table 3.2: Concentration factors $\beta_{\mathrm{k}, \mathrm{i}}$ for gas evolution

\begin{tabular}{|c|c|c|c|c|}
\hline $\mathrm{i}$ & Cellulose & Hemicellulose & Lignin & Tar \\
\hline Tar & .837 & .24 & .21 & N/A \\
\hline $\mathrm{CO}$ & .05 & .24 & .03 & .21 \\
\hline $\mathrm{CO}_{2}$ & .032 & .22 & .41 & .33 \\
\hline $\mathrm{H}_{2} \mathrm{O}$ & .081 & .28 & .31 & .41 \\
\hline $\mathrm{H}_{2}+\mathrm{CH}_{4}$ & .0 & .02 & .04 & .05 \\
\hline
\end{tabular}

*Value was selected to fit data in [5]

+ Used to calculate concentration factors 
Due to the relatively simple nature of the equations and the large timescales of the reactions, an explicit Euler's method was used to solve the kinetic reaction equation with finite differencing and time marching. The equation for the degradation of virgin biomass components into their respective intermediates, Reaction 1-3 in Table 3.1, is seen in Equation 3.3.

$$
Y_{i}^{\text {new }}=Y_{i}^{\text {old }}-Y_{i}^{\text {old }} A_{1, i} e^{-\frac{E_{1, i}}{\bar{R} T}} \Delta t, \quad i=\text { cel, hemi, lig }
$$

Equation 3.4 is used to calculate the total change in the intermediate species, both production and destruction, in competitive Reactions 4-9 in Table 3.1:

$$
\begin{aligned}
& Y_{j}^{\text {new }}=Y_{j}^{\text {old }}+\left(Y_{i}^{\text {old }} A_{1, i} e^{-\frac{E_{1, i}}{\bar{R} T}}-Y_{j}^{\text {old } n} A_{2, j} e^{-\frac{E_{2, j}}{\bar{R} T}}-Y_{j}^{\text {old }} A_{3, j} e^{-\frac{E_{3, j}}{\bar{R} T}}\right) \Delta t, \\
& j=\text { icel, ihemi }, \text { ilig }
\end{aligned}
$$

Equation 3.5 is for the total production of tar from all intermediate species,

Reaction 11-13, as well as the destruction of tar via tar cracking, Reaction 10 in Table 3.1.

$$
Y_{\text {tar }}^{\text {new }}=Y_{\text {tar }}^{\text {old }}+\left(\sum_{j} \beta_{\text {tar }, j} Y_{j}^{\text {old } n} A_{2, j} e^{-\frac{E_{2, j}}{\bar{R} T}}-Y_{\text {tar }}^{\text {old } n} A_{\text {tar }} e^{-\frac{E_{\text {tar }}}{\bar{R} T}}\right) \Delta t
$$

The production of individual gas species is calculated using Equation 3.6, this is for gas produced from primary pyrolysis, Reactions 4-6 and 11-13, and from tar cracking, Reaction 10 and 14.

$$
\begin{aligned}
& Y_{k}^{\text {new }}=Y_{k}^{\text {old }}+\left(\sum_{j} \beta_{k, j} Y_{j}^{\text {old }} A_{2, j} e^{-\frac{E_{2, j}}{\bar{R} T}}+\gamma \beta_{k, t a r} Y_{\text {tar }}^{\text {old }} A_{\text {tar }} e^{-\frac{E_{\text {tar }}}{\bar{R} T}}\right) \Delta t \\
& k=\mathrm{CO}_{2}, \mathrm{CO}, \mathrm{H}_{2} \mathrm{O}, \mathrm{H}_{2}
\end{aligned}
$$

Equation 3.7 is used to calculate the char production, Reactions 7-10 in Table 3.1. 


$$
Y_{\text {char }}^{\text {new }}=Y_{\text {char }}^{\text {old }}+\left(\sum_{j} Y_{j}^{\text {old }}{ }^{n} A_{3, j} e^{-\frac{E_{3, j}}{R T}}+(1-\gamma) Y_{\text {tar }}^{\text {old }} A_{\text {tar }} e^{-\frac{E_{\text {tar }}}{\bar{R} T}}\right) \Delta t
$$

\subsection{Large Particle Model}

Due to the low thermal conductivity for most biomass and the relatively low porosity, particle size can play an important role in how quickly thermal energy enters a particle and how quickly evolved gaseous species leave the particle. As such temperature gradients can develop in the particle and result in drastically different local temperature ramp rates through the biomass particle. Also, the time required for volatile species to leave the particle is strongly dependent on particle size, thereby increasing the vapor residence time in high temperature regions, leading to tar cracking [1].

Several assumptions are made when accounting for large particle sizes;

1) Cellulose, hemicellulose, lignin, as well as the three intermediate forms are assumed to have the same physical and thermal properties as the original biomass.

2) Chars from cellulose, hemicellulose and lignin are assumed to be identical. This is valid because chars are mostly carbon, and should have negligible variation in properties.

3) Tar cracking is assumed to only occur in the particle. This assumption can be justified by the fact that char is known to catalyze tar cracking. Tar to char interface is substantially higher inside the particle. Also in reactors with high sweep gas flow, small bed depth, and/or large particles, in-particle residence times will be higher than in-bed residence times. This assumption may not be valid for 
extremely large bed depths, small particles and/or very low to no sweep gas flows.

4) The process of a single particle approximates the process for the entire bed. This is based on the notion that all particles have similar composition and physical properties and that thermal gradients are minimized by reactor design.

5) Particles are assumed to be a cylinder. This accurately depicts the particles used in this study and is a good approximation for woody and herbaceous biomass particles.

6) Thermal properties are isotropic. Though it has been reported [14] that for wood the thermal conductivity in the grain direction is 2.5 times that of the thermal conductivity in the radial direction, wood was assumed to be thermally isotropic as an engineering approximation and the lower conductivity was used. This gives a worst case scenario for center to edge thermal gradients.

7) Volatile flow is only in the axial direction. It has been shown [16] that the permeability of wood is several orders of magnitude larger in the grain(axial) direction than across the grain (radial) direction. This allows for 1-D axisymmetric analysis.

To determine the internal temperature distribution the energy equation was solved in 2-D axisymmetric coordinates as shown in equation 3.8.

$$
\frac{\partial T}{\partial t}=\alpha\left[\frac{1}{r} \frac{\partial T}{\partial r}+\frac{\partial^{2} T}{\partial r^{2}}+\frac{\partial^{2} T}{\partial x^{2}}\right]
$$

Where: 
$\alpha=\frac{\lambda}{\rho_{\text {solid }} C p}$

$\alpha$ is the thermal diffusivity, $\lambda$ is the thermal conductivity, $\rho$ is the density of the wood, $\mathrm{Cp}$ is the specific heat, $t$ is time, $r$ is the radius, $x$ is the axial position, and $T$ is the local temperature. The system is symmetric in both directions, $\mathrm{r}$ and $\mathrm{x}$ are zero at the center. The resulting equation was solved using a Gauss-Seidel method.

The boundary conditions used were:

$$
\begin{aligned}
& \left.\frac{\partial T}{\partial r}\right|_{r=0}=0 \\
& \left.\frac{\partial T}{\partial x}\right|_{x=0}=0 \\
& \left.T\right|_{r=R}=T(t) \\
& \left.T\right|_{x=L}=T(t)
\end{aligned}
$$

Before solving the heat transfer, mass transport and reaction kinetics all together, the transient heat conduction into a cylinder of wood without mass transport or reactions was analyzed. Table 3.3 lists the parameters used in the thermal analysis. The particles used in the experiments performed in this work where $1 / 4$ " $\mathrm{x} 1 / 4$ " cylinders and the highest heating rate used was $10^{\circ} \mathrm{C} / \mathrm{min}$. Other simulations were performed on wood cylinders $1.5 \mathrm{~cm} \times 1.5 \mathrm{~cm}$ heated at $3^{\circ} \mathrm{C} / \mathrm{min}$, as per the simulated experiments of Konwer et al. [23]. As shown in Figure 3.4, the curves are very close, only $5^{\circ} \mathrm{C}$ difference from center to edge. In these cases, which represent those used in this work, particle sizes and temperature ramp rates are small enough that internal thermal gradients can be neglected. It should be noted that this analysis did not include reactions, as such reaction energies were not included, which could affect internal thermal gradients. While the particle sizes 
are much larger than the size criteria described in [4], the criteria considered internal mass transport and heat transfer affects in establishing a maximum size where particles can be considered kinetically limited. However in this case it can be assumed that heat transfer is negligible and only mass transport need be considered.
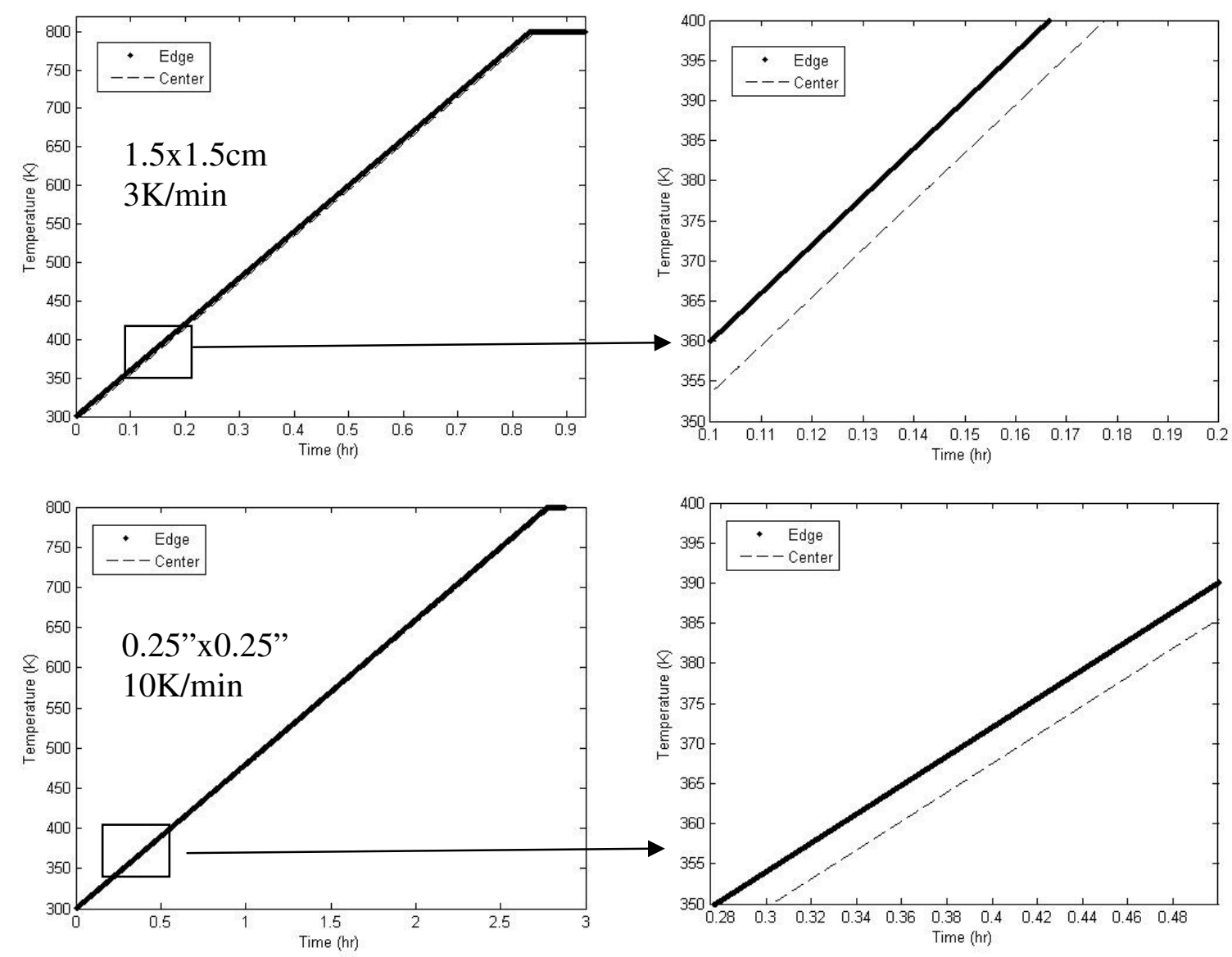

Figure 3.4: Simulations of transient surface and center temperatures for $1.5 \mathrm{~cm}$ and 0.25 " wood cylinders at 3 and $10 \mathrm{~K} / \mathrm{min}$.

Table 3.3: Properties used in thermal analysis

\begin{tabular}{|c|c|c|}
\hline Property & Value & Reference \\
\hline$\rho_{\text {wood }}$ & $630\left(\mathrm{~kg} / \mathrm{m}^{3}\right)$ & {$[14]$} \\
\hline$C_{\text {wood }}$ & $1500+1.0 \mathrm{~T}(\mathrm{~J} / \mathrm{kgK})$ & {$[14]$} \\
\hline$\lambda_{\text {wood }}$ & $.105(\mathrm{~W} / \mathrm{mK})$ & {$[14]$} \\
\hline
\end{tabular}


The thermal analysis performed above leads to a need to develop criteria for determining whether heat transfer need be considered. Taking the worst case scenario for particles where one dimension much greater than the other two (e.g., shredded wood, twigs, etc.), it can be assumed as an infinitely long cylinder, the heat transfer becomes one dimensional in the radial direction as seen in Equation 3.14.

$$
\frac{\partial T}{\partial t}=\alpha\left[\frac{1}{r} \frac{\partial T}{\partial r}+\frac{\partial^{2} T}{\partial r^{2}}\right]
$$

Where $T$ is temperature, $r$ radial position, $t$ is time and $\alpha$ is thermal diffusivity. From the previous thermal analysis, it is apparent that at some point in time, the local time rate of change of temperature equals that of the surface heating rate. Equation 3.14 becomes:

$\alpha\left[\frac{1}{r} \frac{\partial T}{\partial r}+\frac{\partial^{2} T}{\partial r^{2}}\right]=\Omega_{e d g e}$

Where $\Omega_{\text {edge }}$ is the applied surface heating rate. Using the following nondimensional variables:

$$
\begin{aligned}
& \Phi=\frac{T-T_{\text {center }}}{T_{\text {edge }}-T_{\text {center }}} \\
& \eta=\frac{r}{R}
\end{aligned}
$$

Where $R$ is the cylinder radius, $\Phi$ is non-dimensional temperature and $\eta$ is nondimensional position. Equation 3.17 becomes:

$$
\frac{\partial^{2} \Phi}{\partial \eta^{2}}+\frac{1}{\eta} \frac{\partial \Phi}{\partial \eta}=\frac{\Omega_{\text {edge }} R^{2}}{\alpha\left(T_{\text {edge }}-T_{\text {center }}\right)}
$$

The solution to this linear ODE is shown in Equation 3.19. 


$$
\Phi=\frac{\Omega_{\text {edge }} R^{2}}{4 \alpha\left(T_{\text {edge }}-T_{\text {center }}\right)} \eta^{2}+C_{1} \ln \eta+C_{2}
$$

Where $\mathrm{C}_{1}$ and $\mathrm{C}_{2}$ are integration constants. The boundary conditions for this system by definition are:

$\Phi(0)=0$

$\Phi(1)=1$

Applying these boundary condition yields equation 3.22.

$$
\frac{\Omega_{\text {edge }} R^{2}}{\alpha\left(T_{\text {edge }}-T_{\text {center }}\right)}=4
$$

Equation 3.22 is valid for particles heated with a linear ramp rate during the time that the center temperature experiences the same temperature ramp rate that is being applied to the surface. Rearranging and substituting diameter, $D$, in for radius gives an approximation for the maximum center to edge temperature difference during heating.

$$
\left(T_{\text {edge }}-T_{\text {center }}\right)=\frac{\Omega_{\text {edge }} D^{2}}{16 \alpha}
$$

Using Equation 3.23 to approximate the temperature difference in the cases solved numerical yields $3.4^{\circ} \mathrm{C}$ and $6.3^{\circ} \mathrm{C}$ for the $1 / 4$ " cylinders heated at $10^{\circ} \mathrm{C} / \mathrm{min}$ and the $1.5 \mathrm{~cm}$ cylinders heated at $3^{\circ} \mathrm{C} / \mathrm{min}$ respectively, which corresponded to the temperature differences from the numerical simulations.

For the opposite case, where one particle dimension is much smaller than the others (e.g., wood chips, leaves, chopped grasses, dried algae flakes, etc.), the particles can be assumed as infinite flat plates and solved in one dimension in the axial direction. 
The derivation is similar to the previous derivation, with $\eta=x / X$ in Eq. 3.17, and yields Equation 3.24.

$\left(T_{\text {edge }}-T_{\text {center }}\right)=\frac{\Omega_{\text {edge }} X^{2}}{4 \alpha}$

,where $X$ is the smallest particle dimension. Equations 3.23 and 3.24 allow a user to determine if the combination of heating rate and particle size produces an internal temperature gradient which is small enough to neglect and assume constant particle temperatures. For the purposes of these analyses, a temperature difference of less than 10 $\mathrm{K}$ was deemed acceptable between the edge and center of the particle, thus the remainder of the model is developed assuming a constant particle temperature. The developed model does not apply if the above criterion yields an edge to center temperature difference greater than $10 \mathrm{~K}$.

Assuming internal heat transfer effects are negligible, an order of magnitude analysis was then performed to determine the relative contributions of diffusion and convection in the mass transport. Starting with 1-D species transport as seen in Equation 3.25 ,

$$
\frac{\partial C}{\partial t}=D_{d i f} \frac{\partial^{2} C}{\partial x^{2}}-\frac{\partial u C}{\partial x}
$$

Where $C$ is concentration, $u$ is the $x$ direction velocity and $D_{d i f}$ is the diffusion coefficient. Defining non-dimensional variables where $C_{o}, u_{o}, \delta_{o}$, and $t_{o}$ are characteristic concentration, velocity, length and time, respectively:

$$
C^{*}=\frac{C}{C_{o}}
$$




$$
\begin{aligned}
& u^{*}=\frac{u}{u_{o}} \\
& x^{*}=\frac{x}{\delta_{o}} \\
& t^{*}=\frac{t}{t_{o}}
\end{aligned}
$$

Substituting Eq. 3.26-3.29 into Eq 3.25 and simplifying yields Equation 3.30.

$$
\frac{\partial C^{*}}{\partial t^{*}}=\frac{D_{d i f} t_{o}}{\delta_{o}^{2}} \frac{\partial^{2} C^{*}}{\partial x^{* 2}}-\frac{u_{o} t_{o}}{\delta_{o}} \frac{\partial u^{*} C^{*}}{\partial x^{*}}
$$

The derivatives are all order of magnitude 1, so Eq. 3.30 reduces to:

$$
1=\frac{D_{d i f} t_{o}}{\delta_{o}^{2}}-\frac{u_{o} t_{o}}{\delta_{o}}
$$

Defining a non-dimensional number for the ratio of convection to diffusion:

$$
\Pi=\frac{\frac{u_{o} t_{o}}{\delta_{o}}}{\frac{D_{d i f} t_{o}}{\delta_{o}^{2}}}=\frac{u_{o}}{\frac{D_{d i f}}{\delta_{o}}}=\frac{u_{o}}{u_{d i f}}
$$

Where $u_{o}$ is convection velocity and $u_{d i f}$ is the effective diffusion velocity. The convection velocity is given by Darcy's Law

$$
u_{o}=\frac{-K}{\mu \varepsilon} \frac{\partial P}{\partial x}
$$

Where $K$ is permeability, $\mu$ is viscosity, and $\varepsilon$ is porosity. $d P / d x$ is a characteristic pressure gradient given by a typical center pressure divided by length. The orders of magnitude of the pressure velocity using permeability values and pressures from Park et al. [14] are: 


$$
u_{o, \text { wood }}=\frac{K_{\text {wood }}}{\mu \varepsilon_{\text {wood }}} \frac{P-P_{a t m}}{\delta_{o}}=\frac{10^{-16}\left(10^{4}\right)}{10^{-10}(1) 10^{-2}}=1
$$

for wood and

$$
u_{o, \text { char }}=\frac{K_{\text {char }}}{\mu \varepsilon_{\text {char }}} \frac{P-P_{a t m}}{\delta_{o}}=\frac{10^{-13}\left(10^{4}\right)}{10^{-10}(1) 10^{-2}}=10^{3}
$$

for char. The order of the diffusion velocity is given by Equation 3.36, and the order of diffusion is from [25].

$u_{d i f}=\frac{D_{d i f}}{\delta_{o}}=\frac{10^{-4}}{10^{-2}}=10^{-2}$

So the ratio of pressure flow to diffusion flow is

$$
\Pi_{\text {wood }}=\frac{u_{o, \text { wood }}}{u_{\text {dif }}}=\frac{10^{0}}{10^{-2}}=100
$$

for wood and

$$
\Pi_{\text {char }}=\frac{u_{o, \text { char }}}{u_{\text {dif }}}=\frac{10^{3}}{10^{-2}}=10^{5}
$$

for char.

Based on this order of magnitude analysis, convection flow is dominant and diffusion can be neglected with in the particle.

To account for mass transport by convection, Darcy's law was used to relate velocity to pressure, pressure was used to calculate the vapor density using the ideal gas law, and the continuity equation was solved to account for mass balance within the control volume. Since the permeability of wood is generally an order of magnitude or 
more larger in the grain direction [17], the flow was assumed to be only in the axial (grain) direction. The one dimensional continuity equation is given by,

$\frac{\partial \rho}{\partial t}+\frac{\partial \rho u}{\partial x}+S_{\text {source }}=0$

Where $\rho$ is vapor density, $u$ is velocity, and the source term comes from the total vapor (gas and tar) evolution from primary pyrolysis and tar cracking. Darcy's law follows where $K$ is permeability of the wood, $\varepsilon$ is the porosity of the wood defined as pore volume to total volume ratio, $\mu$ is viscosity of the fluid, and $d P / d x$ is the pressure gradient.

$u=-\frac{K}{\varepsilon \mu} \frac{\partial P}{\partial x}$

Assuming the pyrolysis vapor, which contain a large percentage of $\mathrm{H}_{2} \mathrm{O}, \mathrm{CO}$ and $\mathrm{CO}_{2}$, is an ideal gas, we can relate pressure to density.

$P=\rho R_{v} T$

Where $R_{v}$ is $.461 \mathrm{kj} / \mathrm{kgK}$, based on the molecular weight of water. Using equation 3.40 and the ideal gas law, the mass balance of vapor phase in a porous media is given by equation 3.42 .

$\frac{\partial \rho}{\partial t}-\frac{K R_{v} T}{\varepsilon \mu}\left[\rho \frac{\partial^{2} \rho}{\partial x^{2}}+\left(\frac{\partial \rho}{\partial x}\right)^{2}\right]+S_{\text {source }}=0$

Vapor density can be expressed in terms of the total mass fraction of vapor $Y_{v}$, initial density, $\rho_{\text {wood }}$, and porosity, $\varepsilon$, as seen in equation 3.44 .

$Y_{v}=\frac{\text { mass }_{\text {vap }}}{\text { mass }_{\text {wood, ,initial }}}=\frac{\text { volume }_{\text {pores }} \rho_{v}}{\text { volume }_{\text {wood }} \rho_{\text {wood }}}=\frac{\varepsilon \rho_{v}}{(1-\varepsilon) \rho_{\text {wood }}}$ 
$\rho_{v}=\frac{(1-\varepsilon) Y_{v} \rho_{\text {wood }}}{\varepsilon}$

Equation 3.42 becomes:

$$
\frac{\partial Y_{v}}{\partial t}-\frac{K R_{v} T \rho_{\text {wood }}(1-\varepsilon)}{\varepsilon^{2} \mu}\left[Y_{v} \frac{\partial^{2} Y_{v}}{\partial x^{2}}+\left(\frac{\partial Y_{v}}{\partial x}\right)^{2}\right]+S_{\text {source }}=0
$$

For the sake of numerical simplicity, the porosity and permeability were assumed to be constant. While this is not the case for wood pyrolysis, since most of the reaction happens fairly quickly this should be an acceptable assumption for the present work, though this is an area of improvement for future work

Equation 3.45 was discretized using forward differencing schemes and solved semi-implicitly using Gaussian elimination. Equations 3.46 to 3.56 give the discretized equations to be solved.

$$
\begin{aligned}
& \frac{Y_{i}^{\text {new }}-Y_{i}^{\text {old }}}{\Delta t}-\frac{K R_{v} T \rho_{\text {wood }}(1-\varepsilon)}{\varepsilon^{2} \mu}\left[Y_{i}^{\text {old }} \frac{\left(Y_{i-1}^{\text {new }}-2 Y_{i}^{\text {new }}+Y_{i+1}^{\text {new }}\right)}{\Delta x^{2}}+\left(\frac{Y_{i}^{\text {new }}-Y_{i-1}^{\text {new }}}{\Delta x}\right)^{2}\right] \\
& +S_{\text {source }}=0 \\
& a_{i-1} Y_{i-1}^{\text {new }}+a_{i} Y_{i}^{\text {new }}+a_{i+1} Y_{i+1}^{\text {new }}=b \\
& a_{i+1}=-\frac{K R_{v} T \rho_{\text {wood }}(1-\varepsilon)}{\varepsilon^{2} \mu} Y_{i}^{\text {old }} \\
& a_{i-1}=-\frac{K R_{v} T \rho_{\text {wood }}(1-\varepsilon)}{\varepsilon^{2} \mu} Y_{i}^{\text {old }} \\
& a_{i}=1+\frac{K R_{v} T \rho_{\text {wood }}(1-\varepsilon)}{\varepsilon^{2} \mu}\left(Y_{i}^{\text {old }}+Y_{i-1}^{\text {old }}\right) \\
& b=Y_{i}^{\text {old }}
\end{aligned}
$$




$$
S_{\text {source }}=\sum\left[\frac{d Y_{\text {tar }}}{d t}+\frac{d Y_{\text {gas }}}{d t}\right]_{\text {reaction }} \Delta t
$$

The source term is simply the total volatile reaction rate calculated from the reaction kinetics.

The boundary conditions used were; symmetry at the center and Dirichlet condition at the edge. For the symmetry boundary condition, the coefficients are modified to account for identical conditions at the center and the next position.

$a_{i}=a_{i}+a_{i-1}$

$a_{i-1}=0$

For the Dirichlet condition at the edge, the coefficients are modified to use the known condition at the edge

$b=b+a_{i+1} Y_{\text {edge }}$

$a_{i+1}=0$

The values used for the physical properties of wood can be found in table 3.4. Values for density and permeability were taken from the literature, while the porosity was assumed as a representative value since it is very specific to each biomass species and it was not measured for any of the experiments.

\section{Table 3.4: Physical Properties of wood}

\begin{tabular}{|c|c|c|c|}
\hline Property & symbol & Value & Source \\
\hline Density $\left(\mathrm{kg} / \mathrm{m}^{3}\right)$ & $\rho$ & 630 & {$[14]$} \\
\hline Permeability $\left(\mathrm{m}^{2}\right)$ & $\mathrm{K}$ & $10^{-17}$ & {$[18]$} \\
\hline Porosity & $\varepsilon$ & .5 & assumed \\
\hline
\end{tabular}


The algorithm to solve this system given by Equations 3.3-3.7, and 3.35 is as follows:

Calculate source due to reactions (Eq 3.3-3.7)

Solve continuity equation (Eq 3.46-3.56)

Step in time

End when temperature ramp cycle has completed

Several Matlab programs were written following this algorithm to simulate several different types of pyrolysis experiments which can be found in Appendix B. 


\section{Chapter 4: Pyrolysis Experiments}

\subsection{Introduction}

Pyrolysis experiments were performed at the Department of Energy's National Energy Technology Laboratory in Pittsburgh, PA. These tests were performed to validate the model. This Chapter describes the equipment and procedures used in this work.

\subsection{Apparatus}

Figure 4.1 shows a schematic of the equipment used for this study. This device can be used in a fixed bed or drop tube mode, however for this work all experiments were done as a fixed bed. A vertically mounted tubular furnace contains an Inconel tube. This tube acts as the atmospheric containment chamber. It is connected to the sweep gas feed at the top and vented from the bottom. A quartz tube is fitted with a porous quartz frit that acts as a platform for biomass to sit. This tube is supported inside the Inconel tube and a thermocouple is located slightly above the frit. The tube furnace has three separately controlled heating zones; top, middle and bottom. At the bottom of the Inconel tube, filter paper is used to remove any large particles because the Pfeifer OmniStar quadruple mass spectrometer (MS) that samples the volatiles at the exit of the reactor must be protected from droplets and particles. Down stream of the mass spec sampling line, a copper coil is cooled in an ice water bath to condense out tar vapors. After the coil, vapors are plumbed into the house exhaust vent system or to an optional sample bag. 


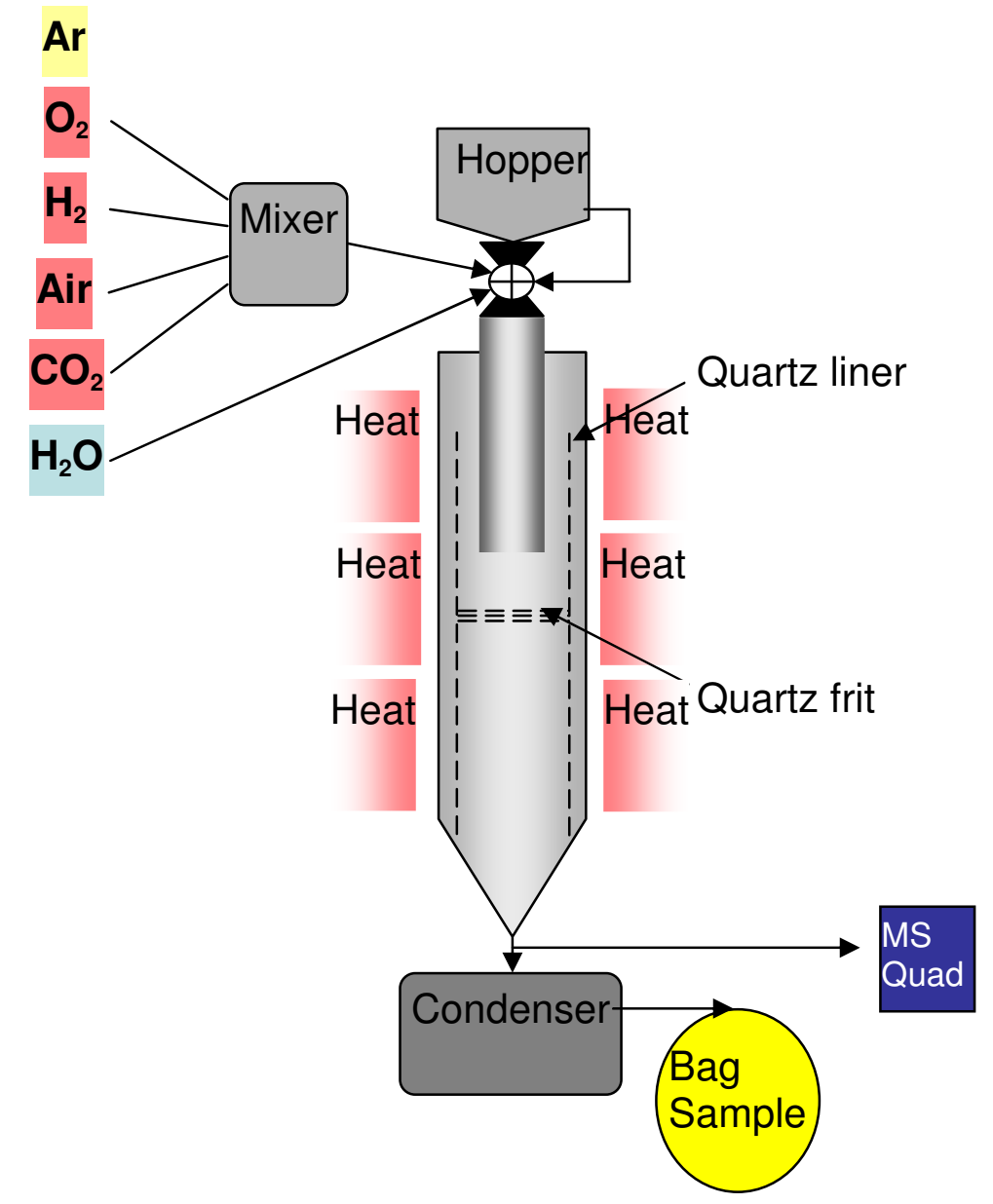

Figure 4.1: Schematic of the fixed bed pyrolysis reactor

\subsection{Biomass Feedstock and Preparation}

The material used for these experiments is red oak wood. The wood was purchased in the form of $1 / 4$ " diameter dowels. For the fixed bed reactor experiments, the dowels were cut into approximately 1/4" long pieces, resulting in 1/4"x 1/4" oak cylinders. Prior to the first set of experiments, oak pieces were placed in the reactor and heated to $105^{\circ} \mathrm{C}$ under argon purge to dry the pieces. Upon examining the MS readings for $\mathrm{H}_{2} \mathrm{O}$, it was determined that for this size pieces, 4 hours was sufficient for complete drying. 
After that, any addition samples where dried in a lab top tube furnace under $\mathrm{N}_{2}$ purge for at least 4 hours prior to loading into the reactor.

Several tests were performed on the biomass samples to characterize its physical and chemical properties. Proximate analysis was performed in house, and ultimate and heating value analyses were performed by Liviu Magean in the Analytical laboratory of the Department of Chemical Engineering, College of Mineral Resources at West Virginia University. Oak samples were ground in a rotary blade mill as per ASTM E 1757-95, and sieved to +20 mesh, $-20 /+80$ mesh, and -80 mesh.

For the proximate analysis, the procedures laid out in ASTM E827-82, E 1534-93 and E 871 -82 were used. Upon visual inspection, there were two "colors" of red oak woods, so they were treated separately. The results of the proximate, ultimate and heating value analyses are shown in Table 4.1 and Table 4.2. Light and dark oak were deemed to be near identical and are not distinguished between hereafter.

Table 4.1: Proximate analysis of red oak

\begin{tabular}{|l|l|l|l|l|}
\hline & $\begin{array}{l}\text { Volatile } \\
(\text { dry basis })\end{array}$ & $\begin{array}{l}\text { Ash } \\
(\text { dry basis })\end{array}$ & $\begin{array}{l}\text { Fixed carbon } \\
(\text { dry basis })\end{array}$ & Moisture \\
\hline Light Oak & $85.4 \pm 0.1$ & $0.4 \pm 0.01$ & $14.2 \pm .1$ & $5.4 \pm .04$ \\
\hline Dark Oak & $86.0 \pm 0.1$ & $0.4 \pm 0.02$ & $13.6 \pm .1$ & $5.5 \pm 0.1$ \\
\hline
\end{tabular}


Table 4.2: Ultimate analysis and heating value for red oak.

\begin{tabular}{|l|l|c|c|l|}
\hline & $\begin{array}{l}\text { Heating } \\
\text { value } \\
\text { (BTU/lb) }\end{array}$ & $\mathrm{C}$ & $\mathrm{H}$ & $\begin{array}{c}\text { O } \\
\text { (difference) }\end{array}$ \\
\hline Light Oak & $7909.1 \pm .60$ & $47.7 \pm .4$ & $6.4 \pm .01$ & 45.4 \\
\hline Dark Oak & $7912.3 \pm .20$ & $47.9 \pm .1$ & $6.4 \pm .01$ & 45.5 \\
\hline
\end{tabular}

\subsection{Procedure and Results}

Prior to a pyrolysis run, the condenser coil, frit, filter, quartz tube, and biomass sample are weighed. The quart tube is then placed in the Inconel tube inside the furnace. The biomass is loaded via a large valve at the top of the system which allows for the sample to fall around the thermocouple, thus locating the thermocouple in the center of the sample bed. Argon purge gas is passed through the system until the MS readings stabilize, indicating that the system is purged of any residual air. The purge gas flow rate is adjusted to the setpoint for the given run, along with the temperature ramp rate and the final hold temperature. One or more of the heating zones is enabled, depending on the parameters of the given run, and the system operates without any more input other than monitoring.

Once the system reaches the final hold temperature and hold time, the heaters are turned off and the system is allowed to cool. Once cooled, the condenser coil, filter, quartz tube, frit and solid residue are weighed and product yields are compared to the initial dried biomass sample. Char yields are determined via the mass of the solid residue, tar yields are determined by the mass change of the tube, coil and filter, and gas yields are computed based on the mass spec data. Overall mass balances may not be 
$100 \%$ due the tar collecting on tubes and fittings that are impractical to remove and weigh each run and trace amounts of gas species that are not found by the MS. The MS was calibrated for argon, $\mathrm{CO}, \mathrm{CO}_{2}, \mathrm{H}_{2}, \mathrm{CH}_{4}$, and $\mathrm{H}_{2} \mathrm{O}$ using pure gases and a gas splitter to obtain known dilutions of each. This calibration was verified using a calibration gas bottle with a known mixture of each species of interest. Table 4.3 shows an example mass balance for a pyrolysis experiment, all of which are listed in Appendix A. The tar is the sum of the differences in mass for the tube, filter, disk, coil and fitting. Since the water is trapped with the tar, the cumulative water mass has been subtracted from the MS gas data to prevent it from being counted twice.

Table 4.3: Mass balance for a fixed bed reactor experiment, Oak at $10^{\circ} \mathrm{C} / \mathrm{min}$ to $500^{\circ} \mathrm{C}$ under $250 \mathrm{~mL} / \mathrm{min}$ of argon

\begin{tabular}{|c|c|c|c|c|c|c|c|c|c|}
\hline & $\begin{array}{c}\text { Tube } \\
(\mathrm{g})\end{array}$ & $\begin{array}{c}\text { Filter } \\
(\mathrm{g})\end{array}$ & $\begin{array}{c}\text { Disk } \\
(\mathrm{g})\end{array}$ & $\begin{array}{c}\text { Coil } \\
(\mathrm{g})\end{array}$ & $\begin{array}{c}\text { Sample } \\
(\mathrm{g})\end{array}$ & $\begin{array}{c}\text { Fitting } \\
(\mathrm{g})\end{array}$ & $\begin{array}{c}\text { Gas } \\
(\mathrm{g})\end{array}$ & $\begin{array}{c}\text { Total } \\
(\mathrm{g})\end{array}$ & $\begin{array}{c}\text { Tar } \\
(\mathrm{g})\end{array}$ \\
\hline Before & 267.88 & 0.305 & 2.760 & 300.82 & 7.973 & 922.58 & ---- & 1502.32 & ----- \\
\hline After & 268.15 & 0.929 & 2.799 & 303.83 & 2.012 & 922.85 & 0.520 & 1501.09 & 4.22 \\
\hline Difference & 0.27 & 0.624 & 0.040 & 3.01 & -5.961 & 0.27 & 0.520 & -1.229 & ---- \\
\hline
\end{tabular}

Table 4.4 is a test matrix for all of the pyrolysis experiments, the details of which are found in Appendix A. 
Table 4.4: Pyrolysis experiment test matrix and product yields

\begin{tabular}{|c|c|c|c|c|c|c|}
\hline Test & Tmax & Rate & Purge Flow & \multicolumn{3}{|c|}{ Product Yields } \\
\hline & & & & Char & Tar & Gas \\
\hline & C & K/min & $\mathrm{mL} / \mathrm{min}$ & $\%$ & $\%$ & $\%$ \\
\hline 1 & 690 & 10 & 250 & 23 & 48 & 16 \\
\hline 2 & 650 & 10 & 250 & 24 & 45 & 6 \\
\hline 3 & 550 & 10 & 250 & 24 & 49 & 10 \\
\hline 4 & 500 & 10 & 250 & 25 & 53 & 7 \\
\hline 5 & 450 & 10 & 250 & 29 & 50 & 22 \\
\hline 6 & 650 & 10 & 500 & 24 & 51 & 17 \\
\hline 7 & 660 & 10 & 1000 & 23 & 33 & 11 \\
\hline 8 & 560 & 5 & 1000 & 26 & 38 & 20 \\
\hline 9 & 650 & 5 & 1000 & 25 & 26 & 27 \\
\hline 10 & 460 & 5 & 1000 & 31 & 41 & 20 \\
\hline
\end{tabular}

In addition to model validation experiments, a set of tests was conducted to determine the affect of purge gas flow rate on yields in this reactor. The data shown in Figure 4.2 for pyrolysis of oak cylinders at $650^{\circ} \mathrm{C}$ and $10^{\circ} \mathrm{C} / \mathrm{min}$ with 250,500 , and 1000 $\mathrm{mL} / \mathrm{min}$ flow of Ar seems to suggest that flow rate has a strong influence on product yields. However, attention must be drawn to the total mass data. It could be argued that the strongest affect flow rate has on this reactor is the ability to capture and measure all of the mass. Lower flow rates should lead to increased tar cracking, while tar yields decrease, gas yields do not, which indicates a deficiency in the measurement of gas for the low flow rate cases. Likewise, there should be an increase in tar yields as flow rates increase, which is not reflected in the measurements, indicating a failure to capture all of the tar in the high flow rate cases. 


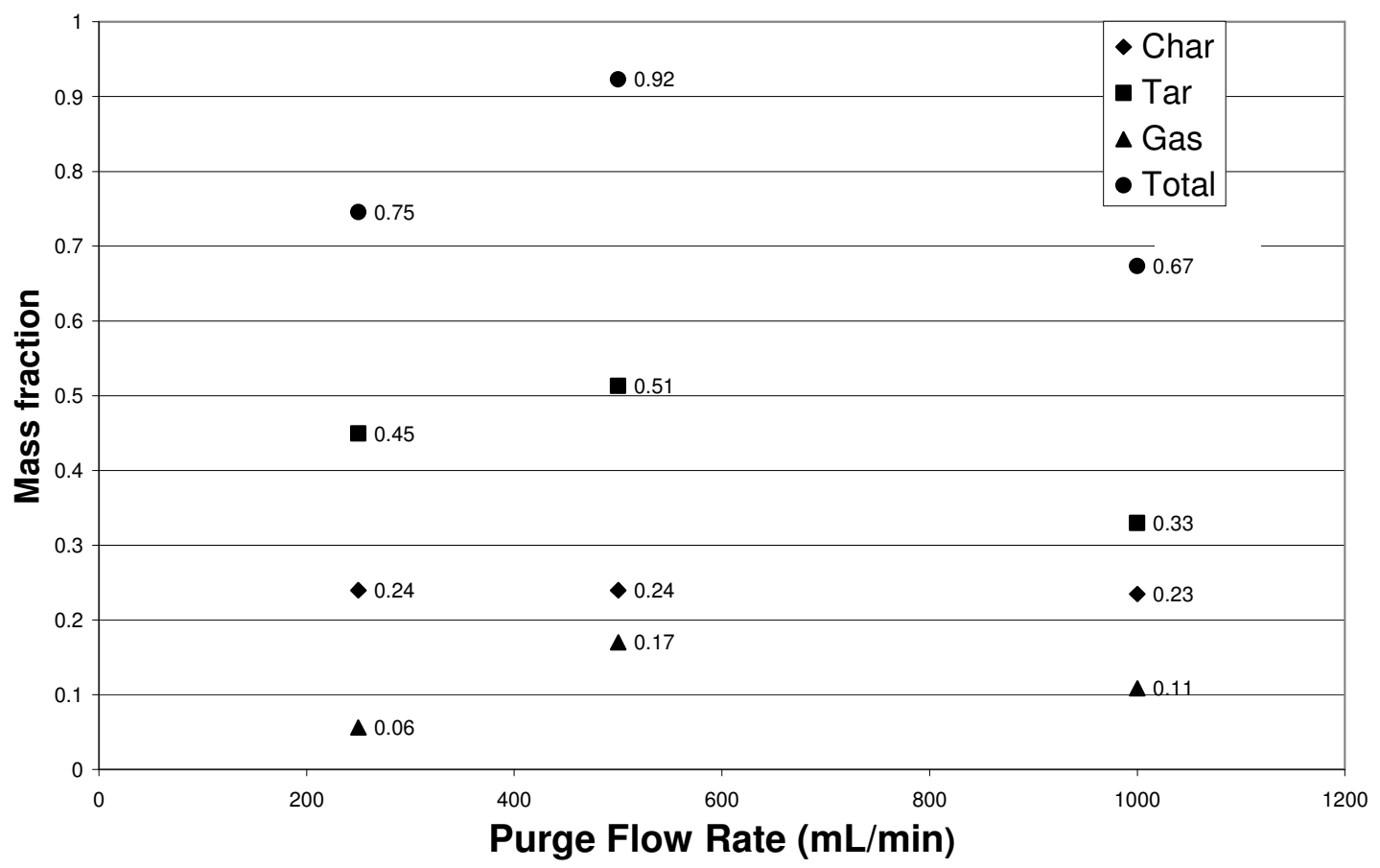

Figure 4.2: Mass fraction yields of oak cylinders at different Argon flow rates, $10^{\circ} \mathrm{C} / \mathrm{min}$ and $650^{\circ} \mathrm{C}$ 


\section{Chapter 5: Model Validation}

\subsection{Introduction}

In order to be confident in the predictions made by the model developed here and the computer simulations that utilize the model, they must be compared to experimental data for validation purposes. Because of the time intensive nature of pyrolysis experiments and the lack of ability to perform many of these experiments in-house, some of the validation data has been obtained from the literature. There are three schemes used for model validation; Thermogravimetric analysis (TGA), Fixed bed with small particle size and fixed bed with large particle size. In this chapter, these schemes are discussed, as well as the results of these validations.

\subsection{Thermogravimetric Analysis (TGA)}

TGA simulations are done to approximate the process of a typical thermogravimetric analysis (TGA), where a small amount of biomass is placed in a vessel, heated at a set temperature ramp and weighed periodically. The result is a temperature dependent residual mass curve. For these models, only kinetic effects are considered because only experiments with low heating rates $(<10 \mathrm{C} / \mathrm{min})$ and small particle sizes are considered. Also, there is usually a high flow rate of purge gas that minimizes tar residence times, thereby minimizing the amount of tar cracking. However, since in many experiments only solid residue is measured, tar cracking has no impact on the results since it does not affect the char yield appreciably. Published TGA data [8, 19, 20, 21] for biomass components and several biomass species were used for this validation. 


\subsection{Fixed Bed With Small Particle Size}

While TGA validation shows the performance of the model at predicting the transient pyrolysis reaction, of more importance for practical use of this model is how well the model predicts product yields. To this end, the kinetic model described in section 3.2 was integrated for a given temperature ramp rate to several hold temperatures

and the final product yields were recorded. A fixed bed simulation curve represents a family of experiments, as opposed to the single experiment that a TGA curve represents. Again, published data was used for this validation using a set of experiments where tar cracking could be neglected due to small particle size and high sweep gas flow [22] as well as a set of experiments where large particles and slow heating rates were used [23]. This comparison aided in the validation of the tar cracking mechanism. Another set of experiments that measured gas species and used small particles was used to examine to accuracy of the gas species prediction. [22]

\subsection{Fixed Bed With Large Particle Size}

While the model in the previous section can give us an idea of the accuracy of the mechanism, in practice particle sizes are generally large enough that mass transport cannot be neglected. To test the model under these conditions simulations were compared to experiments from the literature [23] as well as in-house experiments, which used low heating rates and large particle sizes. 


\section{5: Validation Results}

Table 5.1 contains the dry biomass component composition for each simulation performed in this study as well as the source of this composition, where reported. Any reported extractives are added to the hemicellulose per standard convention and ash is treated as an inert solid.

Table 5.1 biomass composition for simulations

\begin{tabular}{|l|c|c|c|c|c|c|}
\hline Biomass & Cell & Hemi & Lignin & Ash & Use & Source \\
\hline Cellulose & 1 & - & - & - & TGA & - \\
\hline Hemicellulose & - & 1 & - & - & TGA & - \\
\hline Lignin & - & - & 1 & - & TGA & - \\
\hline Hardwood & 0.401 & 0.35 & 0.231 & .018 & TGA & {$[20]$} \\
\hline Pine & 0.498 & 0.208 & 0.267 & .027 & Both & {$[22]$} \\
\hline T Capatta & 0.4167 & 0.2915 & 0.267 & .0248 & Fixed & {$[23]$} \\
\hline Rice husk & 0.3550 & 0.2135 & 0.2495 & .1825 & TGA & {$[21]$} \\
\hline Switchgrass & 0.3348 & 0.261 & 0.1735 & .2307 & TGA & {$[19]$} \\
\hline Oak & .422 & .375 & .202 & .002 & Fixed & {$[24]$} \\
\hline
\end{tabular}

The rest of this section is divided into subsections based on what type of analysis was being performed.

\subsection{1: TGA simulation results}

TGA simulations are one method of examining the kinetic model, and since TGA type experiments are rarely done on large particles, in this sub-section, results are shown 
from simulations using only the kinetic model. The results of biomass component TGA simulations are shown in Figure 5.1. The experimental data in this plot is from the same source as reaction rate constants [8] used in the model. This simulation is done to demonstrate that the model operates correctly and matches the data used to create it. The point of reaction onset and subsequent slope match nicely, as well as the residual mass fraction after the predominant mass loss. The reactions behave as expected with hemicellulose reaction reacting first, lignin having the highest solid residual, and cellulose yielding the lowest solid fraction. It is worth noting that in the data there is a continued devolatilization, especially for hemicellulose. This discrepancy has also been noted in the literature [8] and is a place of possible improvement in the model especially for reactions at higher temperatures or long reaction times.

It was noted in section 3.2 that the reaction orders for the reaction of virgin biomass components to their intermediates were changed from $n=0$ to $n=1$, per suggestion of Miller and Bellan [4]. When the simulations were repeated with the initial reaction order set to zero, as suggested originally by Koufopanos [8], the curves collapsed and the code required modification to prevent negative cellulose, hemicellulose and lignin yields. This suggests that modifying the mechanism to be first order saves computing time, creates a more realistic model while maintaining its accuracy. It was also noted in section 3.2 that the reaction order for lignin reactions 2 and 3 was changed from 1.5 to 3 . This yielded better agreement with the data [8] used to develop the model and supports this modification. 


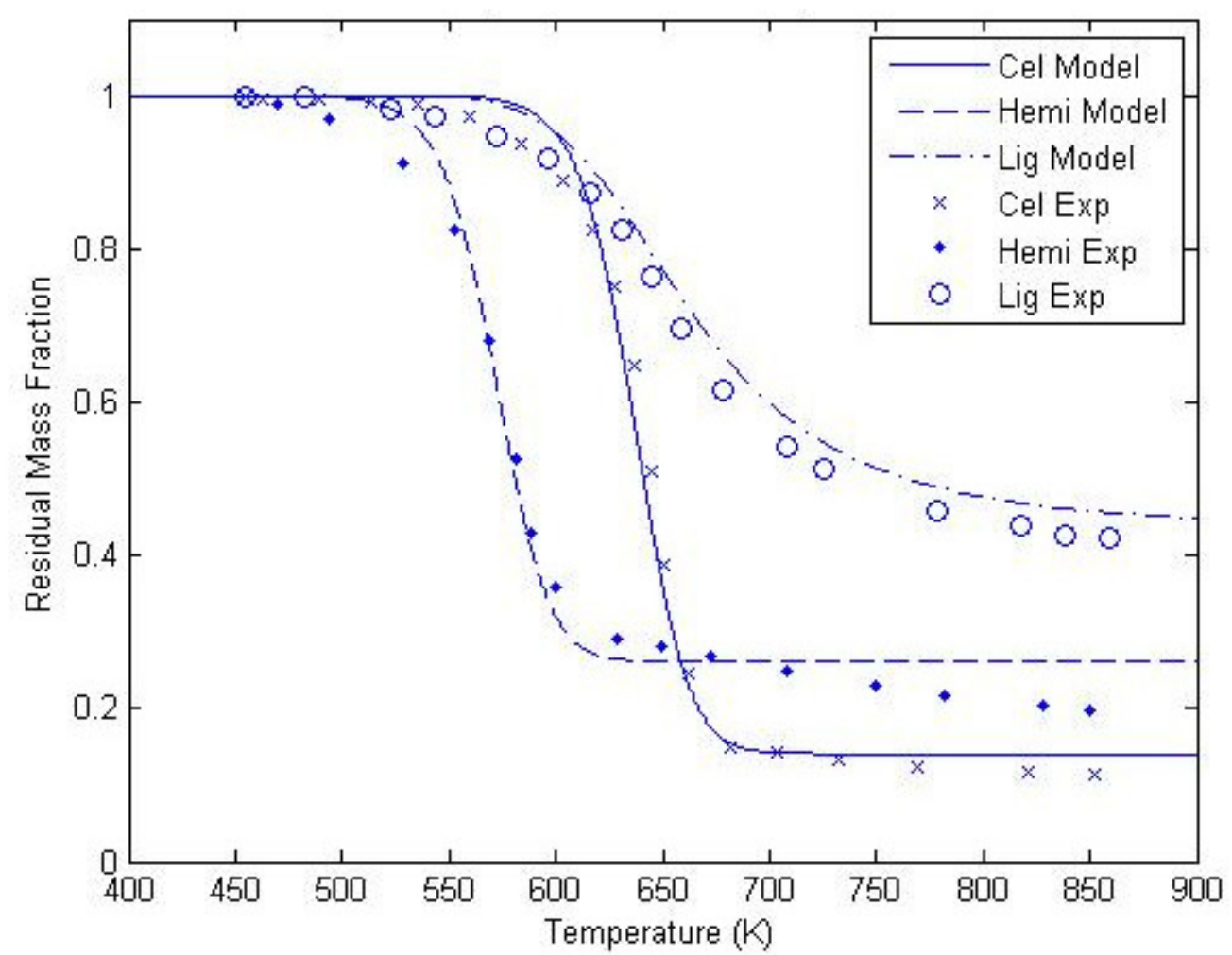

\section{Figure 5.1: TGA simulation and experimental data [8] for cellulose, hemicellulose, and lignin}

TGA plots from the simulations of switchgrass, hardwood and rice husk are shown in Figures 5.2, 5.3 and 5.4, respectively. For switchgrass the agreement with experiments in [19] is excellent throughout the entire temperature range. For hardwood [20], some discrepancies are seen in the final solid mass fraction, probably due to the high hemicellulose content (see Table 5.1) and the lack of continued devolatilization in the model, which is most pronounced in hemicellulose. For the risk husk [21], the final solid fraction and the slope during the predominant mass loss match nicely, however the temperature where the mass loss starts is offset from the experimental data. This is most likely due to the large ash content of the sample, $18.25 \%$, which is known to act as a catalyst in some cases. To an extent, the plots before and after the predominant mass loss are not critical. It is important that the slope of the TGA plot for predominant mass loss 
be accurate, since this is where the majority of the reaction occurs. This will become significant when applying this reaction model to a larger simulation which accounts for mass transport and heat transfer.

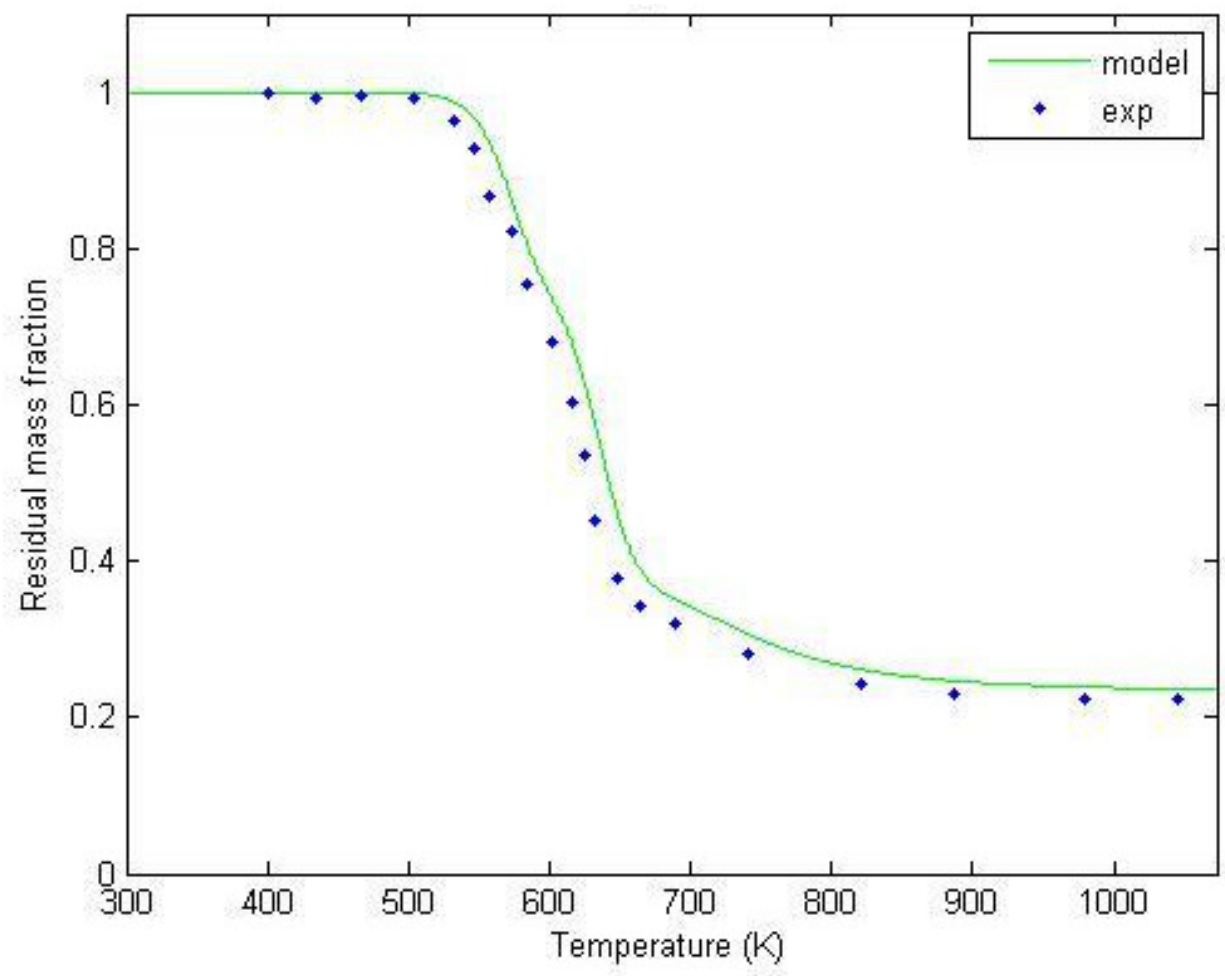

Figure 5.2: TGA of simulation and experimental data [19] for switchgrass 


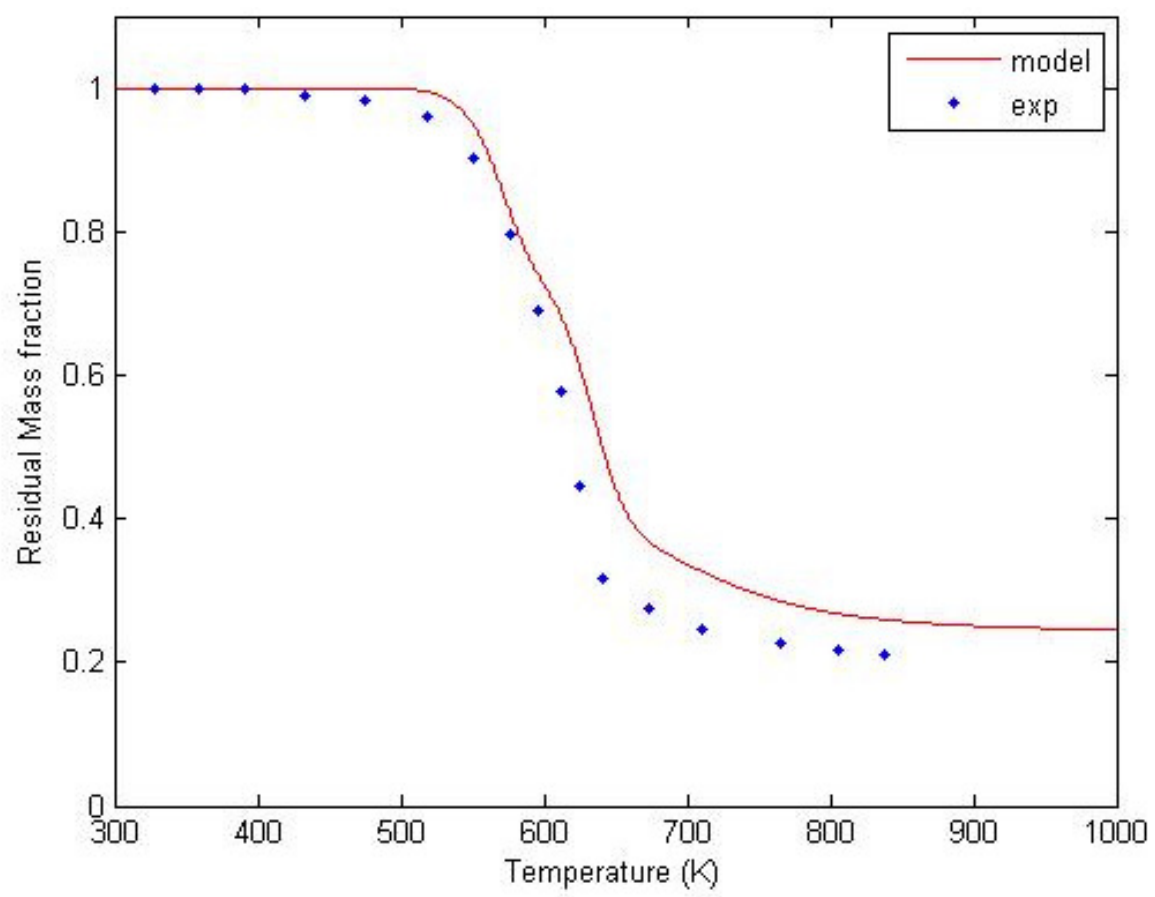

Figure 5.3: TGA model and experimental data [20] for hardwood

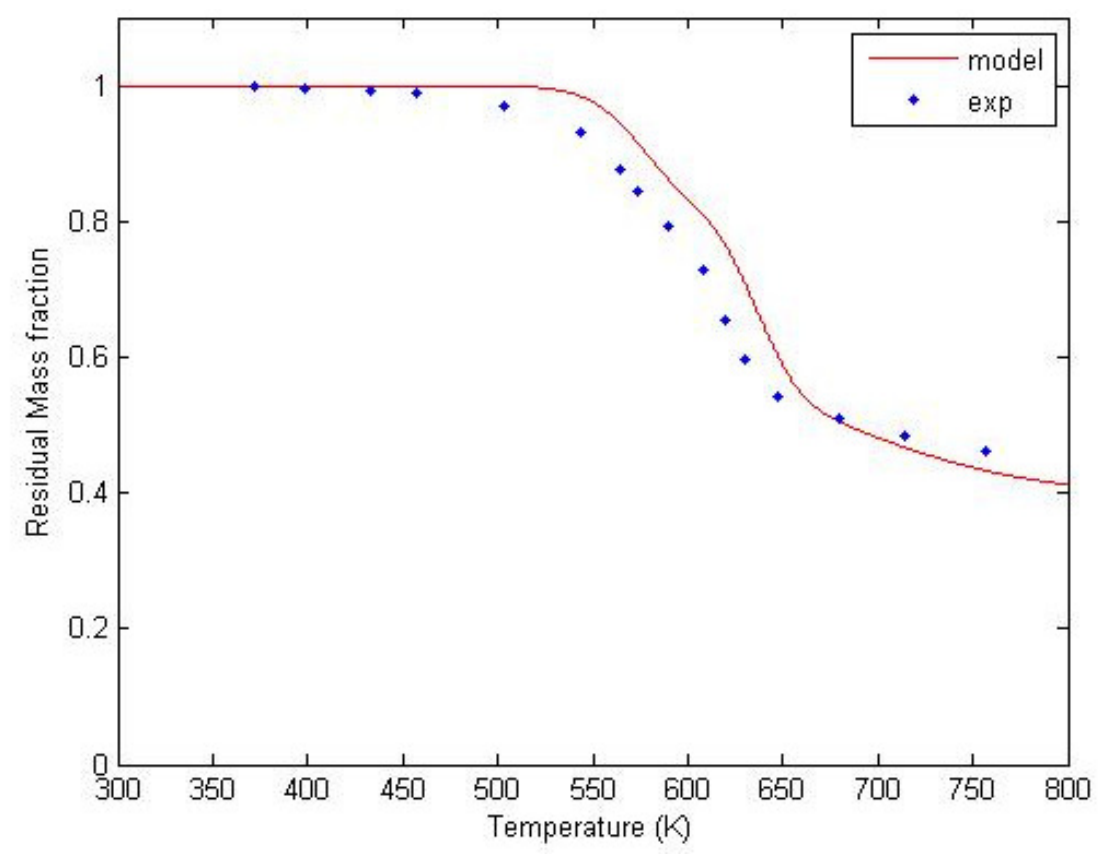

Figure 5.4: TGA model and experimental data [21] for rice husk 


\subsection{2: Fixed bed, kinetic results}

The ability to predict yields when heating rate, maximum temperature and hold time vary is important. To determine the effectiveness of this reaction mechanism, fixed bed simulations were performed. Since pyrolysis product yields for each biomass component at different reaction temperatures could not be found in the literature, the validation for the fixed bed scheme was limited to several species of wood. Figure 5.5 shows the mass fraction yields of char, tar and syngas for pine at different reaction temperatures. Model agreement with experimental data [22] is excellent, but only when tar cracking is turned off by setting the reaction rate pre-exponential for tar cracking, $A_{\text {tar }}$, to zero. This suggests that the purge gas rate in this experiment [22] was high enough to make residence times sufficiently small so that tar cracking was negligible, which was the intended design of the experiments in [22].

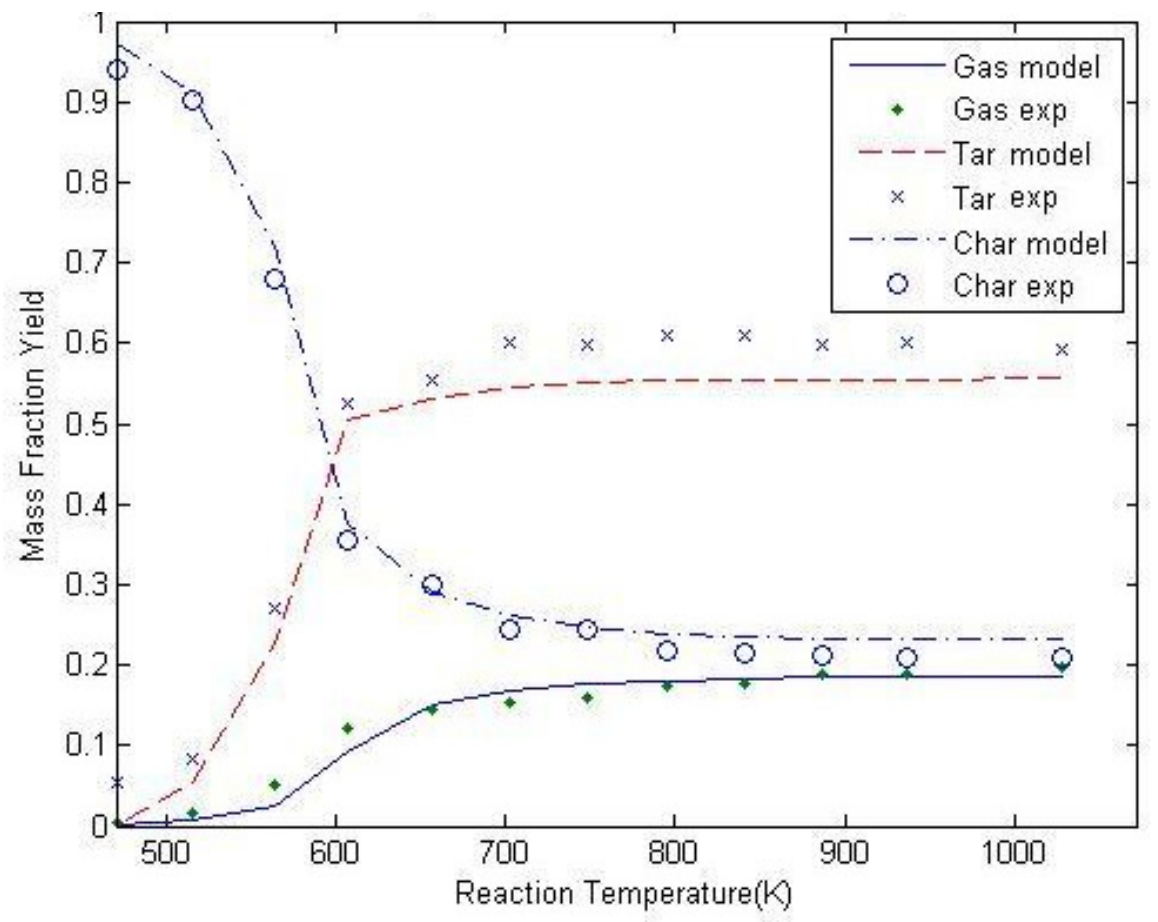

Figure 5.5: Product yields at different pyrolysis temperatures for fine particle pine. Simulation vs. Experiments [22] 

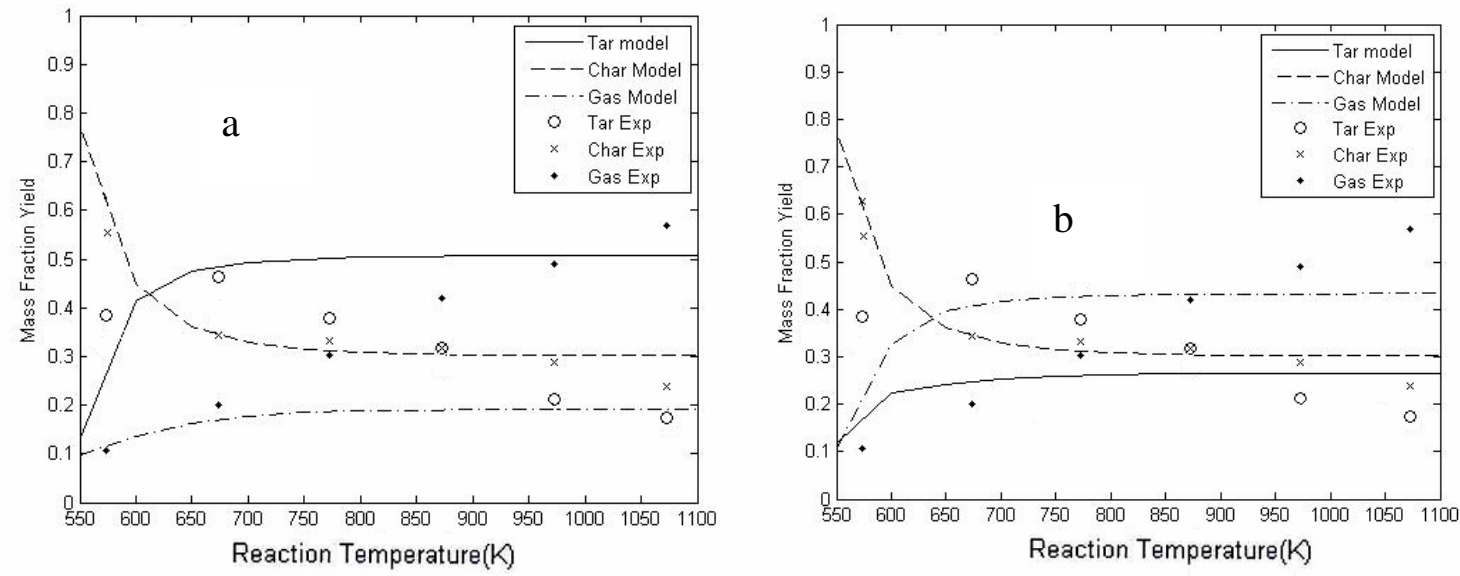

Figure 5.6: Product yields at different pyrolysis temperatures for T. Catappa. Simulation vs. Experiments [23], with (b) and without (a) tar cracking

For the purpose of testing the tar cracking reaction, the kinetic model was compared to data from experiments with low heating rates $\left(3^{\circ} \mathrm{C} / \mathrm{min}\right)$ and large particles $(\sim 1 \mathrm{~cm})[23]$. In this case, the diffusion of tar vapors through large particles increases the effective vapor residence time, allowing sufficient time for tar cracking, while minimizing finite heat transfer effects through slow heating rates. Figure 5.6 shows the product yields as a function of temperature for (Terminalia catappa), an almond tree hardwood indigenous to northeast India. Simulations were done with and without tar cracking. While the reaction conditions may not be purely represented in this case, the plot shows better agreement when tar cracking is used for higher temperatures. Whether the discrepancy is a deficiency in the reaction model or due to heat transfer and mass transport effects will be determined with the large particle model.

\subsection{3: Kinetic gas species results}


Figure 5.7 shows a plot of the mass fractions of each gas species for pyrolysis of pine wood at different reaction temperatures with tar cracking turned off. While the final values are not close, they represent an improvement over previous iterations shown in Figure 5.8 which are based on temperature-dependent concentration factors derived from Ref [7]. The biggest marked improvement is the ability to predict qualitatively which species will be the predominant species, and the relative distribution.

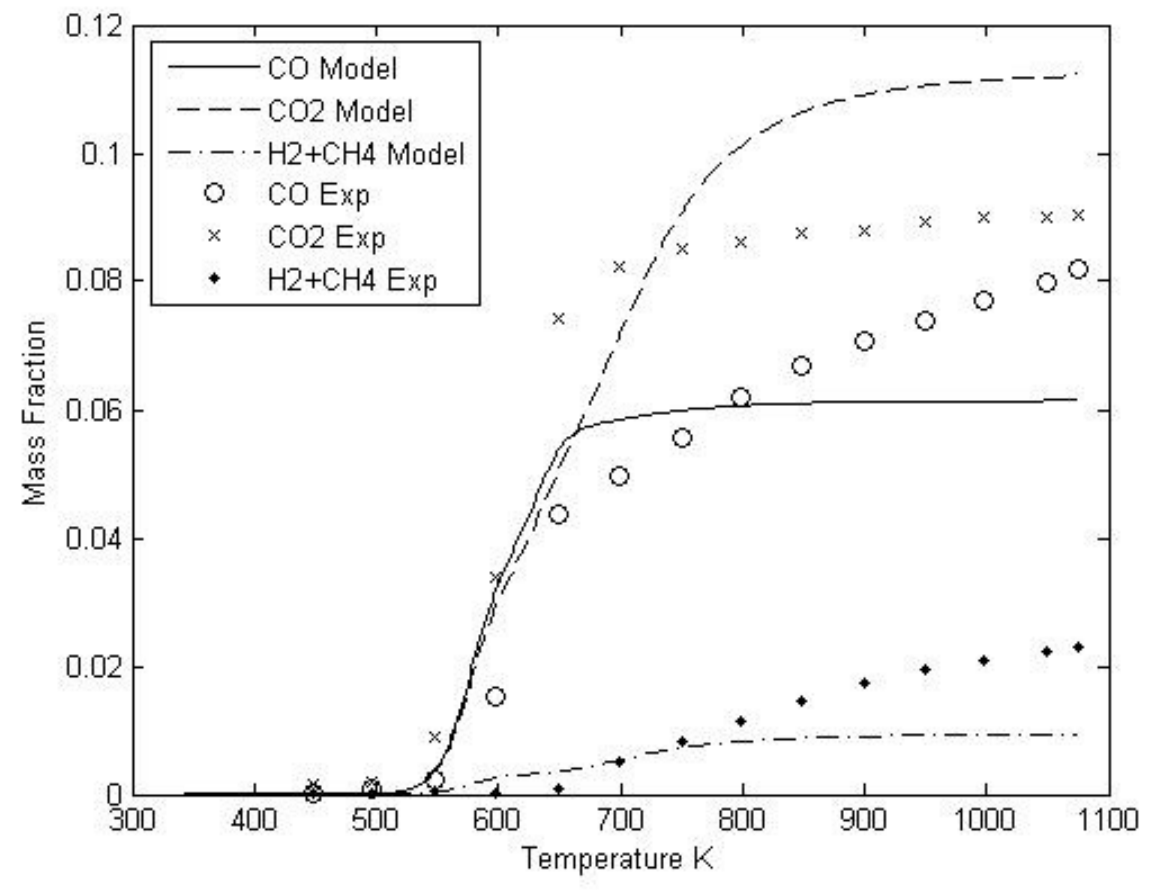

Figure 5.7: Gas species yields at different pyrolysis temperatures for fine particle pine. Simulation vs. Experiments [22], using new concentration factors at $10^{\circ} \mathrm{C} / \mathrm{min}$ 


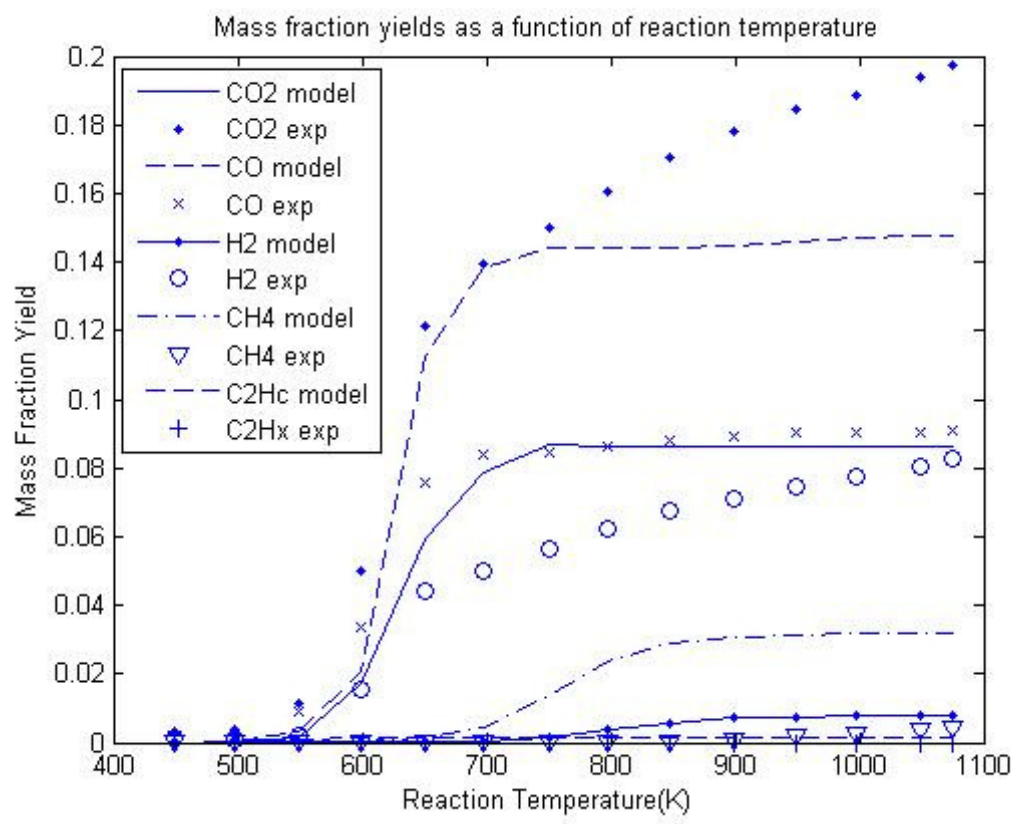

Figure 5.8: Gas species yields at different pyrolysis temperatures for fine particle pine. Simulation vs. Experiments [22], using old concentration factors at $10^{\circ} \mathrm{C} / \mathrm{min}$

\subsection{4: Particle pyrolysis results}

The following section describes the validation for the 1-D mass transfer component of the particle model.

Figure 5.9 shows mass fraction yields for char, tar, and syngas as a function of reaction temperature for quarter inch by quarter inch oak cylinders at (a) $5 \mathrm{~K} / \mathrm{min}$ and 1000 $\mathrm{mL} / \mathrm{min}$ Ar flow and for (b) $10 \mathrm{~K} / \mathrm{min}, 250 \mathrm{~mL} / \mathrm{min}$ Ar flow. These experiments were performed in-house. 

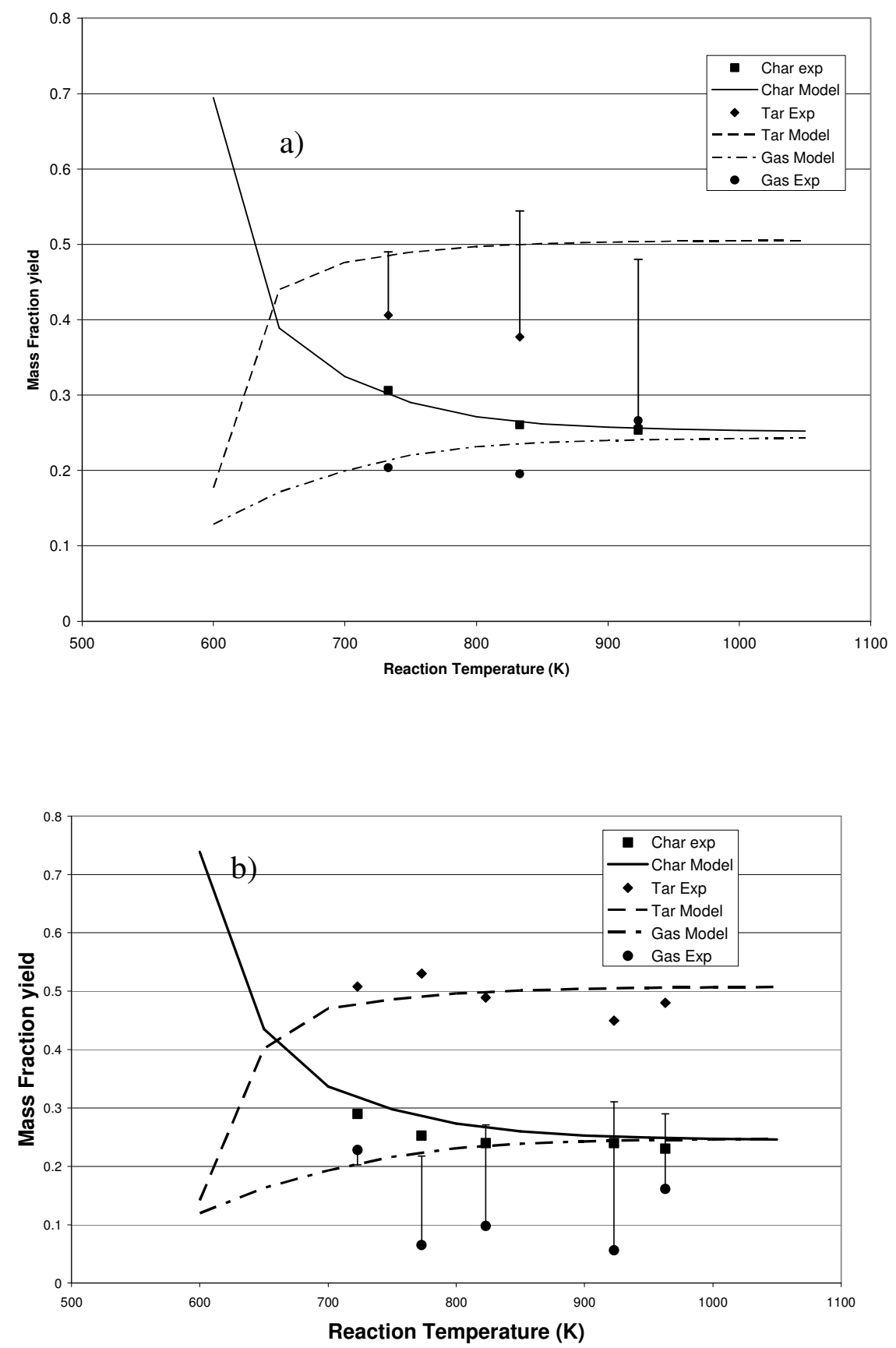

Figure 5.9: Product yields at different pyrolysis temperatures for oak cylinders. Simulation vs. Experiments: at a) $5^{\circ} \mathrm{K} / \mathrm{min}$ and $1000 \mathrm{~mL} / \mathrm{min}$ Ar flow and b) $10^{\circ} \mathrm{K} / \mathrm{min}$ and $250 \mathrm{~mL} / \mathrm{min}$ Ar flow

For both sets of experiments, two out of three predictions are close, char and gas for $5^{\circ} \mathrm{K} / \mathrm{min}$ and char and tar for $10^{\circ} \mathrm{K} / \mathrm{min}$. As discussed in connection with Fig. 4.2 above, this probably has more to do with the change in purge flow rate, which was 
increased from $250 \mathrm{~mL} / \mathrm{min}$ to $1000 \mathrm{~mL} / \mathrm{min}$ to help eliminate noise in the gas measurements, and for the $1000 \mathrm{~mL} / \mathrm{min}$ experiments a different MS calibration was used. Also, it is possible that with a higher flow for purge gas, the tar condenser was not capturing all of the tar vapors. This theory is supported by comparing the water vapor data in Appendix A to the tar data in Appendix A, the water vapor being an MS measurement and the tar being from the mass accumulation. For the low flow cases, the water vapor measurement is much smaller than the tar measurement, indicating an error in the MS, while for two of the high flow cases, the water vapor measurement is more than the tar measure, indicating some of the water was not collected. The error bars represent the "missing mass" from the experimental mass balance. Taking into account this source of error; the previously poor predictions have the potential to be much better if the experimental mass balances can be closed. The char yields are slightly over predicted at the higher heating rate, which could be indicative of the slow heating rate limitation of the reaction mechanism.

Gas species predictions for oak cylinder pyrolysis are shown in Figure 5.10. In Figure 5.10a the gas yields are shown based on the mass of gas per mass of starting wood, however due to the noise related to the gas measurements it is difficult to see any trends. Looking at Figure 5.10b, which is the gas species plotted as a mass fraction of total gas, the predictions come closer and at least follow the experimental trend. There seems to be a temperature dependent trend in the data, which is not shown in the model, but this is to be expected, since the model concentration factors are based on average value over the temperature range. This shows a place for improvement, either through 
better concentration factors or through competitive reaction for each gas species, as well as increasing the number species which are included.
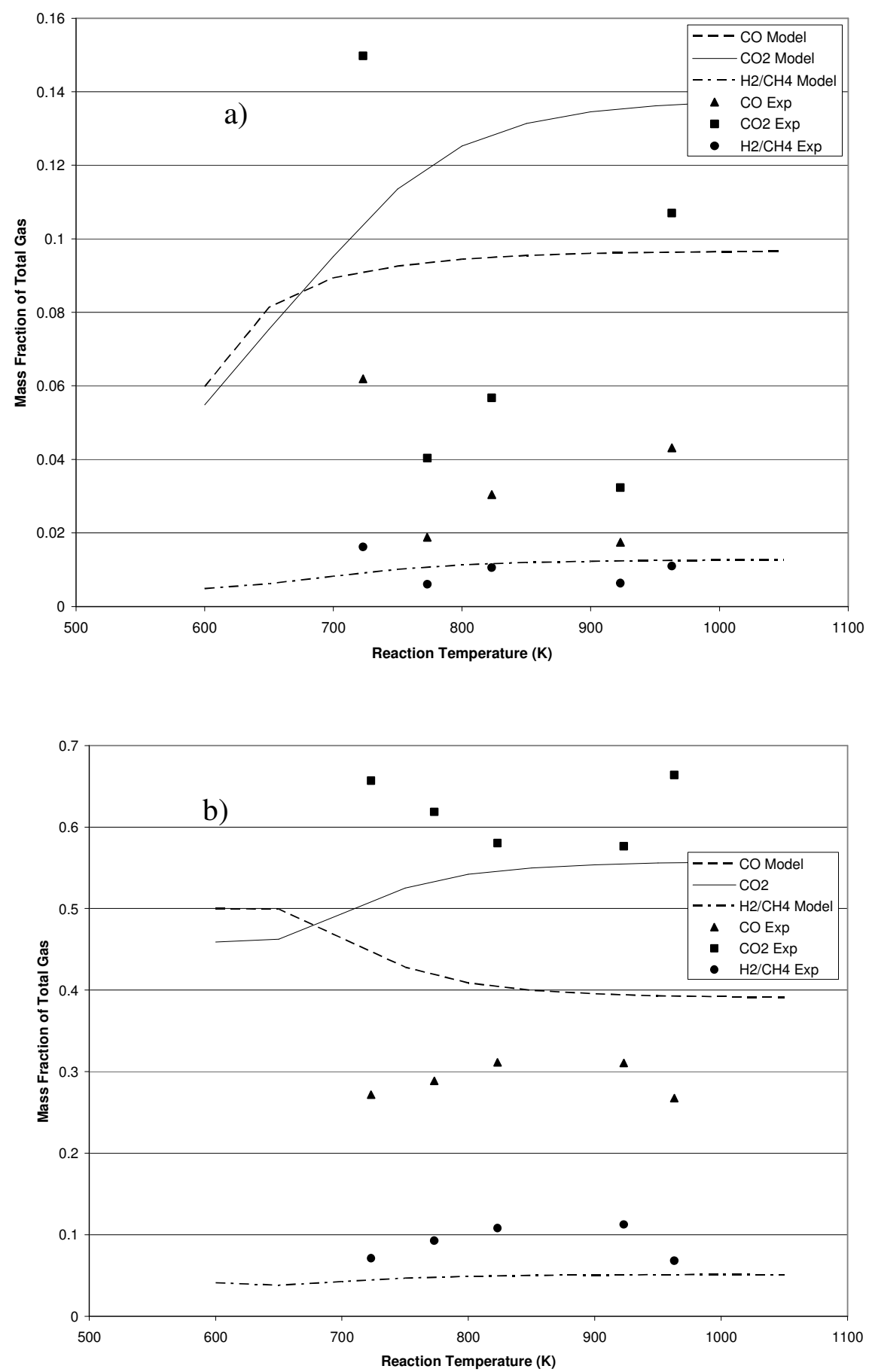

Figure 5.10: Gas species fraction based on a) initial wood mass and b) total gas mass for oak cylinders at $10 \mathrm{~K} / \mathrm{min}$ and $250 \mathrm{~mL} / \mathrm{min} \mathrm{Ar}$ 
Figure 5.11 shows product yields for T. Catappa from experimental data in [23], while simulations were performed with 1D mass transfer to account for the large particle size. This data was previously used as a comparison for the kinetic model, which can be seen in Figure 5.6. Accounting for particle affects, the predictions are closer at low temperature but still fail to predict the apparent tar cracking that is occurring. This is mostly due to the fact the in the experiments [23], no purge gas was used and pyrolysis vapors were forced out of the reactor via natural convection, as such reactor residence times are much greater than if a purge gas was used, allowing more time for tar cracking outside of the particle. This situation points out the need to incorporate the particle model developed here into a larger CFD model which would account for fluid flow inside the reactor.

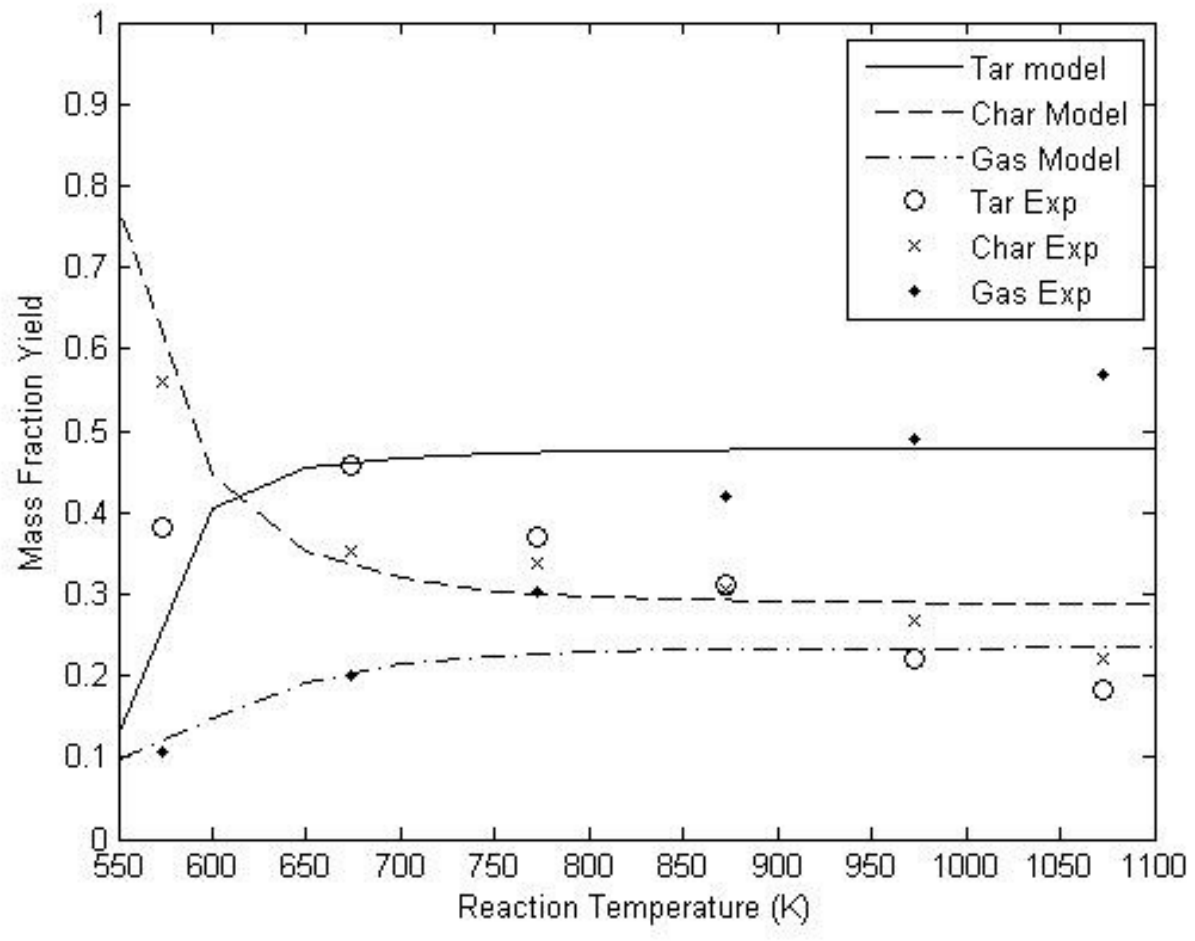

Figure 5.11: Product yields at different reaction temperatures for large particle simulations and experimental [23] pyrolysis of T. Catappa.at $3 \mathrm{~K} / \mathrm{min}$ 


\subsection{5: Comparing modeling schemes}

It is useful to compare the simulations for different modeling schemes.

Simulations were performed for $1.5 \mathrm{~cm}$ cylinders of $T$. Catappa at several final reaction temperatures and the product yields were compared to experimental data [23]. Figure

5.12 shows the tar yields using kinetic only modeling with tar cracking enabled, kinetic only modeling with tar cracking disabled and the full particle model. Note that with the tar cracking disabled, low reaction temperature predictions are close, but at higher temperatures the predictions are too high while with the tar cracking turned on, the low temperature predictions are too low and closer at higher temperatures. With the particle model, tar predictions are lower than kinetic predictions without cracking, but still fail to capture decrease in tar at high temperatures. As mentioned earlier this is most likely due to the lack of purge gas flow in the experiments [23] and the existence of gas phase tar cracking outside of the particle.

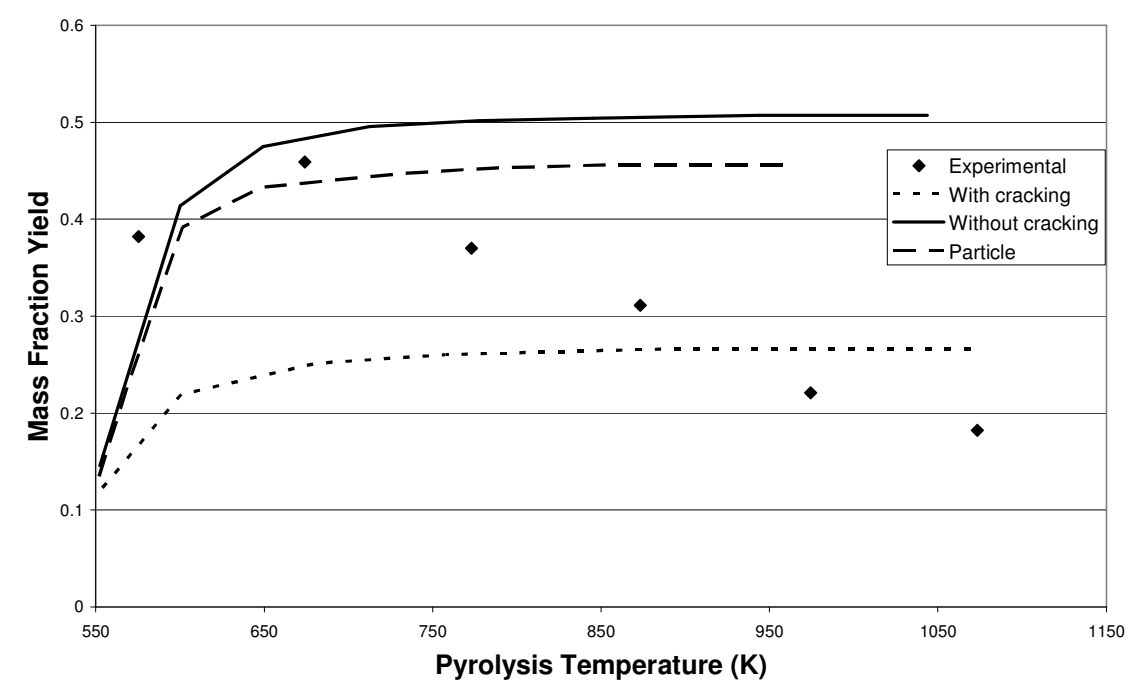

Figure 5.12: Tar yields as at different reaction temperatures for T. Catappa at 3K/min. Several model scheme versus experimental [23] 
Figure 5.13 show the gas yields for this analysis, note the gas predictions are the converse of the tar predictions, low for high temperatures without tar cracking and high for low temperature with cracking, while the particle model lies between them.

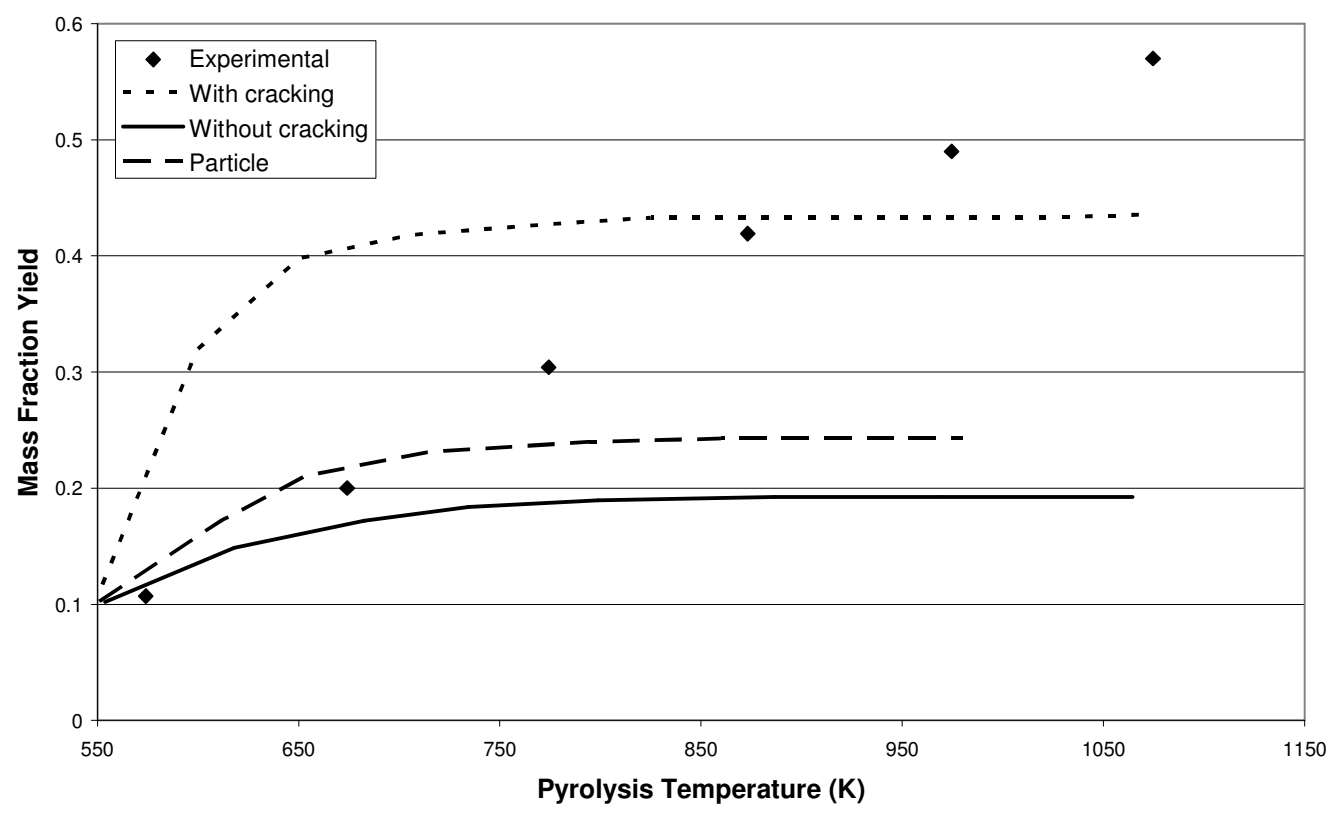

Figure 5.13: Tar yields at different reaction temperatures for T. Catappa at $3 \mathrm{~K} / \mathrm{min}$. Several model scheme versus experimental [23]

Since tar cracking is the primary source of this variation, it has little affect on the char yields which do not change appreciably and as such are not worth plotting here. 


\section{Chapter 6: Conclusions}

\subsection{Conclusions}

A component based pyrolysis model was developed for the prediction of product yield, including gas species that accounts for tar cracking, heat transfer and mass transport. This model was compared to experimental data, both from the published literature as well as from in-house experiments. The transient pyrolysis model closely matches experiments for each component, cellulose, hemicellulose and lignin as well as for several biomass species including hardwood, rice husk and switch grass. The model also closely matches the experimental data for product yields from low heating rate pyrolysis of fine particle pine wood over a range of reaction temperatures. Also for fine particle pine wood, gas species predictions are moderately accurate. It is unclear whether the error is in the gas species predictions or in the assumption that there is no tar cracking. For modeling large particles, if predicted temperature difference between the center and the edge of the particle are less than $10^{\circ} \mathrm{C}$ as calculated with either Eq. 3.23 or Eq. 3.24 above, internal particle heat transfer can be neglected (see section 3.3), this assumption may break down if reaction energies are considered. In the slow pyrolysis regime considered here, particle temperatures can thus be considered to be spatially uniform, and furthermore, mass transfer within the particle is shown to be dominated by convection rather than diffusion. A particle model was then developed that includes tar cracking within the particle and convective mass transfer of vapors out of the particle. When a purge gas is used and out-of-particle residence times are small, the particle model predicts yields within the range of experimental error. However in cases with no purge gas, out-of-particle residence times are large and the model predictions break down at 
temperatures $(>600 \mathrm{~K})$. This leads to a need to develop a reactor model which can account for tar cracking reactions in extra-particle fluid flow. Relative trends of gases species distribution for $\mathrm{CO}, \mathrm{CO}_{2}$, and $\mathrm{H}_{2}+\mathrm{CH}_{4}$ can be predicted, though the model fails to predict absolute values for species yields.

As suggested by Miller and Bellan [4], there are four criteria that a pyrolysis model should meet.

- Time evolution, of which the model developed in this work can achieve to a high accuracy

- Product yields, which this work can again achieve, provided there is no extra-particle tar cracking

- Yield variations with temperature, again provided no out of particle tar cracking exist, can be accomplished

- Variations with different feedstocks, which has been shown for several types of biomass including, woods, switch grass and rice hulls.

Therefore, the kinetic model developed in this work can be deemed a success with in the range of the model's applicability and its use as a kinetic mechanism for CFD models is justified. This model is valid for predicting single particle pyrolysis for biomass particles in the slow pyrolysis regime $\left(<80^{\circ} \mathrm{C} / \mathrm{min}\right)$ where the maximum temperature difference inside the particle is less than $10^{\circ} \mathrm{C}$ and maximum temperatures are less then $1100 \mathrm{~K}$. A new kinetic scheme would be needed to make this model apply to faster heating rates or higher temperatures and internal temperature gradient effects could be considered by incorporating a heat transfer model. 


\subsection{Recommendations for future work}

While the model presented in this work performs adequately, it could benefit from further investigation. By performing the appropriate experiments, it would be possible to develop competitive kinetic rate data for the evolution of gaseous species instead of using concentration factors. The number of species considered can be increased (ethane, propane and other hydrocarbons). Also, the experimental side of this work could be improved by increasing the number of gas species the MS detects and making other modifications to the apparatus that will allow for better closure the mass balances. This model would perform well as part of a larger reactor model to improve tar cracking predictions when residence times are high. While the current model is acceptable for low heating rates, the reaction mechanism used here may fail at higher heating rates, and further improvements could be made by adapting this mechanism or another for use at higher heating rates. Incorporating reaction energies may improve the temperature model to account for the shift from endothermic to exothermic reactions. By using this particle model in conjunction with a CFD code to model the gas movement in a reactor once it leaves the particle, tar cracking can be better predicted. Incorporating other gas phase reactions such as water gas shift, char gasification and methane reforming can improve gas species predictions as well. 


\section{References}

1) C Di Blasi, "Modeling chemical and physical processes of wood and biomass pyrolysis", Progress in Energy and Combustion Science, 34, 47-90, 2008

2) J. Lehmann, "Bio-energy in the black," Front. Ecol. Environ., 5(7): 381-387, 2007.

3) L Fagbemi, L Khezami, R Capart, "Pyrolysis products from different biomasses: application to the thermal cracking of tar," Applied Energy, 69, 293-306, 2001

4) R Miller, J Bellan, "A generalized biomass pyrolysis model based on superimposed cellulose, hemicelluloses and lignin kinetics", Combustion Science and Technology, 126, 97-137, 1997

5) P Basu, P Kaushal, "Modeling of Pyrolysis and Gasification of Biomass in Fluidized Beds: A Review", Chemical Product and Process Modeling, 4, Art 21, 2009

6) Anh Phan, Vida Sharafi, Jim Swithenbank, "Effect of bed depth on characterization of slow pyrolysis products, Fuel, 88, 1383-1387, 2009

7) P Gilbert, C Ryu, V Sharifi, J Swithenbank, "Tar reduction in pyrolysis vapors from biomass over a hot char bed", Bioresource Technology, 100, 6045-6051, 2009

8) C Koufopanos, G Maschio, A Lucchesi, "Kinetic modeling of the Pyrolysis of Biomass and Biomass Components", Canadian Journal of Chemical Engineering, 67, 1989

9) Seing-Beom Lee, Oladiran Fasina, "TG-FTIR analysis of switchgrass pyrolysis", Journal of Applied Pyrolysis, 86. 39-43, 2009

10) Gang Wang, Wen Li, Baoqing Li, Haokan Chen, "TG study on pyrolysis of biomass and its three components under syngas", Fuel, 87, 552-558, 2008

11) H. Yang, R Yan, H. Chen, C. Zheng, D. Lee, D. Laing, "In-depth Investigation of Biomass Pyrolysis Based on Three Major Components: Hemicellulose, Cellulose, and Lignin”, Energy and Fuels, 20, 388-393- 2006

12) N Worasuwannarak, T Sonobe, W Tanthapanichakoon, "Pyrolysis behaviors of rice straw, rice husk, and corncob by TG-MS technique" Journal of Applied and Analytical Pyrolysis, 78, 265-271, 2007

13) E Ranzi, A Cuoci, T Faravelli, A Frassoldati, G Migliavacca, S Pierucci, $S$ Sommariva, "Chemical Kinetics of Biomass Pyrolysis", Energy and Fuels, 22, 42924300, 2008. 
14) W. Park, A. Atreya, H. Baum, "Experimental and theoretical investigation of heat and mass transfer processes during wood pyrolysis", Combustion and Flame, 157, 481494, 2010

15) Haiping Yang, Rong Yan, Hanping Chen, Dong Ho Lee, Chuguang Zheng, "Characteristics of hemicellulose, cellulose and lignin pyrolysis", Fuel, 86, 1781-1788, 2007

16) J Rath, G Staudinger, "Vapor phase cracking of tar from pyrolysis of birch wood", Thermal Science, 5, 83-94, 2001\

17) J. Pokki, V. Laakso, P. Tikka, J. Aittamaa, "Specific Permeability of Wood to Water Part 2: Perpendicular Specific Permeability of Steamed, Impregnated, and Kraft-Cooked Wood”, Ind. Eng. Chem. Res., 49, 2155-2160, 2010

18) U. Sand, J. Sandberg, J. Larfeldt, R. Bel Fdhila, "Numerical prediction of the transport and pyrolysis in the interior and surrounding of dry and wet wood log", Applied Energy, 85, 1208-1224, 2008.

19) S Lee, O Fasina, "TG_FTIR analysis of switchgrass pyrolysis", Journal of Analytical and Applied Pyrolysis, 86, 39-43, 2009

20) M Garcia-Perez, A Chaala, H Pakel, D Kretschmer, C Roy, "Vacuum Pyrolysis of Softwood and Hardwood Biomass Comparison Between Product yields and Bio-Oil Properties", Journal of Analytical and Applied Pyroysis, 78, pp 104-116, 2007

21) K Mansaray, A Ghaly, "Thermal Degradation of Rice Husks in Nitrogen Atmosphere", Bioresource Technology, 65, pp 13-20, 1998

22) Z Wang, J Cao, J Wang, "Pyrolytic characteristics of pine wood in a slowly heating and gas sweeping fixed-bed reactor", Journal of Analytical and Applied Pyrolysis, 84, 179-184, 2009

23) D Konwer, R Kataki, P Saika, "Pyrolysis of Some Indigenous Tree Species on Northeast India: Effect of Pyrolysis Temperature an, Heating Rate on the Products Yield and Char Quality," Energy Sources, 29, 1433-1442, 2007

24) P Koch, "Utilization of Hardwoods Growing on Southern Pine Sites", Agriculture Handbook 605, 368-369 1985

25) Z. Zhan, W. Kobsiriphat, J. Wilson, M. Pillai, I. Kim, S. Barnett, "Syngas Production By Coelectrolysis of CO2/H2O: The Basis for a Renewable Energy Cycle", Energy and Fuels, 23, 3089-3096, 2009 
Appendix A: Experimental Mass Balance

\begin{tabular}{|c|c|c|c|c|c|c|c|c|c|c|c|c|}
\hline Test & & $\begin{array}{l}\text { Tube } \\
(\mathrm{g})\end{array}$ & $\begin{array}{c}\text { Screen } \\
(\mathrm{g})\end{array}$ & $\begin{array}{l}\text { Coil } \\
(\mathrm{g})\end{array}$ & $\begin{array}{c}\text { Filter } 1 \\
(\mathrm{~g})\end{array}$ & $\begin{array}{c}\text { Fitting } \\
(\mathrm{g})\end{array}$ & $\begin{array}{l}\mathrm{Tar}^{+} \\
(\mathrm{g}) \\
\end{array}$ & $\begin{array}{c}\text { Wood/Char } \\
(\mathrm{g})\end{array}$ & $\begin{array}{c}\text { Gas } \\
(\mathrm{g}) \\
\end{array}$ & $\begin{array}{c}\mathrm{H}_{2} \mathrm{O}^{\#} \\
(\mathrm{~g}) \\
\end{array}$ & $\begin{array}{c}\text { Balance } \\
(\mathrm{g})\end{array}$ & $\begin{array}{c}\text { Closure } \\
(\%)\end{array}$ \\
\hline \multirow{3}{*}{1} & Before & 267.88 & 2.76 & 300.91 & 0.51 & ----- & \multirow{3}{*}{3.94} & 8.17 & \multirow{3}{*}{1.32} & \multirow{3}{*}{0.51} & \multirow{3}{*}{1} & \multirow{3}{*}{87.73} \\
\hline & After & 268 & 2.74 & 304.25 & 1.01 & ----- & & 1.91 & & & & \\
\hline & Difference & 0.12 & -0.02 & 3.34 & 0.5 & ----- & & -6.26 & & & & \\
\hline \multirow{3}{*}{ N/A* } & Before & 270.2 & 2.76 & 300.85 & 0.55 & ----- & \multirow{3}{*}{3.54} & 7.83 & \multirow{3}{*}{0} & & \multirow{3}{*}{2.23} & \multirow{3}{*}{71.46} \\
\hline & After & 270.32 & 2.74 & 303.87 & 0.97 & ---- & & 2.05 & & & & \\
\hline & Difference & 0.12 & -0.02 & 3.02 & 0.42 & ----- & & -5.78 & & & & \\
\hline \multirow{3}{*}{2} & Before & 267.86 & 2.76 & 300.82 & 0.52 & ----- & \multirow{3}{*}{3.62} & 8.05 & \multirow{3}{*}{0.45} & \multirow{3}{*}{0.46} & \multirow{3}{*}{2.06} & \multirow{3}{*}{74.41} \\
\hline & After & 268.09 & 2.78 & 303.85 & 0.86 & ----- & & 1.92 & & & & \\
\hline & Difference & 0.23 & 0.02 & 3.03 & 0.34 & ----- & & -6.13 & & & & \\
\hline \multirow{3}{*}{3} & Before & 267.87 & 2.76 & 300.81 & 0.32 & ----- & \multirow{3}{*}{3.89} & 7.96 & \multirow{3}{*}{0.78} & \multirow{3}{*}{0.74} & \multirow{3}{*}{1.38} & \multirow{3}{*}{82.67} \\
\hline & After & 268.13 & 2.78 & 303.84 & 0.9 & ---- & & 1.91 & & & & \\
\hline & Difference & 0.26 & 0.02 & 3.03 & 0.58 & ---- & & -6.05 & & & & \\
\hline \multirow{3}{*}{4} & Before & 267.88 & 2.76 & 300.82 & 0.3 & 922.58 & & 7.97 & & & & \\
\hline & After & 268.15 & 2.8 & 303.83 & 0.93 & 922.85 & 4.22 & 2.01 & 0.52 & 0.54 & 1.23 & 84.62 \\
\hline & Difference & 0.27 & 0.04 & 3.01 & 0.63 & 0.27 & & -5.96 & & & & \\
\hline & Before & 267.86 & 2.76 & 300.8 & 0.32 & 922.56 & & 7.93 & & & & \\
\hline 5 & After & 268.1 & 2.78 & 303.61 & 0.9 & 922.94 & 4.03 & 2.3 & 1.81 & 1.74 & -0.21 & 102.61 \\
\hline & Difference & 0.24 & 0.02 & 2.81 & 0.58 & 0.38 & & -5.63 & & & & \\
\hline & Before & 267.87 & 2.76 & 300.83 & 0.32 & 922.57 & & 8.1 & & & & \\
\hline 6 & After & 268.12 & 2.77 & 303.91 & 0.85 & 922.85 & 4.15 & 1.94 & 1.38 & 1.26 & 0.63 & 92.22 \\
\hline & Difference & 0.25 & 0.01 & 3.08 & 0.53 & 0.28 & & -6.16 & & & & \\
\hline & Before & 270.22 & 2.76 & 300.87 & 0.32 & 922.57 & & 8.05 & & & & \\
\hline 7 & After & 270.36 & 2.78 & 302.63 & 0.87 & 922.76 & 2.66 & 1.89 & 0.87 & 0.84 & 2.63 & 67.33 \\
\hline & Difference & 0.14 & 0.02 & 1.76 & 0.55 & 0.19 & & -6.16 & & & & \\
\hline & Before & 267.87 & 2.76 & 300.81 & 0.52 & 959.88 & & 8.08 & & & & \\
\hline N/A* & After & 268.07 & 2.81 & 303.03 & 1.08 & 960.08 & 3.23 & 2.18 & 0 & 0 & 2.67 & 67 \\
\hline & Difference & 0.2 & 0.05 & 2.22 & 0.56 & 0.2 & & -5.9 & & & & \\
\hline & Before & 267.86 & 2.76 & 300.81 & 0.52 & 959.88 & & 8.19 & & & & \\
\hline 8 & After & 267.99 & 2.78 & 303.17 & 0.99 & 959.99 & 3.09 & 2.14 & 1.6 & 3.53 & 1.37 & 83.31 \\
\hline & Difference & 0.13 & 0.02 & 2.36 & 0.47 & 0.11 & & -6.05 & & & & \\
\hline & Before & 267.88 & 2.76 & 300.8 & 0.52 & 959.88 & & 8.12 & & & & \\
\hline 9 & After & 268.02 & 2.78 & 301.98 & 1.06 & 960.09 & 2.09 & 2.06 & 2.16 & 3.96 & 1.8 & 77.8 \\
\hline & Difference & 0.14 & 0.02 & 1.18 & 0.54 & 0.21 & & -6.06 & & & & \\
\hline & Before & 267.88 & 2.76 & 300.88 & 0.54 & 959.93 & & 8.01 & & & & \\
\hline 10 & After & 268.11 & 2.78 & 303.1 & 1.13 & 960.13 & 3.26 & 2.45 & 1.63 & 2.17 & 0.67 & 91.6 \\
\hline & Difference & 0.23 & 0.02 & 2.22 & 0.59 & 0.2 & & -5.56 & & & & \\
\hline
\end{tabular}

* MS error occurred, experiment repeated.

+ Tar is calculated as the sum of the mass differences for tube, coil, screen, filters and fitting

\# Water value is from MS measurement 


\section{Appendix B1: TGA code}

This program takes the input of Final temperature, initial composition, and heating rate, then performs a simulation of a TGA experiment. It has the option to perform this on an ash free basis or including the ash in the final residual amount. It also has the option to read in a file containing the TGA data from an experiment and plot them on the same graph.

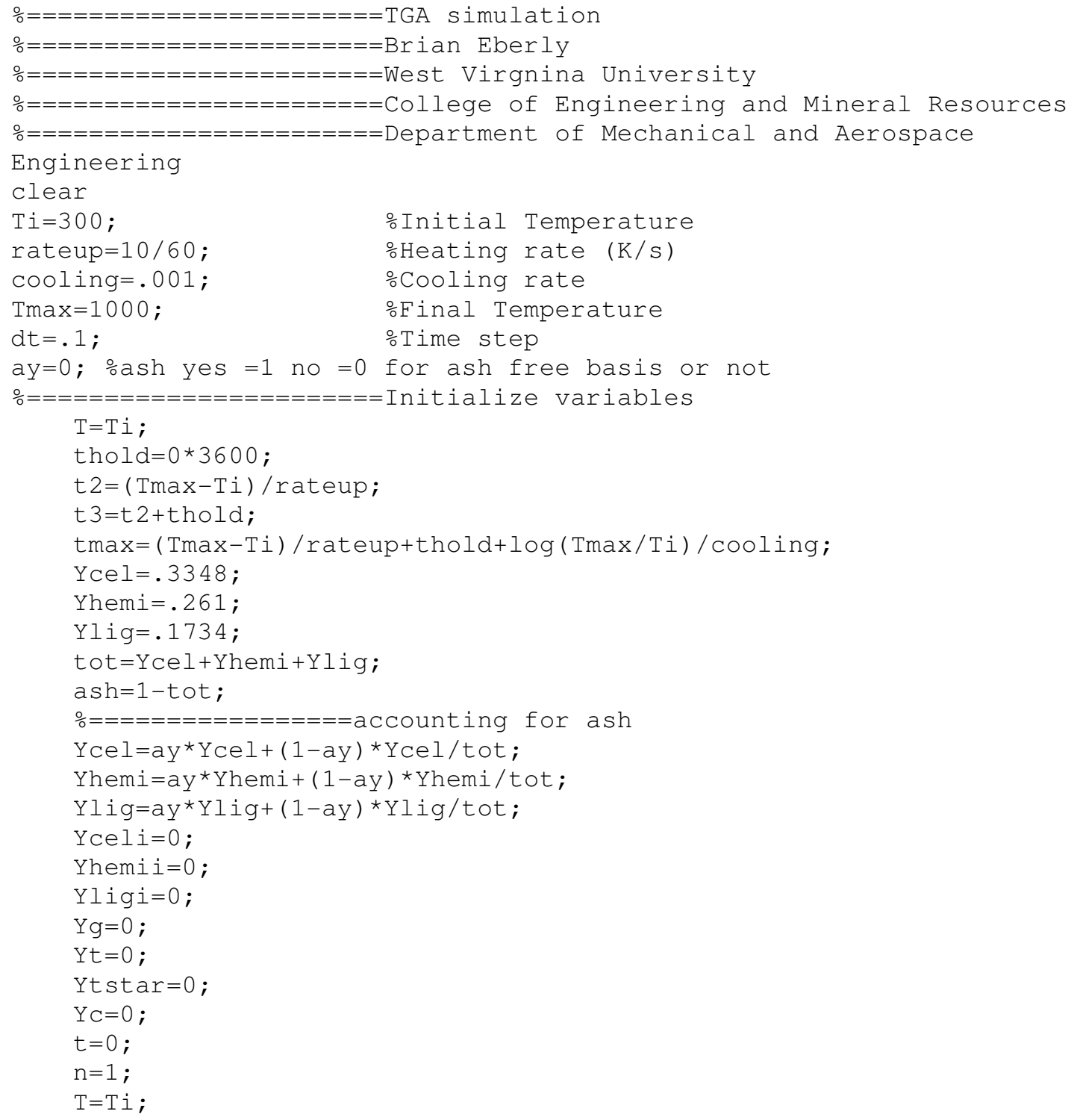




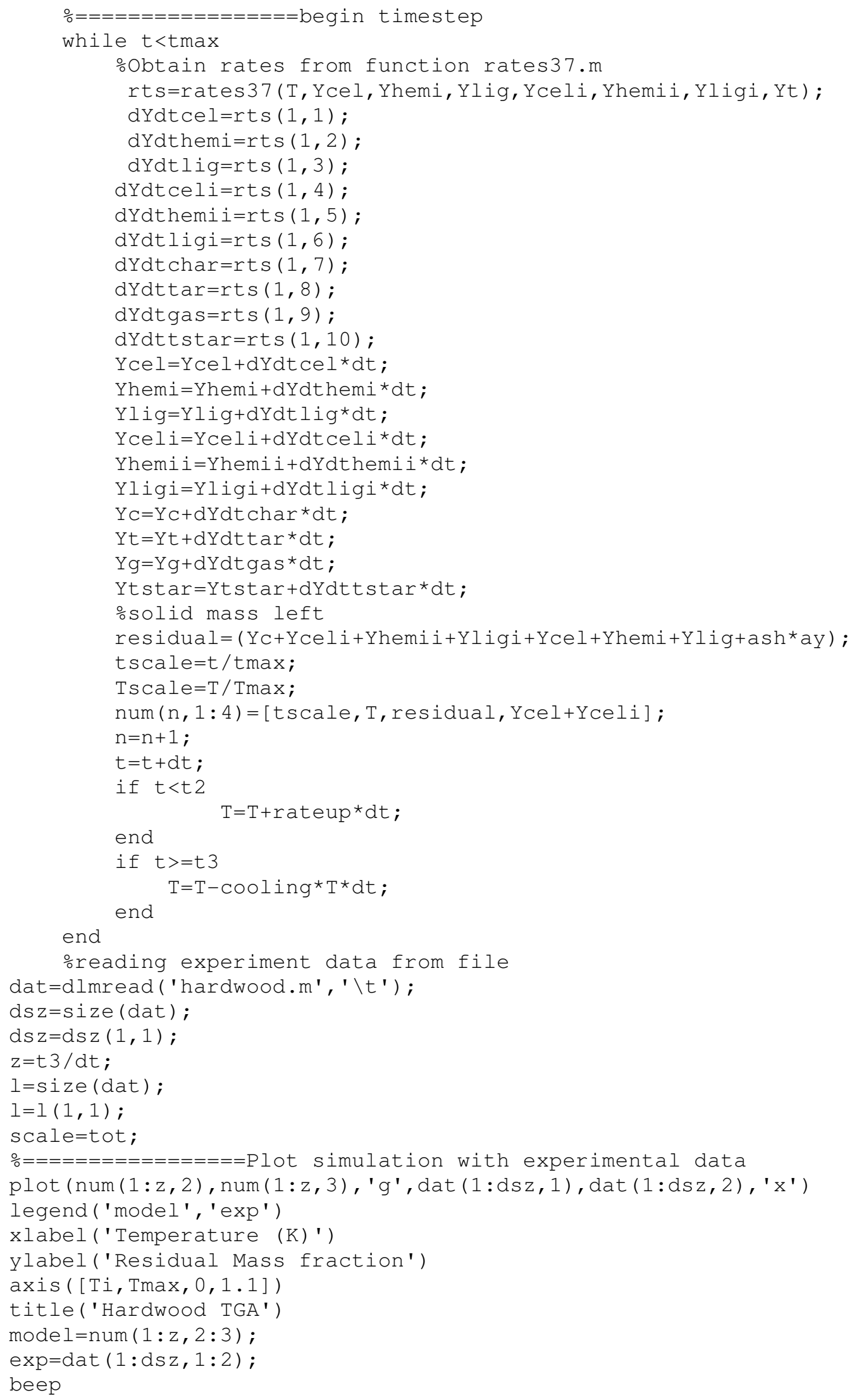




\section{Appendix B2: Fixed bed reactor code}

This program reads in a file containing the data from a set of fixed bed pyrolysis experiments including composition, heating rates, hold times and final temperatures.

Then performs multiple simulations at the given conditions and plots the results of the simulations along with the results of the experiements

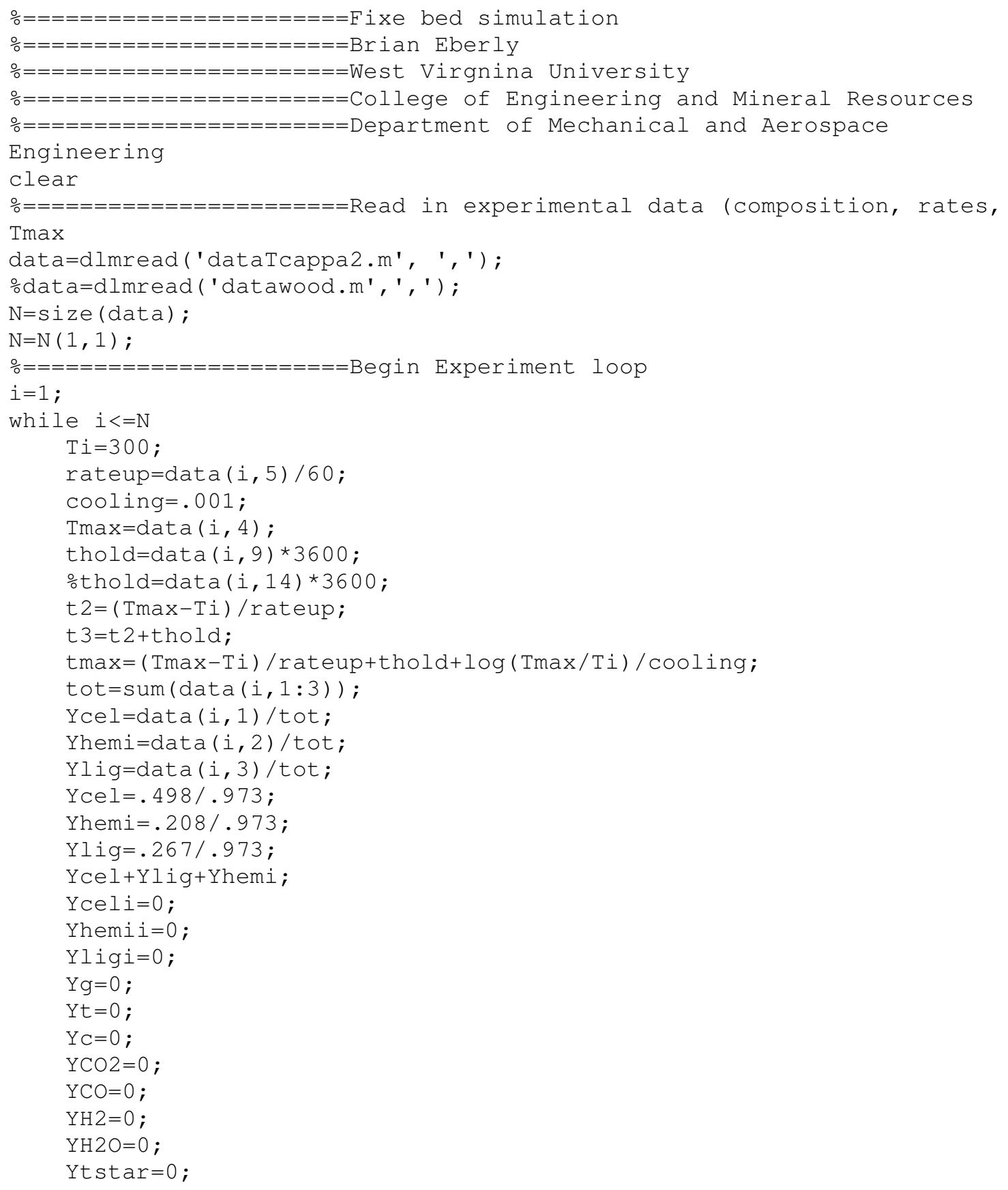




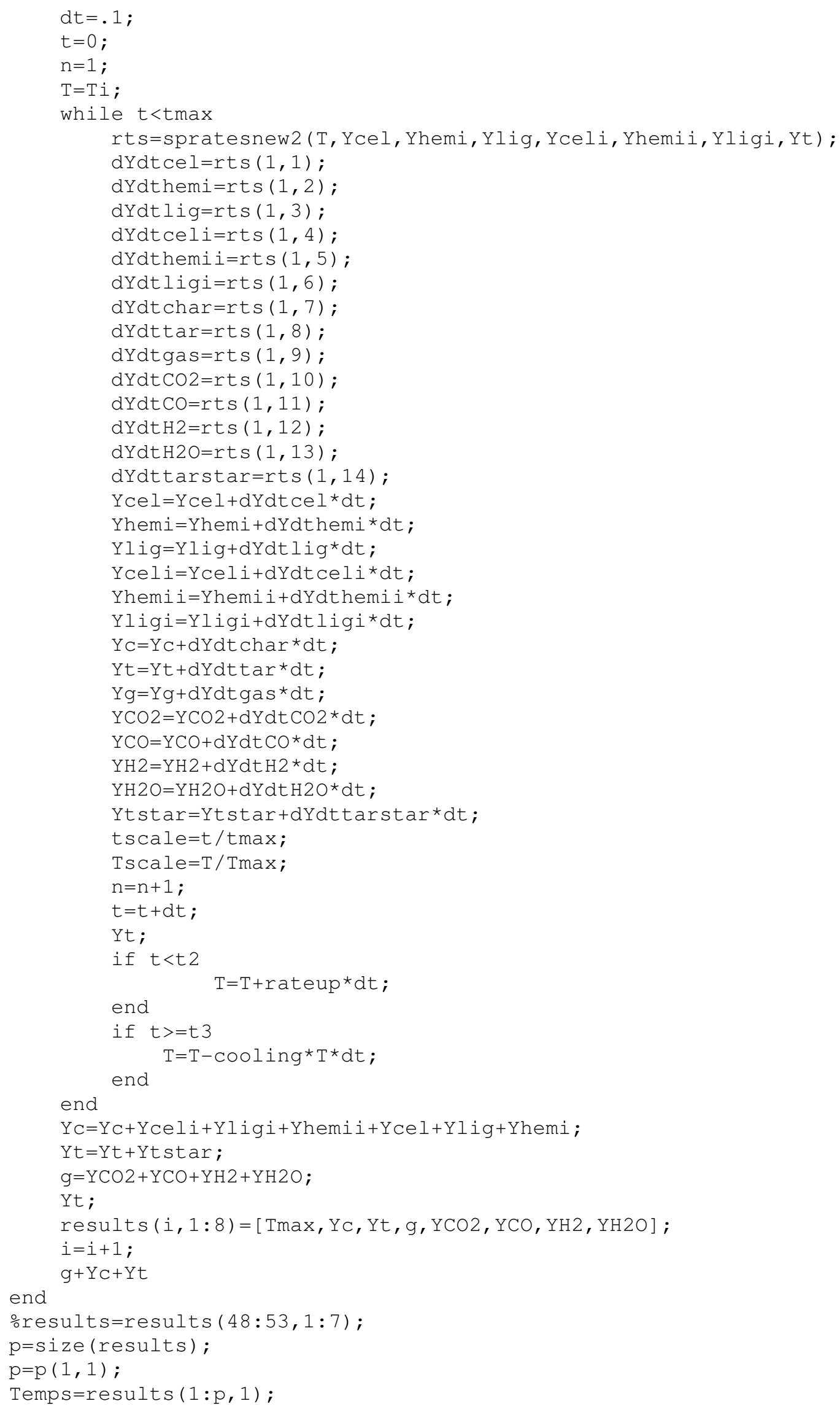




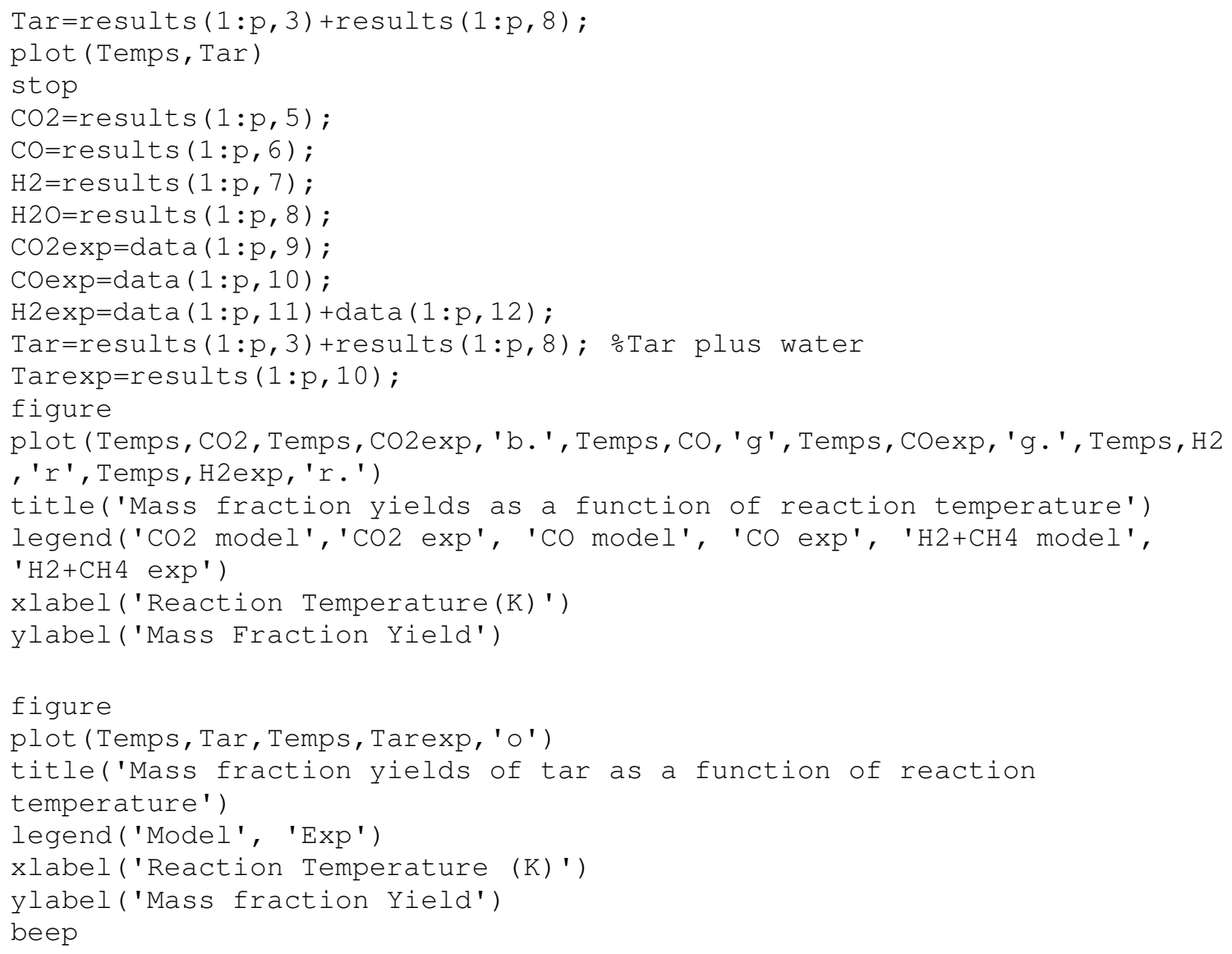




\section{Appendix B3: Particle Pyrolysis code}

This program simulates the pyrolysis of a single particle. It takes the input of

particle size, wood density, permeability, and porosity as well as heating rate and biomass

composition and performs simulations to multiple final temperatures and plots the

product yields as a function of temperature. It can also read in data from a file of

experimental results and plot the simulations compared to the experimental yields.

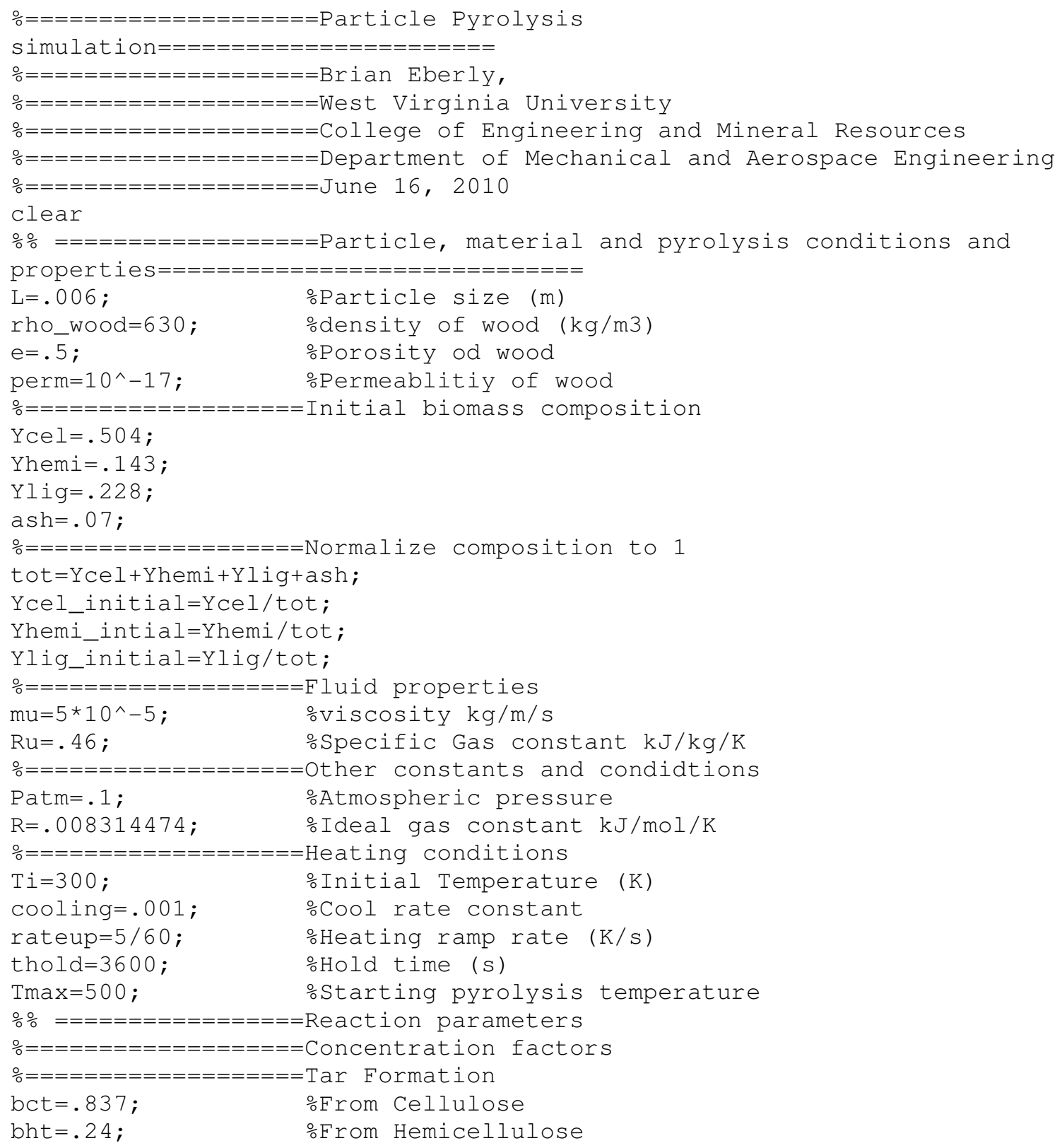




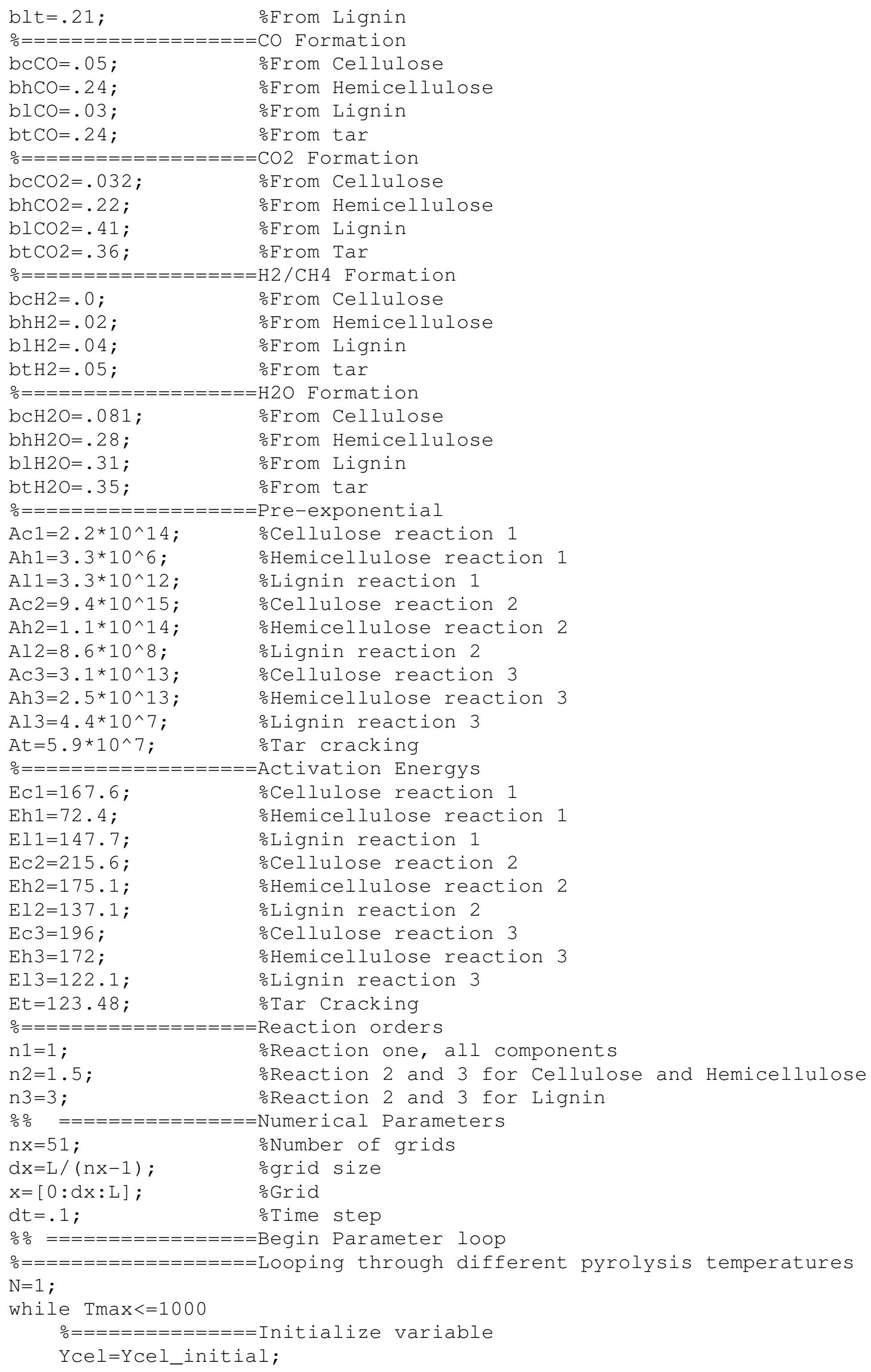




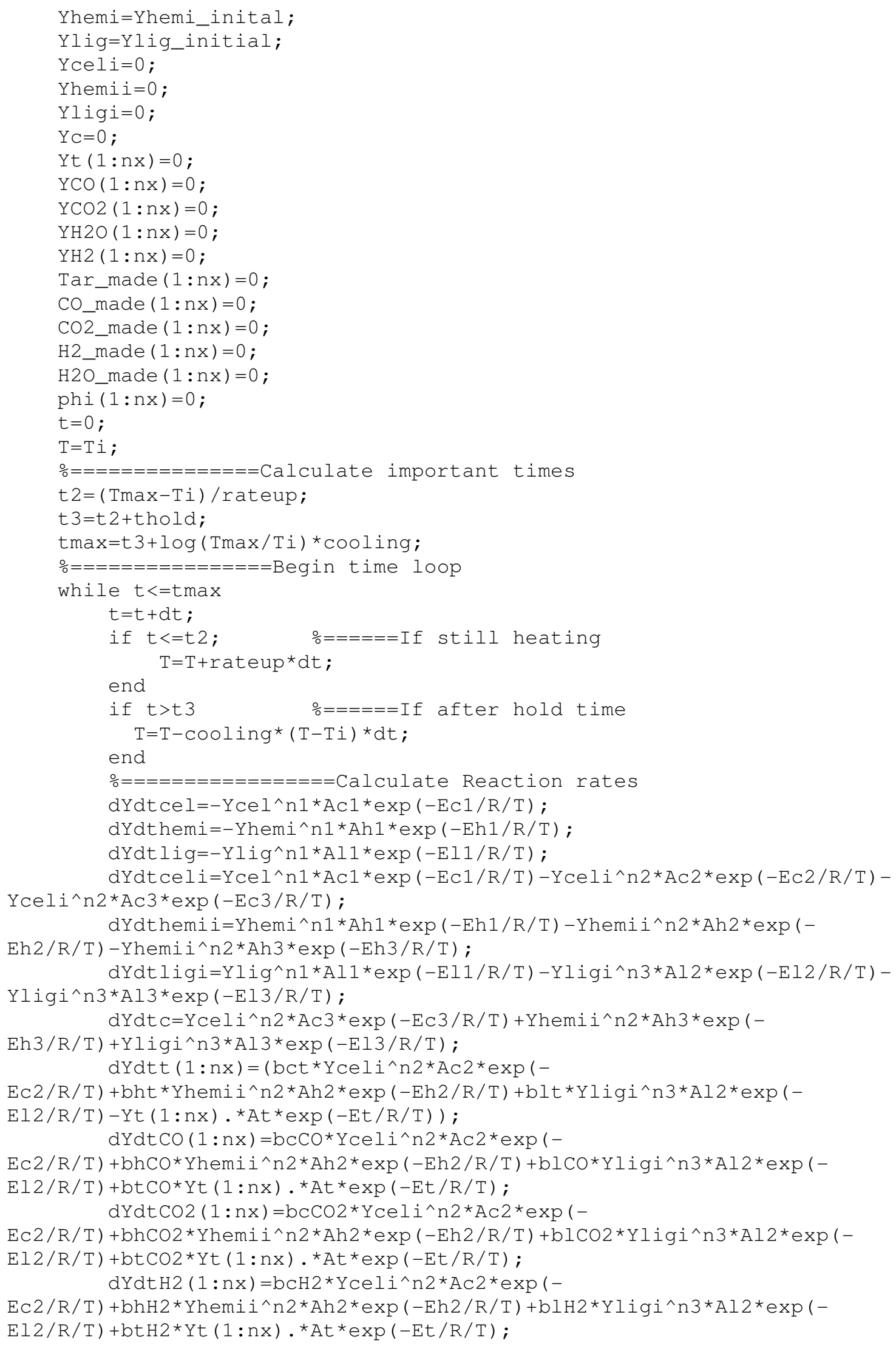




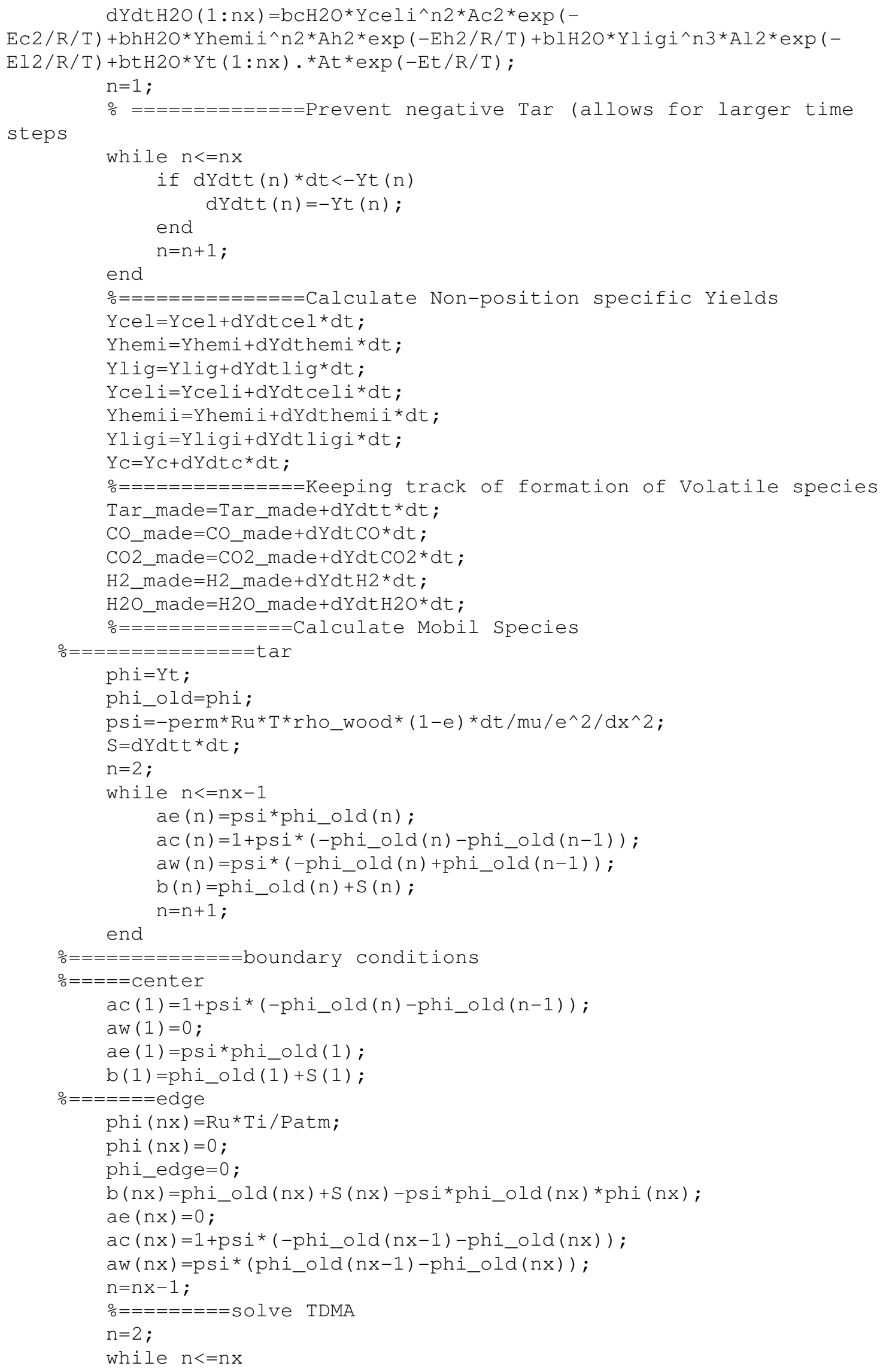




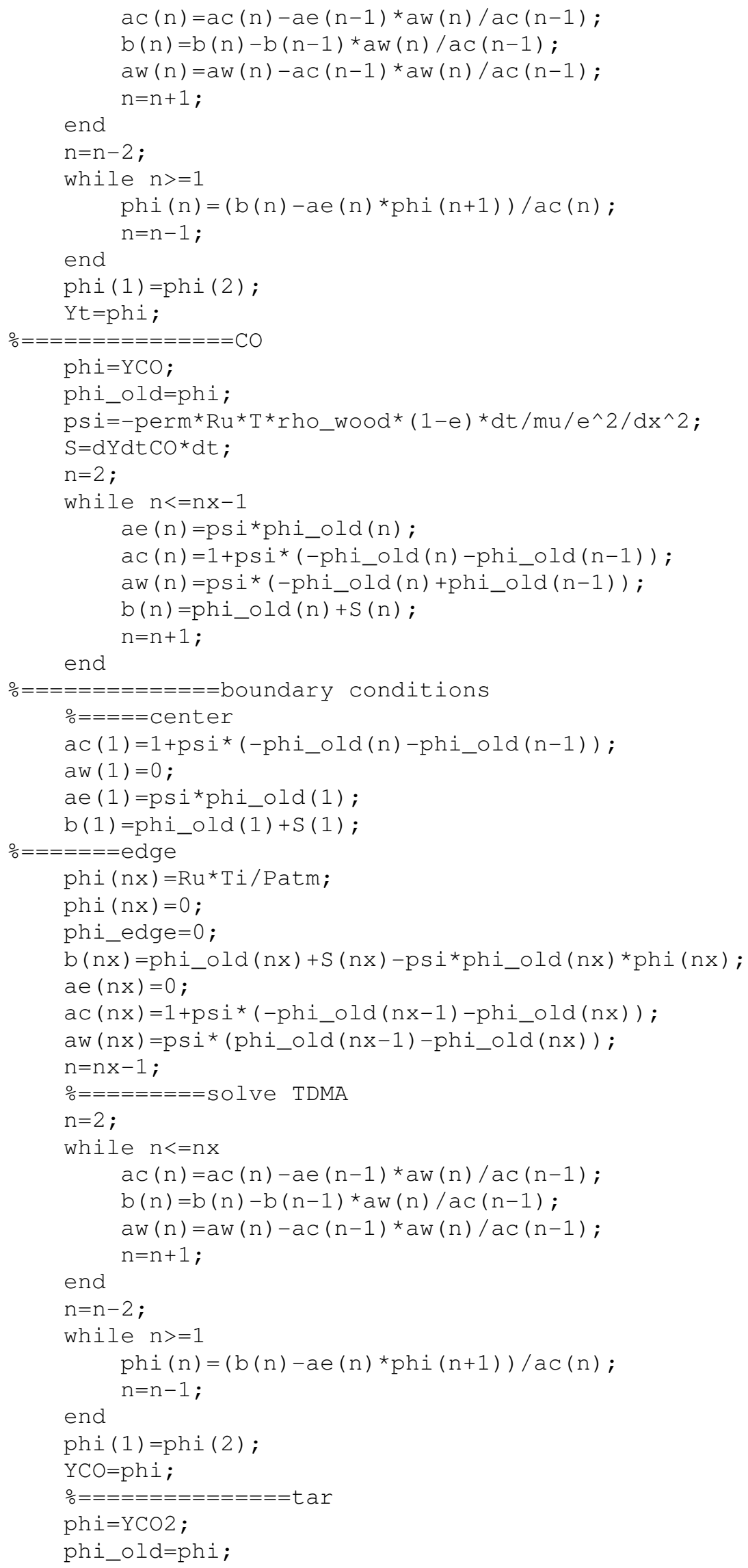




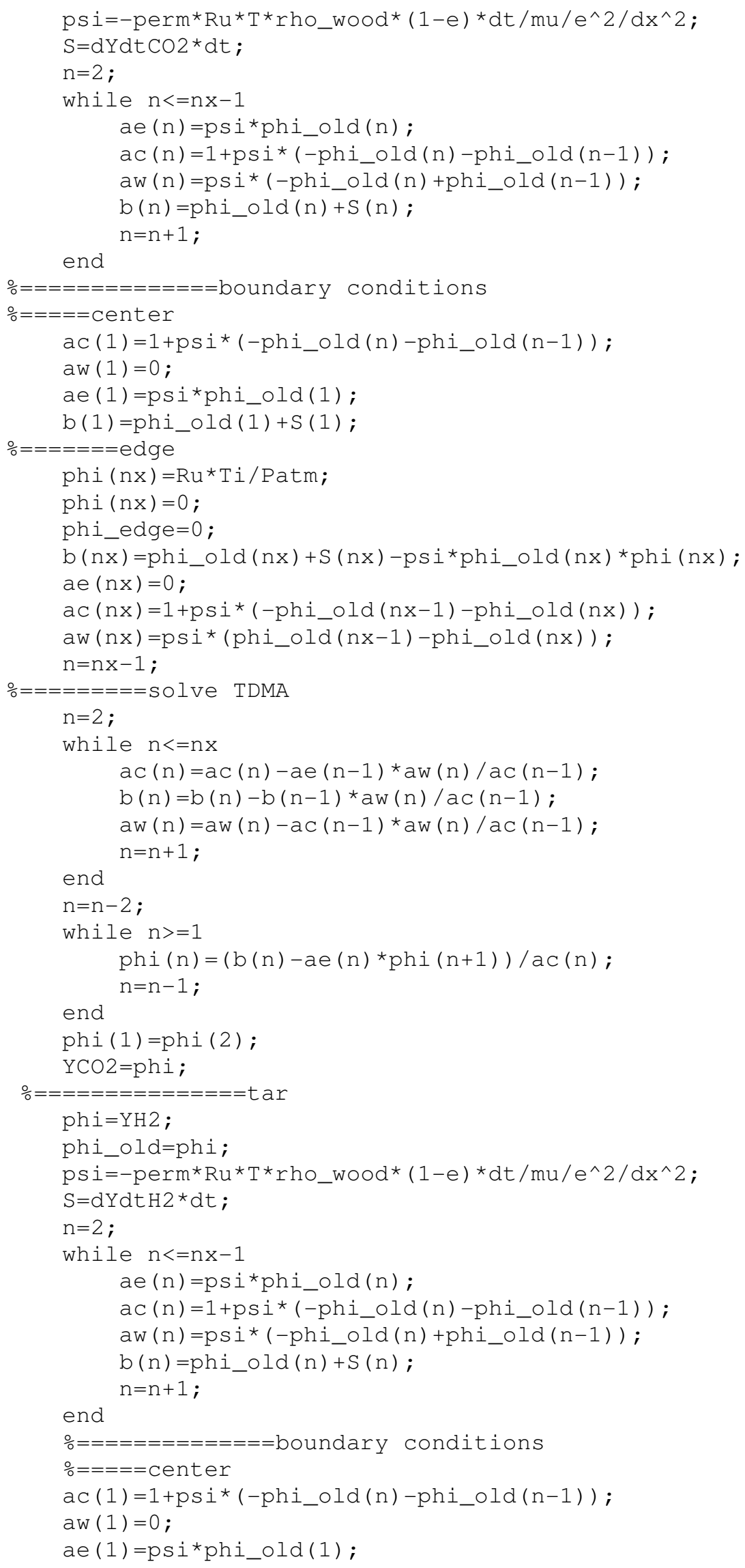




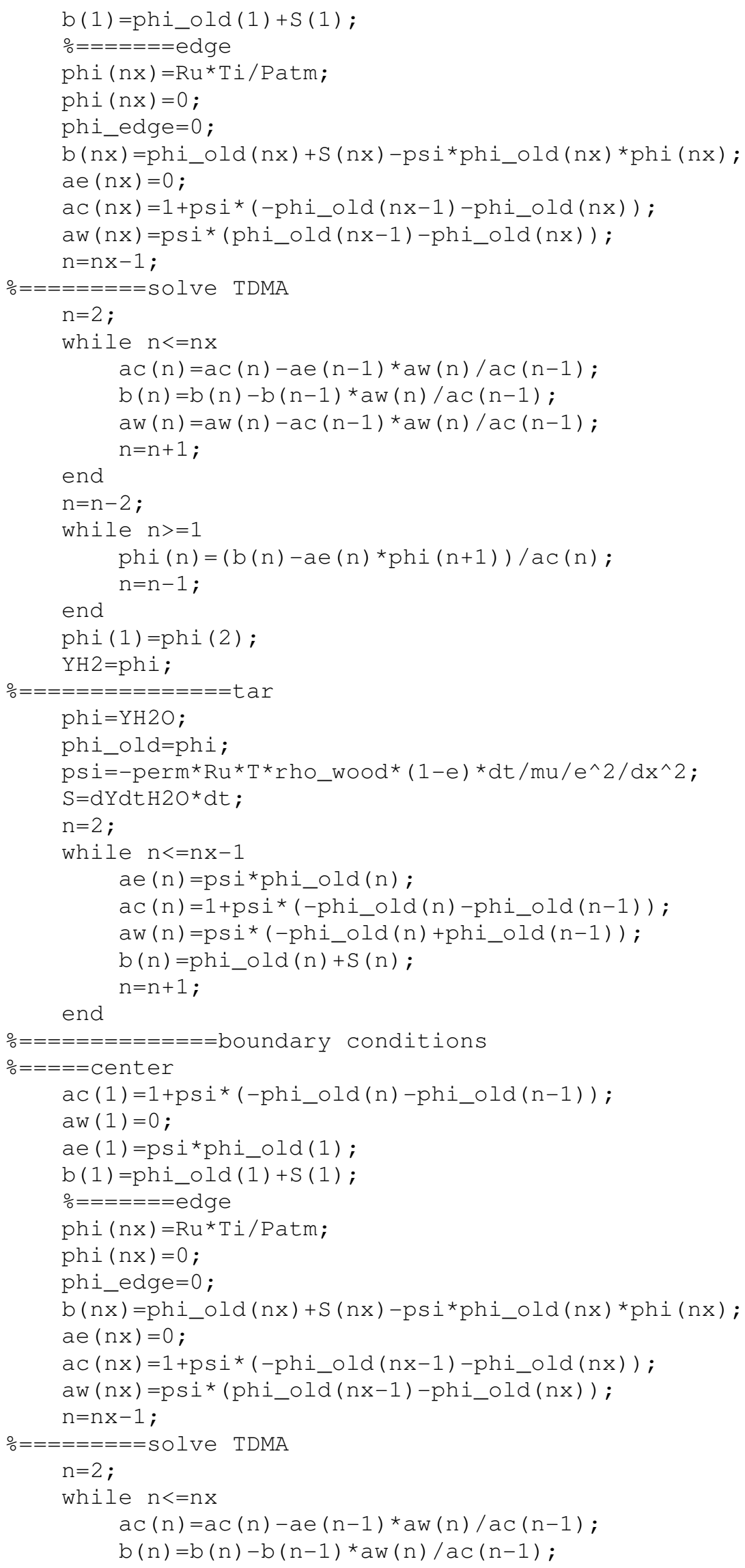




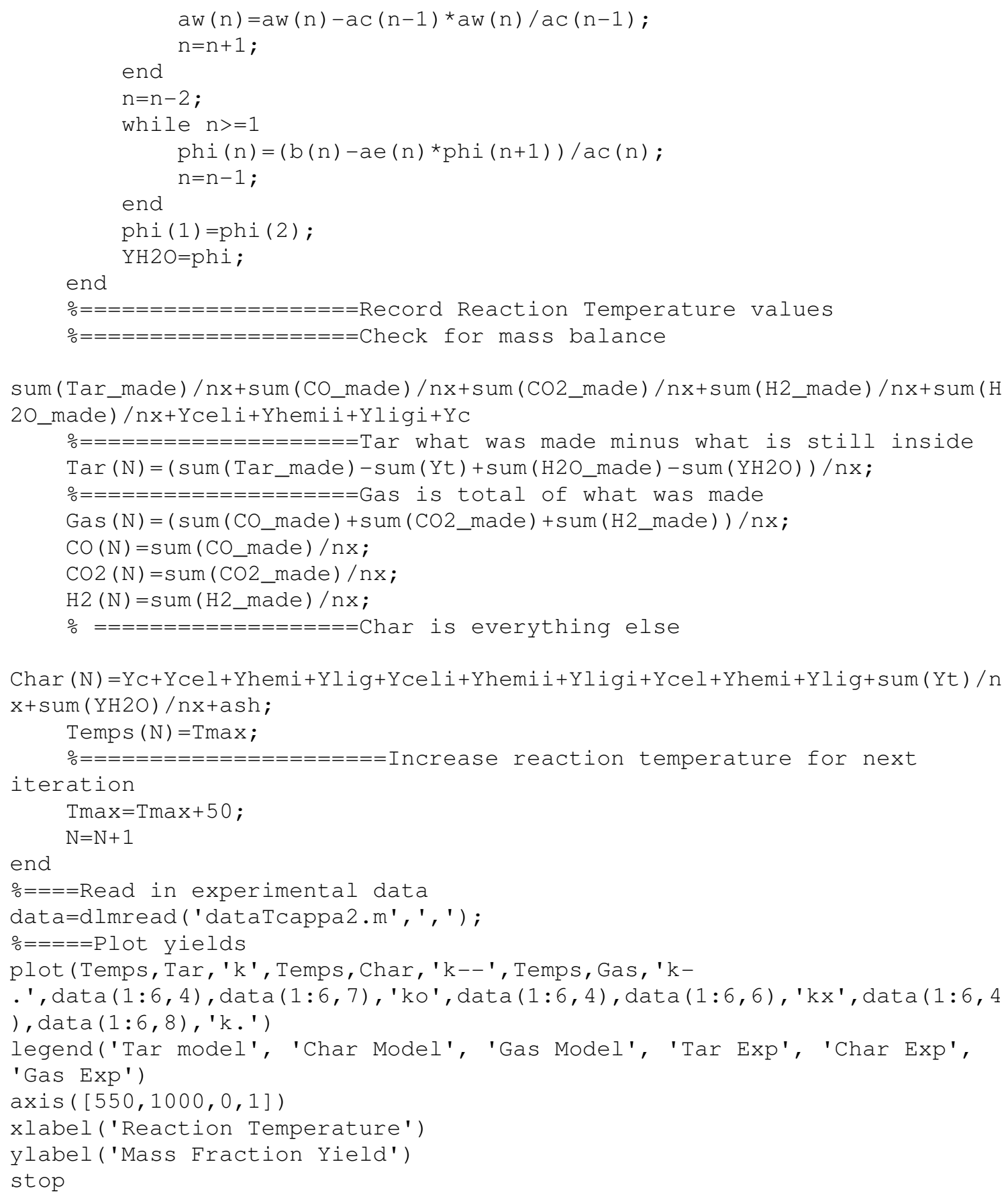




\section{Appendix A4: Rate Function}

Several subroutines were written to take species mass fractions and temperature and output reaction rates. This is an example of one of those subroutine functions.

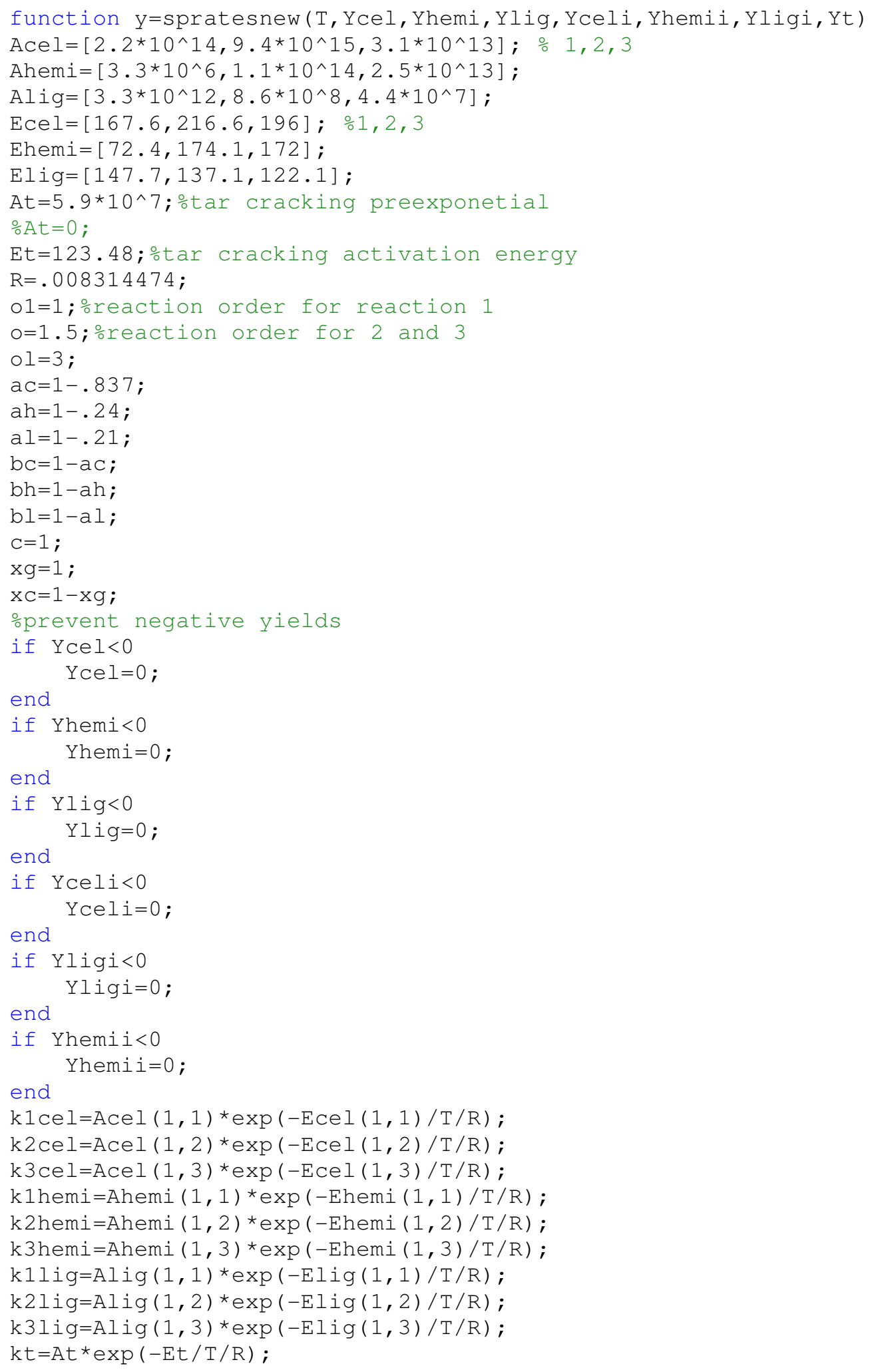




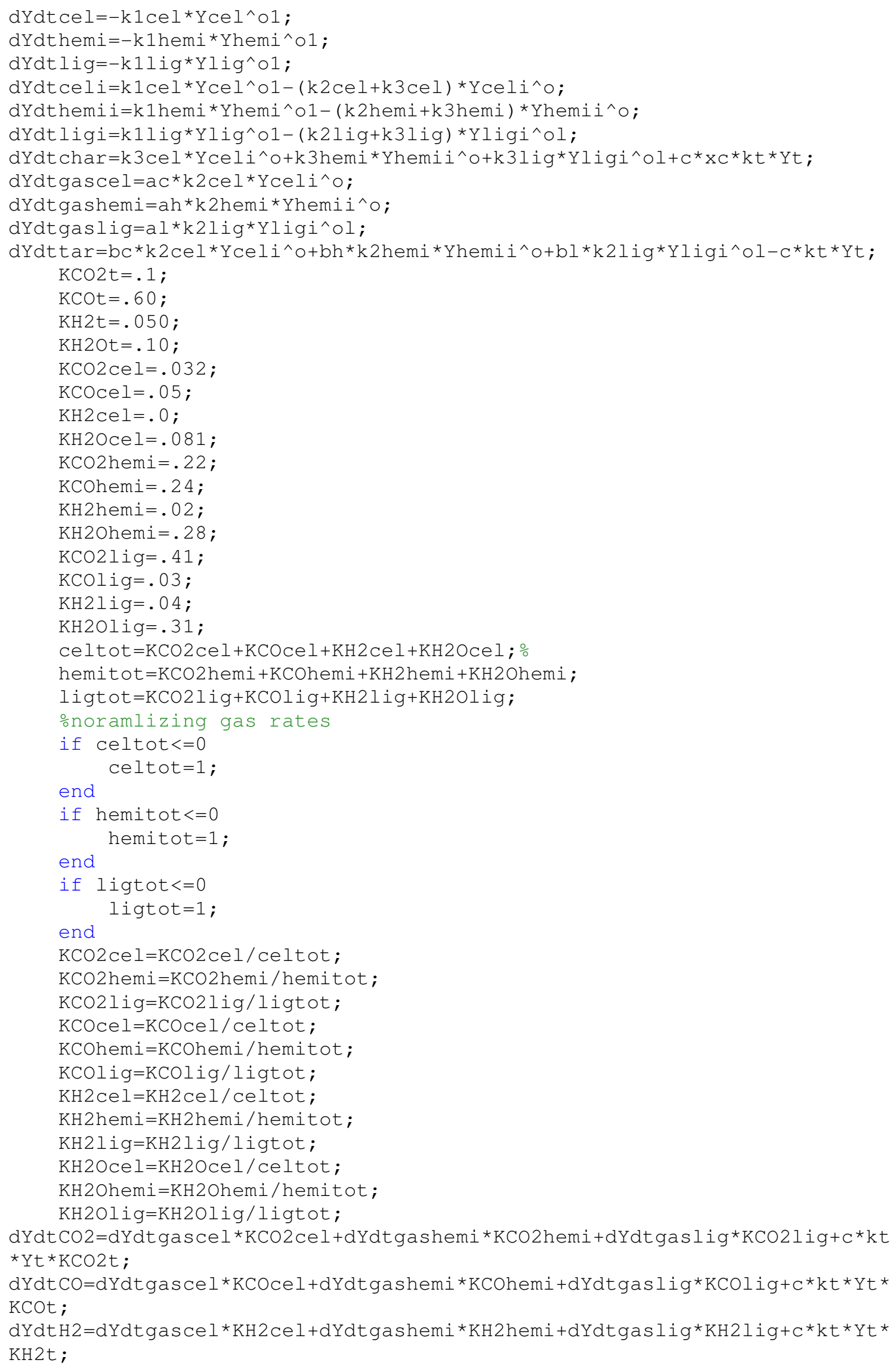


$\mathrm{dYdtH2O=dYdtgascel}$ *KH2Ocel+dYdtgashemi *KH2Ohemi+dYdtgaslig*KH2Olig+c*kt *Yt* KH2Ot;

dYdtgas=dYdtgascel+dYdtgashemi+dYdtgaslig-dYdtCO2-dYdtCO-dYdtH2dYdtH2O;

dYdttar $=\mathrm{bc} * \mathrm{k} 2 \mathrm{cel} * \mathrm{Yceli} \wedge \mathrm{o}+\mathrm{bh} * \mathrm{k} 2 \mathrm{hemi} *$ Yhemii^o+bl*k2lig*Yligi^ol-c*kt*Yt; $\mathrm{y}=[\mathrm{dYdtcel}, \mathrm{dYdthemi}, \mathrm{dYdtlig,dYdtceli,dYdthemii,dYdtligi,dYdtchar,dYdtta}$ r, dYdtgas, dYdtCO2, dYdtCO, dYdtH2, dYdtH2O]; 